\title{
Feasibility of a Skills Based Limited Critical Care Cardiac Ultrasound Course for Acute Care Nurse Practitioners
}

\author{
Abbye Rae Solis \\ Baltimore, MD \\ Bachelor of Science in Nursing, Tennessee Technological University, 2003 \\ Master of Science, Georgetown University, 2008
}

A Capstone Presented to the Graduate Faculty of the of the University of Virginia in Candidacy for the Degree of Doctor of Nursing Practice

School of Nursing

University of Virginia

May 2016

Dorothy Tullmann, PhD, RN, CNL

Deborah Dillon, DNP, ACNP-BC, CCRN, CHFN

Pedro Alejandro Mendez-Tellez, MD

(C) Abbye R. Solis, 2016

All rights reserved. 


\section{Table of Contents}

Abstract

Feasibility of a Skills Based Limited Critical Care Cardiac Ultrasound Course for Acute Care

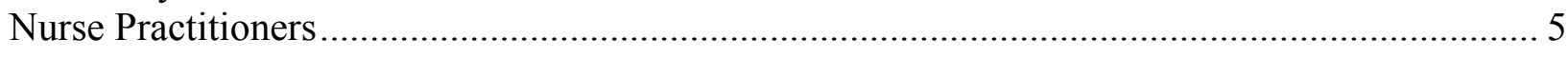

Introduction: Bedside Cardiac Echocardiography and Critical Care Ultrasound ......................... 5

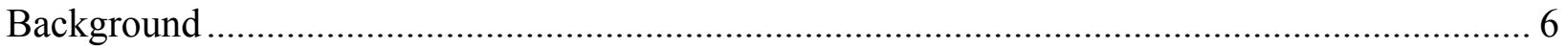

Critical Care Cardiac Ultrasound Competency............................................................. 8

Core Concepts of Critical Care Cardiac Ultrasound ..................................................... 8

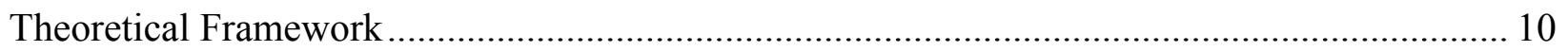

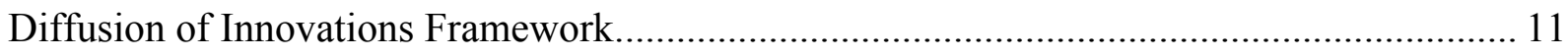

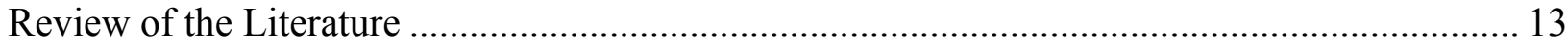

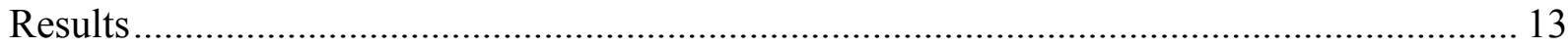

Recommendations for Critical Care Cardiac Ultrasound Training.................................... 14

Findings regarding CCU educational programs ............................................................ 16

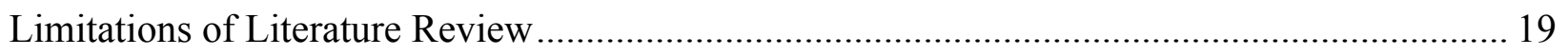

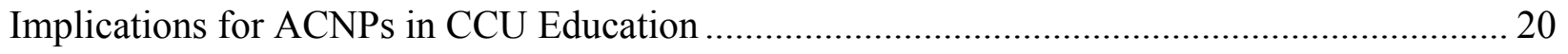

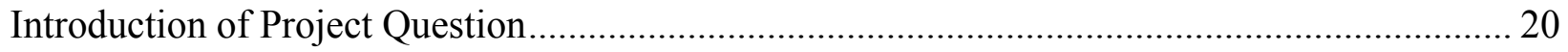

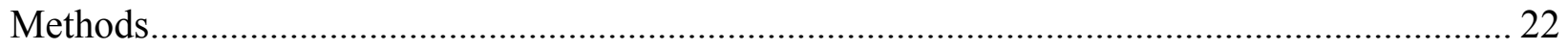

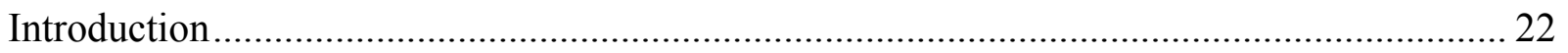

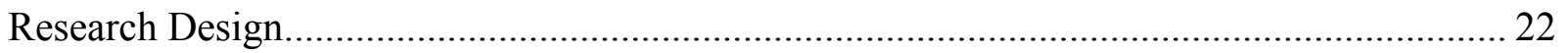

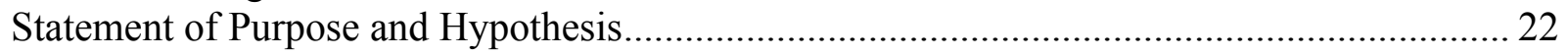

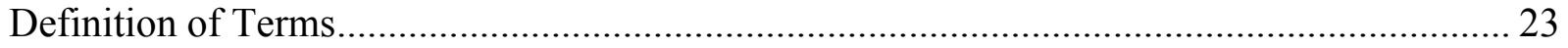

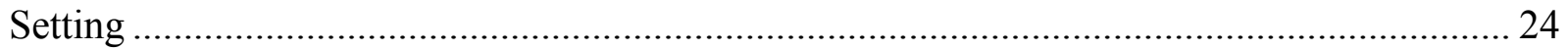

Program Description and Procedures........................................................................... 24

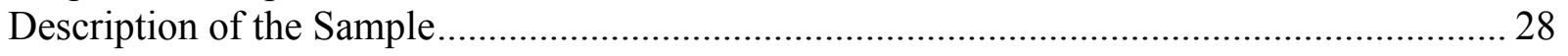

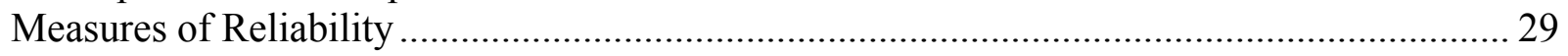

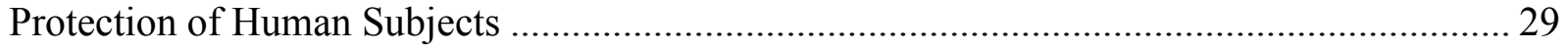

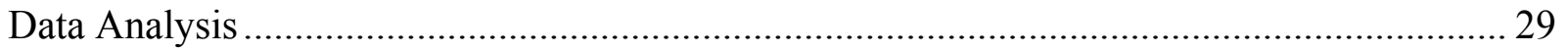

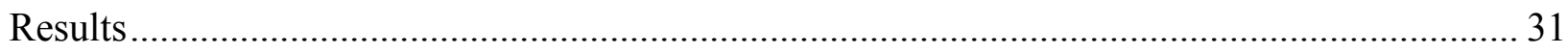

Critical Care Cardiac Ultrasound Knowledge Test ....................................................... 31

Limited Critical Care Cardiac Ultrasound Views Clinical Ability Test ................................ 31

Stroke Volume/Cardiac Output Clinical Ability Test....................................................... 31

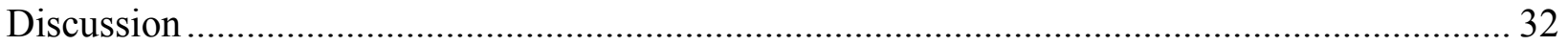

Implications of Results for Feasibility of Future CCUS for ACNPs .................................. 32

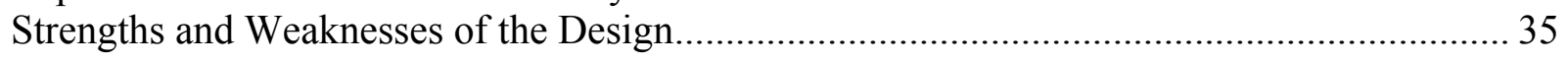

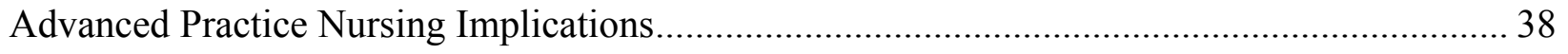

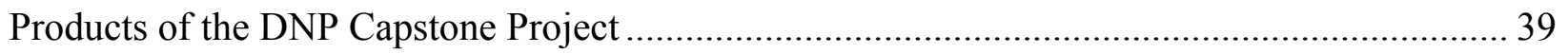

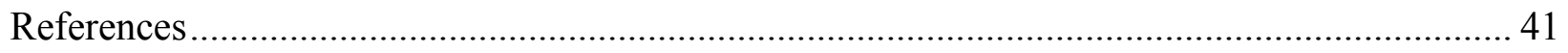


Appendix A: Demographic Data of ACNP Participants..................................................... 48

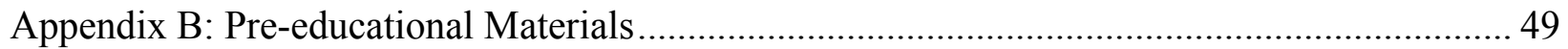

Appendix C: Critical Care Echocardiography Knowledge Test............................................ 50

Appendix D: Introduction to Critical Care Echocardiography Lecture ................................... 57

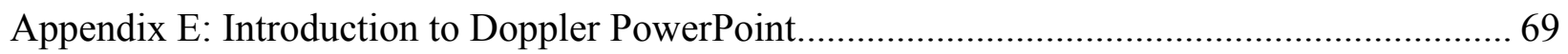

Appendix F: Limited Critical Care Echocardiography Views Clinical Ability Test.................. 80

Appendix G: Stroke Volume/Cardiac Output Clinical Ability Test ...................................... 81

Appendix H: Johns Hopkins Medicine Institutional Review Board Form .............................. 82

Appendix I: UVa IRB: Determination of UVa Agent Form.............................................. 83

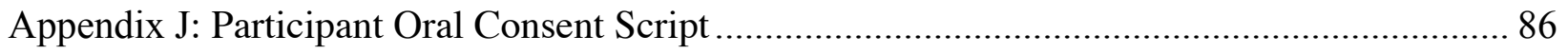

Appendix K: Volunteer Oral Consent Script ................................................................ 88

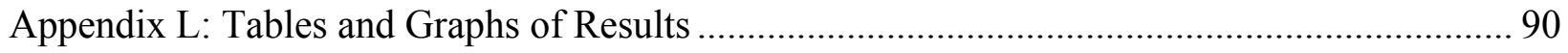

Appendix M: Journal of the American Association of Nurse Practitioners Author's Guidelines

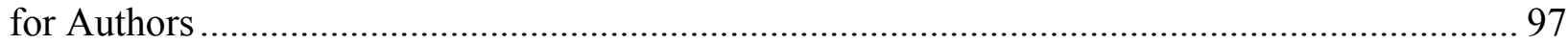

Appendix N: Manuscript Draft................................................. 110 


\begin{abstract}
Critical care ultrasound (CCU) is a skill that is considered standard care for a patient requiring medical care in an intensive care unit (ICU). Despite organizations supporting the use of CCU by all providers in the ICU, no organizations (including nursing organizations) have statements or training programs that include acute care nurse practitioners (ACNPs) as providers who can perform and interpret CCU. This purpose of this study was to examine the feasibility and effectiveness of a Skills Based Limited Critical Care Cardiac Ultrasound (SBLCCU) Course in which basic LCCU knowledge and skill concepts are taught to ACNPs who currently work in a surgical ICU setting. This feasibility study examined whether participation in the Skills Based Limited Critical Care Cardiac Ultrasound Course for ACNPs improves knowledge level and clinical ability to conduct and interpret LCCU for the specific clinical question of measuring stroke volume and cardiac output. Knowledge was evaluated using a multiple-choice test that was taken pre-education, day of education, and post-education. Clinical ability of the ACNP to obtain adequate views was examined as well as the ability of the ACNP to calculate stroke volume and cardiac output. It is feasible to teach ACNPs the skill of LCCU for obtaining adequate cardiac views and for the evaluation of stroke volume and cardiac output. A one-day, eight-hour design is feasible to introduce basic CCU skills, just as some physicians have also learned CCU. ACNPs need support from trained CCU personnel to learn and sustain this skill. However, more inquires examining ACNP LCCU education need to be conducted before these results can be generalized.
\end{abstract}




\section{Feasibility of a Skills Based Limited Critical Care Cardiac Ultrasound Course for Acute Care Nurse Practitioners}

\section{Introduction: Focused Cardiac Ultrasound and Critical Care Ultrasound}

Use of ultrasound in the healthcare setting is not a new technology; the first cardiac ultrasound was applied in the clinical setting in 1956 to diagnose patients with pericardial effusions by Edler and Hertz (as cited in Singh \& Goyal, 2007) who pioneered the use of Doppler and M-mode ultrasonography. Recent applications of echocardiography include its use in the critical care setting and is seen as "the true stethoscope, for it permits us to see what occurs beneath the surface of the skin" (Singh \& Goyal, 2007, p. 437). Progress in bioengineering has led to the miniaturization of ultrasound machines (Roelandt, 2004), allowing for critical care ultrasound, and specifically critical care ultrasound (CCU) to emerge as a feasible skill for the clinician in daily practice. A leader of the CCU movement, Paul Mayo, states “echocardiography has unparalleled utility in the intensive care unit...allow[ing] the clinician to make immediate visual diagnosis and to guide the ongoing management of the case...[and is] a key skill for the frontline intensivist" (Mayo, 2011, no page).

Numerous national and international organizations have supported the use of CCU in the intensive care unit (ICU) setting (Intensive Care Medicine, 2014; Intensive Care Medicine, 2011; Mayo et al., 2009; Price et al., 2008). Pustavoitau et al. (n.d.) reported that the American Medical Association, the American College of Emergency Physicians, and The American Society of Echocardiography support the use of limited cardiac echography/critical care cardiac ultrasound by trained providers in ICU settings for patients requiring intensive care. Additionally, standardization of proficiency for ICU providers in bedside, or basic/limited, echocardiography is supported by both the Society of Critical Care Medicine and Pulmonary Critical Care 
Medicine's recommendations for competencies for their respective fellowships (Buckley et al., 2009). In fact, the Society of Critical Care Medicine published an official statement regarding recommendations for limited critical care echocardiography, supporting the standardization of echocardiography and critical care cardiac ultrasound in all ICUs (Buckley et al., 2009).

Internationally, the Competency-Based Training in Intensive Care Medecine in Europe (CoBaTrICE), sponsored by the European Society of Intensive Care Medicine, is a suborganization whose mission is to standardize training in intensive care medicine worldwide. CoBaTrICE lists "a method for measuring cardiac output and derived hemodynamic variables" (European Society of Intensive Care Medicine, n.d.) as a competency of which all ICU providers should be proficient.

Despite the overwhelming support of intensive care organizations for CCU, no society has taken an official position regarding training and/or competency of acute care nurse practitioners (ACNP) who employ critical care ultrasound diagnostically. Critical care cardiac ultrasound core objectives allow for measuring of hemodynamic states and can assist the ACNP in achieving this important ICU skill. Moreover, this skill is important for evaluating patients and could greatly improve the care of the critically ill patient, saving lives.

\section{Background}

Providing care for patients in an intensive care unit requires specialty education by a multi-disciplinary team of providers. Due to physician shortages and implementation of acute care nurse practitioner programs in the early 1990's, modern definitions of the term "provider" in intensive care units have evolved. In 2004, over 5,000 acute care nurse practitioners were licensed by the American Nurses Credentialing Center, of which 68\% (about 2,800) were working in an intensive care setting (Kleinpell \& Goolsby, 2004). Acute care nurse practitioners 
(ACNPs) are educated in proficiencies that include critical care education and skills in coursework of advanced pharmacology, physiology, pathophysiology, and patient care management (Kleinpell, Ely, \& Grabenkort, 2008). ACNPs are specifically prepared to perform basic intensive care skills such as chest tube insertion, arterial and central line placement, endotracheal intubation, ventilator management, and hemodynamic monitoring (Kleinpell, Hravnak, \& Werner, 2006; Kleinpell et al., 2008).

The Accreditation Council for Graduate Medical Education's (ACGME) oversight and restriction on physician residency hours adds to the paradigm shift for how the term "provider" is defined in the ICU. Estimates indicate that there will be insufficient numbers of ICU trained physicians as high as $22 \%$ of demand by 2020 and as high as $35 \%$ of demand by 2030 (Angus, Shorr, White, Schmitz, \& Kelley, 2006). Acute care nurse practitioners (ACNPs) have the education and training to become proficient ICU care providers (Pastores et al., 2011). Given the opportunity to obtain proficiency in bedside critical care echocardiography, ACNPs that work in an ICU setting have the ability, and perhaps even the duty, to provide evidence-based practice medicine for all of their patients.

A report by the Health and Human Resources and Services Administration (HRSA, 2003), concluded that the increased demand of critical care trained personnel could be addressed by the use of non-physician providers, such as nurse practitioners (Squires, King, Wagner, Ashby, \& Parmley, 2013). The Society of Critical Care Medicine's (SCCM) position paper on ICU staffing incorporates HRSA's recommendations. In fact, SCCM has taken a major stance in removing language that only refers to physicians, noting that ACNPs, if properly trained, can become safe and efficient providers in the ICU setting (P. Lipsett, personal communication, September 19, 2014). 


\section{Critical Care Cardiac Ultrasound Competency}

Competence is the combination of knowledge, skills, and behavior required to perform a specific function in an adequate and well-qualified manner (Mayo et al., 2014). Competency standards are used extensively in healthcare, especially within ACNP education and training (O’Connell, Gardner, \& Coyer, 2014). A national survey by Becker et al. (2006), found that 67\% of ACNP respondents currently worked in an ICU setting. The concept of competency within the scope of education and training of intensivists [general term encompassing ACNPs] has been of discussion since the introduction and daily integration of CCU for the care of the ICU patient. Mayo et al. (2014) described CCU as "a standard skill for the intensivist" (p. 655) and competence within that skill is defined as achievement in a minimum standard for routine ICU skills, including CCU (Mayo, 2011).

Standards of competency for expert echocardiographers have been well established with physician residencies and certification exams (Intensive Care Medicine, 2011). However, expert panels and societal position statements have concluded that an intensivist should not be expected to achieve competencies equal to that of an expert echocardiographer; intensivists need only to achieve competency in basic echocardiography (Fagley et al., 2015, Intensive Care Medicine, 2014; Intensive Care Medicine, 2011; Mayo et al., 2009; Price et al., 2008). Defining how intensivists meet competency in CCU remains a controversial subject and has yet to be resolved. In addition, the standardization of how ACNPs achieve competency in CCU has also not yet been resolved. This project is an initial step to resolving how to train and evaluate ACNPs for competency in CCU.

\section{Core Concepts of Critical Care Cardiac Ultrasound}

Core concepts in critical care cardiac ultrasound are important to define when identifying 
goals for any educational program—basic or advanced. CCU allows the provider to enhance their diagnostic skills in hemodynamic monitoring to detect cardiovascular insufficiency, leading to a diagnosis of underlying pathophysiology (Strugess et al., in Lumb, 2014).

According to the Society of Critical Care Medicine, any CCU educational program should begin with reviewing the basic physics of ultrasound, ultrasound anatomy of the heart, concepts of Doppler ultrasound, and basic functions of ultrasound machines--including 'knobology', which is step by step instruction about what knob on the echocardiography machine does what function (Fagley et al., 2015). It is of upmost importance to understand these concepts to perform even the most basic CCU task.

Understanding the echocardiographic anatomy of the heart can be challenging to the novice CCU performer and interpreter. Images, collected in a non-invasive manner, are obtained using ultrasound wave trajectories that are sometimes misinterpreted because images are flipped, or are mirror images, from traditional understanding of anatomy. Determining one's orientation in accordance with probe dynamics and resulting images should be an initial focus when attempting to attain basic cardiac images (Odom, 2015).

CCU views are obtained from three areas of the thorax: left parasternal, apical, and subcostal. Critical care cardiac ultrasound examination from the left parasternal view allows for parasternal long axis (PLAX) and parasternal short axis views (SAX). The apical area results in an apical four-chamber (A4C) view of the heart. Subcostal critical care cardiac ultrasound view allows for obtaining subcostal long-axis view as well as views of the inferior vena cava. These five views of the heart are considered to be paramount to interpreting any information obtained from CCU and, therefore, are called a "FOCUS exam" (Odom, 2015; Fagley et al., 2015; Strugess et al., in Lumb, 2014). 
Determining a critically ill patient's volume status is a clinical question that many intensivists have when caring for a critically ill patient. Cardiac output is the product of stroke volume and heart rate. Two measures are widely used to determine stroke volumes: the biplane method of disks and the product of the Doppler Velocity Time Integral (VTI) and crosssectional area (CSA) of the sampling site. The biplane method of disks, also called the modified Simpson rule, calculates volume estimations of the left ventricle, thereby estimating stroke volume. Fractional area change compares area volume at end diastole and at end systole to determine the percentage of blood exiting the ventricle. Left ventricular outflow tract (LVOT) is measured from views obtained in the parasternal long axis view. Stroke volume (SV) is directly calculated by the product of the Doppler velocity time integral (VTI) and the cross-sectional area (CSA) of the Left ventricle outflow tract (LVOT). The mathematical equation is $\mathrm{SV}=\mathrm{CSA} \mathrm{x}$ VTI. Heart rate can then be used to calculate the cardiac output $(\mathrm{CO}=\mathrm{HR}$ x $\mathrm{SV})$. These methods of determining stroke volume are widely used from FOCUS exam basic views (Strugess et al., in Lumb, 2014).

\section{Theoretical Framework}

The impact that the ACNP can have with CCU use is supported by a systematic review by Kleinpell, Ely, and Grabenkort (2008) that found that nurse practitioners spend 20\% more time performing a physical assessment than other ICU providers. If ACNPs spend more time physically assessing their patients, that physical assessment should include all clinical resources available — and employ techniques and technologies used by other providers. An electronic search for studies on the integration of CCU for ACNPs for this proposal revealed that no studies have examined the feasibility of educating ACNPs in the new skill of CCU to augment patient care. This project is a first step in filling that void. 


\section{Diffusion of Innovations Framework}

Introduction of new skills (or innovation) to a well-established role (or care

environment), such as an ACNP in the ICU setting, can be adapted well within the diffusion of innovations framework. The diffusion of innovations (DOI) framework is an approach that is "less theory driven and more of a description of a process for how behavior tends to change in groups of people or communities" (Edberg, 2015, p. 61). Use of the DOI framework originated in the field of agriculture in the 1940s when mechanical innovations were lending to change in practice for farmers (Waterman et al., 2007). Modern applications of the DOI framework address an innovation and outline how the innovation should be communicated across social channels over time among members of the same social system. Several key concepts that are central to this theory are innovation development, dissemination, adoption, implementation, and maintenance (Edberg, 2015). The diffusion of innovations framework lays a well-structured pathway for recommending groundwork for the development of ACNPs in competent and basic CCU to aid in care required for modern ICU intensivists.

Innovation. Development of an innovation stems from "an idea, object, or practice that is thought to be new by an individual, organization, or community" (US Department of Health and Human Services, 2005, p. 27). Therefore, an innovation does not have to be a new technology or gadget to use in clinical practice. Within the concept of this review, the innovation is applying CCU to the daily practice of intensivists, including ACNPs.

Current literature supports the utility of CCU in the care of the critically ill patient and that CCU has a positive impact on patient care. Critical care echocardiography should be a standard practice in the ICU setting and aid in the interpretation of complex clinical scenarios, aiming to answer specific clinical questions. These recommendations are not limited to 
physicians but should encompass all ICU providers, including ACNPs.

Dissemination and Adoption. Dissemination is "the means of transmitting the new idea from one person to another" (US Department of Health and Human Services, 2005, p. 27). Edberg (2015) stated that foci are often aimed at improving the self-efficacy and skills of those adopting the innovation. For most applications of the DOI framework, effective dissemination of the innovation is often achieved by developing an educational program for teaching new adopters the skill (Edberg, 2015; Waterman et al., 2007). Formal educational programs are necessary to teach all ICU providers, including ACNPs, basic CCU skills. Although all curricula reviewed used a combination of didactic and simulation/hands-on-training, it is unclear how these programs could or should be organized. Time required to obtain competencies and number of exams necessary to achieve and maintain competencies is also unclear. However, the need for qualified educators and instructors to teach CCU is supported in the literature. Despite lack of terminology including ACNPs in these educational programs, it is of the opinion of this author that ACNPs have the foundational education necessary to become competent learners of the CCU skillset.

Quantitative studies addressing the education and evaluation of the CCU educational program are sparse and lack rigorous design. However, other quantitative studies that evaluate the impact that adopting CCU has in the daily care of the ICU patient support its use. Additionally, it is clear that CCU can inform diagnoses and potentially impact plans of care, leading to changes in that plan of care. Adoption is the acceptance of the new skill/behavior by the intended audience (Edberg, 2015). This project follows this idea and parallels educational training of intensivists to the concept of CCU as dissemination and eventual adoption in to daily clinical practice, specifically with ACNPs. 
Implementation and Maintenance. Implementation of the innovation refers to the initial use of the practice or technology. Foci of this concept includes improving the self-efficacy and skill set of the innovation adopters. Essential to implementation is having an educator to act as a resource, especially in early phases. Maintenance focuses on sustainability of the innovation within the social system to which the innovation was introduced (Edberg, 2015; Waterman et al., 2007). While this author appreciates the concepts of implementation and maintenance for fully integrating the DOI framework to the introduction of a new skill, this project focuses primarily on the concepts of innovation, dissemination, and adoption.

Despite the overwhelming support of intensive care organizations for $\mathrm{CCU}$, no society has an official position about acute care nurse practitioners (ACNP) and the use of bedside cardiac ultrasound although some already perform this skill. Because knowledge is the key element at beginning any attempt to acquire a new clinical skill (Mayo et al., 2014), providing education is an appropriate first step to acquiring knowledge. This project presents this question: can a skills based educational program be effective in teaching ACNPs core concepts of limited critical care cardiac ultrasound?

\section{Review of the Literature}

As previously mentioned, inquiries into the integration of CCU for ACNPs revealed that no studies have examined the feasibility of educating ACNPs in the new skill of CCU to maintain competent ICU skills and/or to augment patient care. Therefore, an approach to identify current literature about how other intensivists are educated in CCU was the secondary goal for this literature review.

\section{Results}

A search of the literature was conducted in July 2015 to identify existing literature 
evaluating current educational programs or curricula for the education in the skill of CCU. Literature from 2005-2015 was examined utilizing the databases of Ovid MEDLINE, PsychINFO, CINAHL, and PubMed. Limitations of the results included studies with full text availability and written in the English language. The keywords of "transthoracic echocardiogram", “echocardiogram", "intensive care unit", "training”, and "education” were used to search available studies. Inclusion criteria were the following: (1) addressed CCU education; (2) delineated CCU education different than expert echocardiography education; (3) discussed transthoracic echocardiography; (4) identified any key components of necessary CCU education curriculum. Exclusion criteria were the following: (1) reported studies completed on medical students; (2) discussed advanced CCU educational programs; (3) identified education for non-critical care bedside echocardiography/cardiac ultrasound (as with application for heart failure clinics).

From all databases, a total of 434 articles were found using the keywords. Review of all titles led to only 14 studies meeting inclusion criteria. Due to the small number of remaining articles, full text review was achievable with the 14 studies. However, only three met inclusion criteria after review. Ancestral searches of these documents resulted in 22 additional articles that were considered for review. A total of nine articles were selected and analyzed.

\section{Recommendations for Critical Care Cardiac Ultrasound Training}

Numerous U.S. and internationally based medical organizations have convened and published recommendations supporting formal educational programs for CCU. All five reports were compiled from expert panel agreements addressing what CCU training programs should encompass.

Programmatic goals to produce intensivists that are capable of answering clinical 
questions based upon basic CCU examinations are agreed upon by prominent critical care organizations (Fagley et al., 2015; Intensive Care Medicine, 2014; Intensive Care Medicine, 2011; Mayo et al., 2009; Price et al., 2008. Intensive Care Medicine, 2014; and Intensive Care Medicine, 2011). Education goals of a CCU training course should be to enhance anesthesiology/critical care training (Fagley et al., 2015), to answer specific clinical questions (Price et al., 2008; Mayo et al., 2009), and be regarded as a standard skill for the intensivist (Intensive Care Medicine, 2014). The Society of Critical Care Medicine distinguishes between goals of basic CCU and advanced CCU, noting that advanced CCU is an optional component of training (Intensive Care Medicine, 2014). Consensus was also found among the position statements that CCU should be viewed as a standard and necessary skill for the intensivist (Fagley et al., 2015; Intensive Care Medicine, 2014; Intensive Care Medicine, 2011; Mayo et al., 2009; Price et al., 2008. Intensive Care Medicine, 2014; and Intensive Care Medicine, 2011). Despite this consensus, Fagley et al., (2015) report that only $60 \%$ of accredited programs by the Society for Critical Care Anesthesiology offered formal ultrasound and echocardiography/cardiac ultrasound training to their critical care fellows and residents.

Recommendations for CCU learning goals included acquiring competency at obtaining standard CCU views (Fagley et al., 2015; Intensive Care Medicine, 2014; Intensive Care Medicine 2011; Mayo et al., 2009), such as parasternal long axis and parasternal short axis, and apical views. All recommendations included a combination of didactic and hands on training. But recommended time frames to achieve these views (and subsequent interpretation) varied. Fagley et al. (2015) delineated necessary time frames for becoming familiar with the CCU equipment (45 minutes) and obtaining standard CCU views (180 minutes), stating that didactic time ranges from 4-10 hours. This conflicts with Intensive Care Medicine's (2011) statement that 
a total of 10 hours of lecture and didactic time is needed to achieve basic competency.

The most variability between consensus statements was the number of practice exams suggested to become proficient at the basic CCU level; Fagley et al. (2015) report 30-50 exams but Intensive Care Medicine (2011) report 30 exams are suggested. Intensive Care Medicine (2014) state that determination of image acquisition skill for basic CCU is the responsibility of the local expert, but delineate 100 transthoracic echocardiogram exams are needed to achieve advanced CCU. Intensive Care Medicine (2011) reports that there was no evidence-based literature to support number of images needed to achieve basic $\mathrm{CCU}$, nor a consensus among societies. The World Interactive Network Focused on Critical Ultrasound's (WINFOCUS) position statement for training of CCU outline levels of competence, starting with emergent echo (basic) and leading to level 3 (expert with TEE). WINFOCUS does not specify how many images are needed to be competent at the emergent or level 1 phase, only noting that a logbook should be kept to track cases as learning progresses (Price et al., 2008).

\section{Findings regarding CCU educational programs}

While societal stances support the use of CCU in the intensive care setting, few studies have actually examined the efficacy of the process by which one becomes proficient in any level of CCU. Breitkreutz et al. (2009) sought to enable novice echocardiographers to perform a focused CCU and interpret findings in the context of the clinical scenario. This prospective observational study was of interest to this author because of its one-day course design with a blended format (didactic with hands on training). The participants were given pre-educational materials from which they familiarized themselves with how to use the CCU machine and how to obtain basic views. The on-site course consisted of four hours of additional didactic and four hours of hands on training (HOT). Breitkreutz et al.'s (2009) approach to the HOT was to use 
problem-based approaches, using a combination of healthy and 'chronic disease state' (e.g., pericardial effusions) models from which to practice CCU views. Skill acquisition was established from pre-program testing of pre-educational materials; the HOT instructors gave participants scores for their HOT efforts. Although Breitkreutz et al. (2009) concluded "this newly-developed blended learning peri-resuscitation echocardiography programme [sic] may serve as entry level...for both emergency physicians and critical care physicians" (p. 292). However, the authors did not include supporting data analyses to make this conclusion.

To integrate CCU training into a surgical critical care fellowship program, Killu et al. (2014) assessed the impact that an extended, short course training in CCU might have on patient care in the ICU setting. The critical care fellows received twelve disease-focused sessions that were conducted over a year's time. Each session was designed to have thirty minutes of didactic training followed by sixty minutes of HOT. Each fellow was required to obtain 25-50 exams for the evaluation of their patient, however each participant and supervising interpreter was not blinded to the patient's admission. The retrospective review included 203 patients for 873 exams $-27.4 \%$ of which were cardiac CCU. The fellows reported that, of these cardiac exams, CCU resulted in at least one new diagnosis in $65.52 \%$ of patients $(95 \% \mathrm{CI}[0.590,0.720])$ and the exam resulted in a change in management in $36.95 \%$ of patients $(95 \% \mathrm{CI}[0.303,04.35])$. Although statistics were not reported, Killu et al. (2014) stated the fellows reported selfsufficiency was obtained at an average of three months' time.

A shortened course for CCU basic proficiency was also of interest to Sekiguchi et al. (2012). The study reported the efficacy of a multimedia approach to didactic and HOT would have to teaching CCU to ICU attendings and critical care medicine fellows. Sekiguchi et al.'s (2012) approach to training was three hours of web-based didactic lectures followed by 120 
minutes of a HOT workshop in a simulation center. Immediately after the HOT session, the participants were required to test their HOT skills by obtaining three diagnostic tasks within five minutes. The participants were tested on their timing to complete the tasks and quality of the CCU images obtained. Theory knowledge was tested at three different time points: preworkshop, after the three hours of web-based didactic lectures and post-workshop after their HOT testing. Knowledge and interpretation of CCU images improved pre- compared to postworkshop with mean (SD) scores of 16.4 (4.9) and 24.2 (3.8), respectively, out of a maximum score of $30(p<0.001)$. Subjective confidence scores were examined (on a ten point Likert scale) and were found to improve, with median scores (25-75 percentile) of $1.0(1.0-2.3)$ improving to $7.0(6.0-8.0)$ after the workshop $(p<0.001)$.

Vignon et al. (2007) abbreviated the goals of CCU to performing goal-oriented echocardiography in critically ill ICU patients. This modified curriculum was preferred in order "to answer the following "rule in, rule out" clinical questions: presence of a left ventricular (LV) systolic dysfunction (eye-ball evaluated ejection fraction $\leq 50 \%$ ), LV dilatation, right ventricular (RV) dilatation (cor pulmonale), uncomplicated pericardial effusion or tamponade, and presence of pleural effusion" (p.1796). The course included three hours of didactic instruction with five hours of supervised HOT. The hands on training component utilized actual ICU patients rather than healthy models. The critical care residents then obtained 10-12 patient exams over a twomonth period. An experienced CCU intensivist observed and then compared his exam to the resident results. The trained intensivist had significantly less unaddressed clinical questions than the residents $(0.8 \%$ vs $27 \%$ of 366 clinical questions; $p<0.001)$ but supported the hypothesis that a focused training session could be of assistance to an ICU provider to answer complex, but focused, clinical questions. 
The aforementioned four studies support the idea that CCU educational curricula can vary in format (real-time versus web-based), time required for hands on training, and setting for hands on training (simulation versus real patients). However, the variation in training structure leads to the same multi-organizational outcome goal of training providers that are capable of answering clinical questions based upon basic CCU examinations (Fagley et al., 2015; Intensive Care Medicine, 2014; Intensive Care Medicine, 2011; Mayo et al., 2009; Price et al., 2008. Intensive Care Medicine, 2014; and Intensive Care Medicine, 2011).

\section{Limitations of Literature Review}

Despite the utility of CCU to augment traditional care for patients requiring medical care in the ICU, training for CCU in the ICU setting remains a debated and sparsely studied subject. This was evident when searching for quality evidenced-based research examining the literature for a standard training program. However, the view of the importance of CCU in the care of ICU patients is obvious by the numerous, major national and international societal position statements regarding CCU's use. Mayo (2011) reports that statements "of competence are very specific; statements on training are less so" (no page).

More studies are needed to determine the best strategies for developing CCU educational programs, with inclusion of ACNPs as part of skilled providers. Although many organizations have published position statements regarding CCU use in the ICU setting, few studies have been conducted examining how or why providers actually change their approach to care. More specific outcomes need to be identified when assessing quality of educational curricula, including how many exams are needed to deem one competent in CCU. The overarching limitation is lack of ACNP inclusion in societal statements and studies that examine the utility of CCU in the ICU setting. Moreover, more studies should examine the potential impact that 
ACNPs could have when utilizing CCU in the care they provide to critically ill patients.

\section{Implications for ACNPs in CCU Education}

The American Association of Colleges of Nursing (AACN), the professional body by which ACNP programs are accredited, states a core competency of ACNP education is diagnosis of health status. ACNPs are educated to manage and evaluate acute, critical, and chronically ill patients "through ordering, interpretation, performance, and supervision of diagnostic testing and clinical procedures" (AACN, 2012, p. 18). Because ACNPs are being utilized currently and will be utilized more as part of ICU provider models in the near future (Squires et al., 2013), education and maintenance of core competencies for ICU providers must include ACNPs. A current structure exists for ACNPs to be included in the concept that "basic level critical care echocardiography should be a required part of training of every ICU physician" (Mayo, 2011, no page) but acceptance of ACNPs has yet to be achieved — at least in the language of position statements and formal recommendations for training.

\section{Introduction of Project Question}

ACNPs are competent ICU providers who will continue to be key players in providing care for intensive care patients. Future inclusion of ACNPs is necessary for continued and formal education to maintain modern skills for the care of ICU patients. However, ACNPs must also meet standards and competencies set for ICU physicians in basic critical care cardiac ultrasound to continue to provide safe and effective care. This project presents this question: is it feasible for a skills based limited educational program to be effective in teaching ACNPs core concepts of critical care cardiac ultrasound? Focusing on critical care cardiac ultrasound's core objectives allow for measuring of hemodynamic states and can assist the ACNP in achieving this important ICU skill. Moreover, this skill is important for evaluating patients and could greatly affect the 
care of the critically ill patient, saving lives.

The major goal of this project was to evaluate the feasibility of a skills based limited critical care cardiac ultrasound (SBLCCU) educational program for ACNPs to determine whether the program was effective in teaching ACNPs the skill set necessary to use LCCU as a diagnostic tool. It is important to note that a limited CCU differs from standard CCU, as discussed. For purposes of this project, terminology of a 'limited critical care cardiac ultrasound' (LCCU) will be used because participants were not taught the full, extensive traditional critical care cardiac ultrasound. Instead, participants were only taught one aspect of the CCU. 


\section{Methods}

\section{Introduction}

Acute care nurse practitioners are competent intensivists who currently provide and will continue provide care to ICU patients in the future, especially as the need for adequately skilled providers increases as physician shortages worsen. ACNPs should maintain required diagnostic skills, both basic and advanced, that are required of all intensivists. The absolute lack of literature addressing ACNP utilization and education of CCU requires that a basic foundation should be constructed and then evaluated before making determinations of skill ability. This project began to build that foundation by examining the effectiveness of a skills based education program that teaches ACNPs basic LCCU skills. Because volume status is a clinical question that intensivists address frequently in clinical practice (Strugess et al., in Lumb, 2014), the focus of the educational program included evaluating effectiveness of a focused educational course, obtaining basic views for calculating stroke volume/cardiac output, and calculating stroke volume/cardiac output.

\section{Research Design}

This quasi-experimental feasibility study utilized examined whether participation in the Skills Based Limited Critical Care Cardiac Ultrasound Course for ACNPs (SBLCCU) improves knowledge level and clinical ability to conduct and to interpret LCCU.

\section{Statement of Purpose and Hypothesis}

The purpose of the study was to evaluate the feasibility of a skills based limited critical care cardiac ultrasound educational program for acute care nurse practitioners (SBLCCU) aimed at evaluating volume status. The three-part hypothesis for this study was: Participation in this SBLCCE, will improve ACNPs' 
1) ability to understand core concepts of LCCE,

2) ability to obtain basic echocardiograph views necessary to evaluate a patient's volume status, and

3) ability to calculate stroke volume/cardiac output accurately.

\section{Definition of Terms}

Operational definitions of several key terms are described as the following:

- An acute care nurse practitioner (ACNP) is a master's-prepared or doctoralprepared nurse who has undergone board certification in the care of adults in the acute care (or hospital) setting.

- An intensivist is a provider, physician or nurse practitioner, who provides care for patients in an intensive care unit.

- Critical care cardiac ultrasound (CCU) is the structural evaluation, by way of ultrasonography, the organ system of the heart. Terminology of a 'limited critical care cardiac ultrasound' (LCCU) replaces CCU because participants were not taught the full, extensive traditional critical care echocardiograph/cardiac ultrasound. Instead, participants were taught only one aspect of CCU. Additionally, the term critical care was only used in theoretical applications, as no patients requiring critical care were evaluated in this study.

- Skills based education is meant to include the instruction of basic concepts of limited critical care cardiac ultrasound and educating intensivists to evaluate a single clinical question.

- Determination of volume status was the single clinical question upon which this skills based educational program focused. Stroke volume and cardiac output are 
directly related to a patient's volume status and these terms were used, in the context of this study, interchangeably.

- Proficiency of the ACNPs ability to obtain adequate views to evaluate a patient's volume status was determined by two board certified anesthesiologists who also have a specialty certification in echocardiography. This operational definition mimics how physicians were deemed proficient in key research previously conducted (Beraud, Rizk, Pearl, Liang, \& Patterson, 2013; Breitkreutz et al., 2009; Killu et al., 2014; Sekiguchi et al., 2012; Vignon et al., 2007).

\section{Setting}

The setting was an academic tertiary medical center in a metropolitan city in the midAtlantic region of the United States. The actual program/educational intervention took place in a simulation center adjacent to this academic tertiary medical center. Setting approval for this study was obtained from the lead ACNP of the participants, the director of surgical nurse practitioners, and by the anesthesiologists leading the course. All persons involved in the setting approval were provided an electronic copy of the study proposal prior to the course. The actual program/educational intervention was held on January 21, 2016.

\section{Program Description and Procedures}

Recruitment. Participants were voluntarily recruited via email from a group of ACNPs who currently work in a surgical ICU and, after inclusion/exclusion criteria were confirmed, verbal consent was obtained from all participants on the day of the SBLCCU.

Study procedures. The ACNPs knowledge level was measured by a multiple-choice test, the Critical Care Cardiac Ultrasound Knowledge Test (See Appendix C), at three interval test points: (1) before participation in the course and before any LCCU education was provided; (2) 
after participation in the Skills Based Limited Critical Care Ultrasound Course for ACNPs; and (3) between one to two weeks following participation in the Skills Based Limited Critical Care Ultrasound Course for ACNPS. Additionally, this study measured the clinical ability of the ACNPs to obtain adequate LCCU views needed to calculate cardiac output, via the Limited Critical Care Ultrasound Views Clinical Ability Test (at one point during the formalized LCCU program). This study also tested the ability of the ACNP to calculate stroke volume/cardiac output, called the Stroke Volume/Cardiac Output Clinical Ability Test, at the end of the educational course and one week after the SBLCCU.

The first knowledge level was assessed approximately two weeks before the SBLCCU via the Critical Care Cardiac Ultrasound Knowledge Test, a multiple choice knowledge level 16item pre-test (See Appendix C). The test was collected from but not reviewed by the instructor with the participants. This test was used to establish a baseline understanding of LCCU and was used in data analyses.

Approximately two weeks before the educational program, participants were emailed preeducational materials in the format of three training videos previously developed by Vanderbilt University’s Emergency Medicine Ultrasound Fellowship, directed by Rob Ferre, MD (Ferre, R., n.d.; Ferre, R., n.d.; Ferre, R., n.d.). The three training video's foci include: (1) introduction to echocardiography physics; (2) introduction to Doppler; and (3) basic and advanced CCU views. Internet link addresses to these open-access videos can be found in Appendix B. Additionally, one article about LCCU was emailed for the participants to review prior to the formalized education (Beaulieu \& Marik, 2005) (See Appendix B). It was estimated that pre-educational material review took approximately one hour to one and a half hours to complete.

On the day of the Skills Based Limited Critical Care Ultrasound Course for ACNPs', 
participants met in the simulation lab. The course instructor, an anesthesiologist who is also board certified in echocardiography and critical care medicine, conducted a four-hour didactic power-point presentation. Objectives of the power-points were to describe basic concepts of critical care cardiac ultrasound and Doppler as well as how to obtain basic critical care cardiac ultrasound views needed to stroke volume/calculate cardiac output (See Appendices D and E). This was an interactive learning activity, meaning that participants asked questions during the lecture and the anesthesiologist used the echocardiograph machine to demonstrate concepts presented. Additionally, the participants were able to watch the anesthesiologist practice obtaining views on a medical model (a live person) to begin understanding proper technique of obtaining the standard views.

The same Critical Care Cardiac Ultrasound Knowledge Test was then given to the participants and completed after the lectures but not reviewed with the participants.

After this didactic portion of the Skills Based Limited Critical Care Ultrasound Course for $A C N P s^{\prime}$, the anesthesiologist led the hands-on-training portion of the program. An additional anesthesiologist, also board certified in both echocardiography and critical care medicine, also assisted participants in the hands-on-training. The hands on training was conducted on two healthy volunteers (one per training station). Therefore, the instructor to student ratio was one anesthesiologist (instructor) for every two or three participants (student). Training objectives for the hands-on-training included: (1) demonstration of how to obtain basic echocardiography views; (2) instruction on how to use views to obtain measurements needed to determine volume status/cardiac output; and (3) participants demonstrated return ability these skills with immediate feedback from the anesthesiologists. It was during this hands-on-training that the two anesthesiologists assured that the participants understood how to obtain necessary LCCU views 
and how to accurately calculate measurements of stroke volume/cardiac output via fractional area change and left ventricular outflow tract measurement/velocity time interval.

The clinical ability examination portion of the study had two parts. The first part included obtaining the four adequate views needed for measuring stroke volume/cardiac output, called the Limited Critical Care Ultrasound Views Clinical Ability Test (see Appendix F). One at a time, the ACNPs demonstrated these four LCCU views and both anesthesiologists evaluated if the ACNP correctly obtained the views. Only the ACNP and the two anesthesiologists were present during the examination. The second part of the clinical ability testing, called the Stroke Volume/Cardiac Output Clinical Ability Test, was a pre-determined echocardiography simulation case taken from one of the medical models that was reviewed by the ACNP participant to calculate stroke volume/cardiac output using fractional area change and left ventricular outflow tract measurement/velocity time interval. See Appendix G for the Stoke Volume/Cardiac Output Clinical Ability Test sheet. The combined hands-on-training and clinical ability testing was estimated to take five hours.

One week after the Skills Based Limited Critical Care Ultrasound Course for ACNPs', an email was sent to all ACNP participants with the same Critical Care Cardiac Ultrasound Knowledge Test questions and were asked to repeat the same Stroke Volume/Cardiac Output Clinical Ability Test (on the same medical model electronic simulation case). Participants answered the knowledge test on their own time but completed the Stroke Volume/Cardiac Output Clinical Ability Test while working within one to two weeks after the educational course. To summarize:

- Two weeks before course: email of the Limited Critical Care Cardiac Ultrasound Knowledge Test (participants emailed back answers) 
- Approximately two weeks before course: emailed link to the pre-educational materials

- Day of course:

- In morning: lectures presented then participants retook Critical Care Cardiac Ultrasound Knowledge Test

- In afternoon: Hands on Training (HOT) then participants completed 1) Limited Critical Care Cardiac Ultrasound Views Clinical Ability Test; and 2) Stroke Volume/Cardiac Output Clinical Ability Test

- One to two weeks after course: email of Critical Care Cardiac Ultrasound Knowledge Test (participants emailed back answers) and participants retook the same Stroke Volume/Cardiac Output Clinical Ability Test

\section{Description of the Sample}

The number of participants for this study was five, who were obtained from a convenience sample of ACNPs who currently work in a surgical intensive care unit. Inclusion criteria from this sample included willingness to voluntarily participate all components of course (including all knowledge level and clinical ability testing) and English-speaking. Exclusion criteria from this sample were any formalized CCU or LCCU education, inability to participate in any component of the course, and non-English speaking. Drop-outs were not experienced during this feasibility study.

Of the five study participants, all were masters-prepared advanced practice nurses and all were board certified as acute care nurse practitioners (ACNPs). All participants identified themselves as females and the average age of the participants was 34.6. The average number of years as an ACNP in an ICU setting was 3.6 years. 


\section{Measures of Reliability}

Inter-relater reliability was anticipated for the knowledge test by expert agreement (among two anesthesiologists who are board certified in echocardiography) on the questions and multiple-choice answers. Reliability of the Limited Critical Care Cardiac Ultrasound Views Clinical Ability Test (See Appendix F) was anticipated with agreement, of real-time scores, between the same anesthesiologists. The second Stroke Volume/Cardiac Output Clinical Ability Test (Appendix G) was anticipated to be achieved based upon the inter-relater reliability of the two expert anesthesiologists. However, the second anesthesiologist was not able to calculate stroke volume/cardiac output because of time constraints.

\section{Protection of Human Subjects}

Institutional Review Board (IRB) policies and procedures of the academic tertiary medical center were followed, which included approval from the IRB board (see Appendix H). Additional approval was obtained from the University of Virginia's IRB board (see Appendix I).

The risk to the ACNP participants and the two medical models was minimal. Per the IRB requirements, consent was obtained from the participants and the medical models. Copies of the consents were given to the participants and medical models. Additional information for a "subsequent findings plan" was given to the medical models. Both participants and medical models were encouraged to verbalize any concerns or discomfort.

\section{Data Analysis}

Descriptive measures were used to evaluate the data utilizing Stata/MP (StataCorp, 2015). Evaluation of knowledge level of each participant, by scores of the Critical Care Cardiac Ultrasound Knowledge Test (see Appendix C), was determined using a paired $t$-test to evaluate if 
differences existed between knowledge levels at three different time periods. A McNemar's chisquare test evaluated the clinical abilities of the ACNPs to obtain adequate LCCU views. ACNP performance evaluation of the Stroke Volume/Cardiac Output Clinical Ability Test at two points in time (immediately post-education and at one week post-education) was completed using a paired $t$-test.

However, Leon, Davis, \& Kraemer (2011) suggest that pilot/feasibility studies should not aim to produce statistically significant results, i.e. $p$ values. Instead, feasibility studies should be used to evaluate recruitment, interventional design, and implementation of the novel intervention-leading to larger scale studies that utilize inferential statistics (Leon, Davis, \& Kraemer, 2011). 


\section{Results}

\section{Critical Care Cardiac Ultrasound Knowledge Test}

Mean scores of the Critical Care Cardiac Ultrasound Knowledge Test were obtained preeducation, the day of education (day-education), and one to two weeks after the SBLCCU course (post-education). The mean scores are raw scores out of the sixteen-item multiple-choice test. Mean pre-education scores (SD) were 7 (1.73) and improved to 9 (2.16) the day of the course (day-education). Post-education scores were 10 (3.74). When comparing differences between the groups, mean scores pre-education were not significantly different than the day-education scores $(p=0.141)$. Additionally, there was no significant difference between the mean scores of the preeducation scores and the post-education scores $(p=0.158)$. However, there was no significant difference between day-education scores and post-education scores $(p=0.675)$. See Appendix L.

\section{Limited Critical Care Cardiac Ultrasound Views Clinical Ability Test}

When the two anesthesiologists evaluated the ACNPs for their ability to obtain adequate basic LCCU views, there was no significant difference in their evaluation of the twenty distinct views $(p=0.317)$. Qualitative evaluation of the views test revealed that four of the five participants were able to achieve satisfactory images of all four basic views. One participant was able to obtain two satisfactory views (parasternal short axis and apical four chamber), while not achieving adequate views on the remaining two views (parasternal long axis and apical five chamber). See Appendix L for the graphical representation of these results.

\section{Stroke Volume/Cardiac Output Clinical Ability Test}

Evaluating ability for the ACNPs to adequately measure calculate stroke volume/cardiac output was completed from the medical model electronic simulation case. Allowance for $10 \%$ 
variance of answers of both Fractional Area Change (FAC) and Cardiac Output (CO) were deemed satisfactory/correct (Vieillard-Baron et al., 2003), with the correct answer of FAC being 61\% (range 54.9-67.1) and CO being 4.5 liters (range 4.05-4.95). For FAC, only two of the five participants achieved satisfaction the day of education; no participants achieved correct scores post-education. Comparison of raw scores of FAC for the day-education (63.44 \pm 16.6$)$ was not significantly different than post-education scores $(62.78 \pm 23.69)(p=0.936)$, even though the mean for the post-education FAC was closer to the correct FAC. For CO, three of the five participants achieved satisfaction the day of education; no participants achieved correct scores post-education. Comparison of raw scores for $\mathrm{CO}$ for the day-education $(4.33 \pm 0.76)$ was not significantly different than post-education scores $(3.84 \pm 0.91)(p=0.377)$. Qualitative evaluation of the scores revealed that for both $\mathrm{FAC}$ and $\mathrm{CO}$ the range of answers were wider for the post-education testing, meaning they were more incorrect when tested one to two weeks after the SBLCCU. Additionally, if one person was incorrect in their FAC or CO measurements for the day-education, they were more likely to be incorrect for the post-education measurements ( $p$ $=0.083)$. See Appendix L for these findings.

\section{Discussion}

\section{Implications of Results for Feasibility of Future CCUS for ACNPs}

Despite the overwhelming recommendations that all intensivists should be proficient in CCU (Fagley et al., 2015; Intensive Care Medicine, 2014; Intensive Care Medicine, 2011; Mayo et al., 2009; Price et al., 2008. Intensive Care Medicine, 2014; and Intensive Care Medicine, 2011), there have been no studies to date that have examined how ACNPs can be educated in CCU. Bowen, et al. (2009) state performing a feasibility study is indicated when "there are few previously published studies or existing data using a specific intervention technique" (p. 2) and 
"the population or intervention target has been shown empirically to need unique consideration of the topic, method, or outcome". (p.3). This feasibility study was one step toward the goal of educating ACNPs that work collaboratively with physicians, both as intensivists, to maintain guidelines of care.

The primary focus of this project was to examine the feasibility of implementing a skillsbased limited CCU course for ACNPs. Implementation is one of eight general areas upon which feasibility studies can be focused (Bowen et al, 2009) when examining the "concern[ing] the extent, likelihood, and manner in which an intervention can be fully implemented as planned and proposed, often in an uncontrolled design" (p.3). The first step in this project was to gain insight in to how the administrators viewed the ACNP's role in the surgical ICU. Although not previously discussed in this manuscript, major stakeholders (ICU surgical and anesthesia directors) overwhelmingly supported the concept of ACNPs being educated in CCU/LCCU, as well as potentially being educators for surgical and anesthesia residents who train in the same surgical ICU. This acceptance was critical when examining the potential of expanding nonphysician intensivist diagnostic skills. Additionally, insight in to how the ACNPs viewed their potential acceptance and integration of CCU/LCCU into their daily practice was key; all five ACNPs were eager to learn this skill that they witnessed other intensivists employing on a daily basis. The ACNPs were confident in their clinical expertise to become knowledgeable in $\mathrm{CCU} / \mathrm{LCCU}$, adding to their ability to properly care for their ICU patients by more accurately evaluating measures of volume status and cardiac function. Acceptance by the ACNPs is equivocal in importance to gaining acceptance by stakeholders.

Access to trained and proficient providers of CCU is also another component of this project that was important. The individuals teaching CCU should have extensive background in 
basic and advanced CCU concepts, performing CCU, and implementing CCU in to clinical practice (Society of Critical Care Anesthesiologists, 2015; Fagley et al. 2015). Both anesthesiologists are board certified in both anesthesiology and echocardiography; both were enthusiastic about being a part of this project and willing to teach the ACNPs basic concepts of CCU and LCCU. Additionally, both anesthesiologists routinely hold CCU courses at major teaching institutions and are part of CCU task forces for several national organizations. It goes without saying that having knowledgeable individuals at the same institution that the ACNPs work in was paramount to being able to plan and implement the SBLCCU course.

The data analysis for this project could be improved upon in future LCCU courses. Although there were qualitative improvements of the ACNP's knowledge over time, this was not statistically significant. However, it was interesting to observe that the ACNPs retained the knowledge taught during the SBLCCU course at one to two weeks post-education despite not having formalized reinforcement of the information. Inferences could be made that ACNPs do have the capacity to understand and maintain core CCU/LCCU concepts needed to perform LCCU.

The ACNPs ability to obtain adequate LCCU images is important to discuss despite having non-statistical significance with any of the project inquires. Observationally, there was agreement between the two anesthesiologists that the ACNPs could obtain adequate views. Of the twenty images obtained, $90 \%$ (18 out of 20 ) of the images were deemed, by both anesthesiologists, adequate to make perform diagnostic calculations of cardiac function. Additionally, four ACNPs obtained all four views (100\%) adequately. The fact that one ACNP had difficulty with two views supports that additional one-on-one reinforcement of technique could improve the ACNP's ability to adequately obtain all views for LCCU. 
When analyzing the ability of the ACNPs to adequately perform the Stroke Volume/Cardiac Output Clinical Ability Test, it was interesting to discover that so few participants were able to adequately calculate FAC and $\mathrm{CO}$. In fact, it was alarming that none of the participants were able to correctly perform either test post-education (one to two weeks after SBLCCU). One hypothesis for these results is that the medical model electronic simulation case was not as standardized as the study coordinator originally thought. The video clips were three to five seconds in length. Variability in FAC and/or CO could be normal differences of stroke volume with each heartbeat (Vieillard-Baron et al., 2003), i.e. if one ACNP measured FAC and/or at the first heartbeat vs the third heartbeat, they would achieve different answers. Standardizing which heartbeat to measure FAC and/or $\mathrm{CO}$ is not feasible, as judgments in which heartbeat is best could differ from participant to participant. In addition, it would be interesting to examine components of $\mathrm{FAC} / \mathrm{CO}$ to see where the most errors were made. For example, if participants estimated ventricular area at systole accurately but struggled with diastole (for FAC) then re-education would only need to be focused at one area. The same approach could be employed when examining Cardiac Output answers; did participants estimate velocity time interval (VTI) accurately but have varying answers for left ventricular outflow tract and/or HR (or any variation thereof)? This also could be opportunity for focused re-education where standard deviations in answers had the most variation.

\section{Strengths and Weaknesses of the Design}

A major strength of this study design is that the Skills Based Limited Critical Care Cardiac Ultrasound Course for ACNPs' simulates numerous other shortened courses aimed at educating physician providers in concepts of traditional CCE (Manasia et al., 2005; Breitkreutz et al., 2009; Killu et al. 2014; Sekiguchi et al., 2012; Vignon et al., 2007). In contrast to these 
studies, however, this study uses ACNPs as participants, which is something that, to this author's knowledge, has not been studied before. The Skills Based Limited Echocardiography Course for $A C N P s^{\prime}$ is a one-day course, which is more feasible than more formalized, multiday courses offered by large organizations. This feasibility includes decreased time and decreased cost required for the course. The course is also easily re-producible for multiple providers, given its one-day design. Aspects that allowed for decreased cost of SBLCCU were the project coordinator's ability to borrow, free of charge, three ultrasound machines from the institution's medical simulation lab and the anesthesiologists who taught the course volunteered their time. Additionally, classroom space was available free of charge. The study coordinator also employed Bachelors of Science in Nursing students as the medical model volunteers instead of using more costly medical models already established with the institution.

The ability to keep the number of participants limited could be considered a strength of this feasibility study. Sekiguchi et al. (2012) had trainee to instructor ratios of 2:1 for their hands on training sessions; no other studies reported their trainee to instructor ratio nor do organizations suggest standardized trainee to instructor ratios. For SBLCCU, the hands on training portion of the study allowed for a trainee to instructor ratio of $2.5: 1$.

Generalizability of the objectives, focus, and design of this SBLCCU course in other settings should be met with caution. Additionally, interpreting this study's results to be that ACNPs do not have the skills necessary to become proficient in LCCU would be of great concern. There are many weaknesses of the design to this feasibility study.

One of the major weaknesses (from a data analysis perspective) of the Skills Base Limited Echocardiography Course for ACNPs' includes the small number of participants. It was necessary to limit the number of participants for this particular one-day design because not all 
ACNPs could be absent from patient care in the ICU during an eight-hour period. However, the limited number of participants was problematic when attempting to identify statistically significant differences between the variables. Factor analysis for an appropriate sample size for SBLCCU was not attempted, thus establishing statistical power with these results was not achieved (Munro, 2005). However, it is suggested that establishing power for feasibility studies is not always required to discern if a particular study design is feasible to reproduce on a larger scale (Bowen et al. (2009); Leon et al, 2011).

Although using healthy volunteers and a case study lent to the ease of the course, this could also be seen as a weakness. Reproducing images on sick patients in an ICU setting can be one of the most difficult aspects of obtaining adequate LCCU images (Odom, 2005). The Skills Based Limited Echocardiography Course for ACNPs' only focuses on evaluating a patient's cardiac output, which is one aspect of many questions that can be answered with a full CCU examination. All providers who are beginning to incorporate $\mathrm{CCU}$ in to their clinical skillset must understand limitations to all LCCU examinations and seek advice of more experienced CCU providers when clinical questions arise. Most importantly, all providers using LCCU in their clinical practice must acknowledge that LCCU does not replace formalized echocardiography examinations that are performed by echocardiography technicians and interpreted by certified echocardiologists and cardiologists.

Retrospectively, one drawback to this study's design was the lack of knowledge reinforcement from the day-education to the post-education. The ACNP participants were neither encouraged nor discouraged from practicing LCCU on their ICU patients. Neither the instructors nor the study coordinator discussed concepts of LCCU with the participants after the course. This could have resulted in the outcome that none of the participants were able to correctly 
perform the Stroke Volume/Cardiac Output Clinical Ability Test one to two weeks posteducation.

An additional unexpected change to the original course design was the inability to teach the biplane method of disks, also called the Modified Simpson's Rule. The biplane method of disks is a test that calculates volume estimations of the left ventricle, thereby estimating stroke volume, and is considered one of the three basic exams (along with FAC and $\mathrm{CO}$ ) to determine a patient's volume status (Strugess et al., in Lumb, 2014). It was a goal of the study coordinator to have the participants learn and complete the biplane method of disks. However, on the day of the SBLCCU the anesthesiologists could not get the computer program to work correctly. The study coordinator determined that this would be taught at a later time.

\section{Advanced Practice Nursing Implications}

The Centers for Medicare and Medicaid Services (CMS) have begun, as of October 10, 2015, requiring that ICU providers document assessment of volume status and tissue perfusion for patients with diagnosed shock. This assessment includes a bedside cardiovascular ultrasound/echocardiograph and documentation of assessment of fluid responsiveness. The Centers for Medicare and Medicaid Services have designated that a critical care echocardiograph is an appropriate way to obtain this assessment. This 'core measure' assessment is to be completed within six hours of the patient's presentation to an acute care setting (Kleinpell, 2015). Septic patients are admitted to critical care units at all hours of the day and all ICU providers must be competent in assessing a patient's cardiovascular assessment and fluid responsiveness, as this core measure stipulates. For ACNPs to comply with these CMS requirements, ACNPs must be skilled in all ICU procedures to provide adequate care.

In accordance with multiple critical care society's position statements on critical care 
skills, ACNPs should have the education to become proficient LCCU and CCU performers. This is an initial step at supporting this statement, potentially proving that ACNPs can adequately perform this necessary ICU skill. Although data has been shown that skills based LCCU programs are a valid way to educate physicians for $\mathrm{CCU}$, no published studies were found that aim education only for ACNPs that care for patients requiring critical care. This project examined the effectiveness of just one educational design.

Advancing nursing practice is a focus of the American Association of Colleges of Nursing, an organization through which all of the participants and the surgical ICU's ACNPs are licensed through as advanced practice nurses. Two main foci of "The Essentials of Doctoral Education for Advanced Nursing Practice" is using technology to improve patient care and collaborating with other professionals to improve patient outcomes (AACN, 2006). This study addresses both of those foci by incorporating the technology of critical care cardiac ultrasound into a collaborative practice with our physician intensivist counterparts.

\section{Products of the DNP Capstone Project}

Review of the results and re-design of the course will be completed, as necessary, with the anesthesiologists that conducted the educational component. One variable already discussed is lengthening the time between the day-education and post-education evaluations. Breitkreutz et al. (2009) allowed for 50 exams before evaluating providers on efficiency. Killu et al. (2014) required 25-50 exams before determining hemodynamic status. Vignon et al. (2007) allowed for two months of practice before testing ICU residents for goal-oriented LCCU exams. All of these studies suggest that giving the ACNPs one to two weeks to process LCCU was not enough time. Future examinations of ability to perform LCCU and calculate SV/CO could be determined at longer time intervals. 
The overall goal of this program is to develop a critical care echocardiography course that can be taught to other ICU providers, physicians and non-physicians, on a quarterly basis. A goal of this author is to develop similar skills based LCCU programs that can answer other clinical questions (e.g. valvular abnormalities or cardiac wall motion abnormalities) that any acute care provider needs answered to deliver efficient, timely, and cost-effective care.

Future courses to teach the remaining ACNPs LCCU are already underway. Additional analyses could strengthen these results, lending to more generalizability of the course for future intensivists. It will also be interesting to evaluate the ACNPs satisfaction with the design and objectives of the course. A course evaluation will be added to future courses to evaluate the ACNPs confidence at performing LCCU. Sekiguchi et al. (2014) reported that the greater the confidence of physicians to perform CCU at pre-workshop, the greater the skills test scores postworkshop. This could also be a variable of interest as more ICU providers learn LCCU/CCU. As of February 2016, two posters have been presented at conferences. The information contained on the posters are direct products of this DNP proposal (Solis, 2015, May.; Solis, 2015, September.; Solis, 2015, November.)

A formal manuscript will be written per guidelines of the Journal of the American Association of Nurse Practitioners. See Appendix M for the guidelines of this specific journal. Although one of the primary interests of this specific journal is to publish original research, the intent of this author's manuscript is to publish a 'brief report' on the current state of CCU/LCCU and its potential clinical application and role development for practicing ACNPs. 


\section{References}

American Association of Colleges of Nursing. (2006). The essentials of doctoral education for advanced nursing practice. Retrieved from http://www.aacn.nche.edu/dnp/Essentials.pdf.

American Association of Colleges of Nursing. (2012). Adult-gerontology acute care nurse practitioner competencies. Washington, DC: American Association of Colleges of Nursing.

Angus, D.C., Shorr, A.F., White, A., Schmitz, R.J., Kelley, M.A. (2006). Critical care delivery in the United States: Distribution of services and compliance with leapfrog recommendations. Critical Care Medicine, 34,1016-1024.

Beaulieu, Y., \& Marik, P.E. (2005). Bedside ultrasonography in the ICU; Part I. Chest, 128(2), $881-895$.

Becker, D., Kaplow, R., Muenzen, P., \& Hartigan, C. (2006). Activities performed by acute and critical care advanced practice nurses: American association of critical-care nurses study of practice. American Journal of Critical Care, 15, 130-148.

Beraud, A.S., Rizk, N.W., Pearl, R.G., Liang, D.H., \& Patterson, A.J. Focused transthoracic echocardiography during critical care medicine training: Curriculum implementation and evaluation of proficiency. Critical Care Medicine, 41(8), e179-e181.

Breitkreutz, R., Uddin, S., Steiger, H., Ilper, H., Steche, M., Walcher, F., Via, G., \& Price, S. (2009). Focused echocardiography entry level: New concept of a 1-day training course. Minerva Anestesiologica, 75(5), 285-292.

Buckley, J.D., Addrizzo-Harris, D.J., Clay, A.S., Curtis, J.R., Kotloff, R.M., Lorin, S.M., Murin, S., Sessler, C.N., Rogers, P.L., Rosen, M.J., Spevetz, A., King, T.E., Malhotra, A., \& 
Parsons, P.E. (2009). Multisociety Task Force Recommendations of Competencies in Pulmonary and Critical Care Medicine. American Journal of Respiratory and Critical Care Medicine, 180(4), 290-295.

Bowen, D.J., Kreuter, M., Spring, B., Cofta-Woerpel, L., Linnan, L., Weiner, D., Bakken, S., Kaplan, C.P., Squiers, L., Fabrizio, C., Fernandez, M. (2009). How we design feasibility studies, American Journal of Preventative Medicine, 36(5), 452-457.

Edberg, Mark. (2015). Essentials of health behavior: Social and behavioral theory in public health. Burlington, MA: Jones \& Barlett Learning.

European Society of Intensive Care Medicine (n.d.) Competency-Based training in intensive care medecine in Europe: CoBaTrICE. Retrieved from the CoBaTrICE website: http://www.cobatrice.org/en/index.asp.

Fagley, R., Haney, M., Beraud, A., Comfere, T., Kohl, B., Merkel, M., Pustavoitau, A., von Homeyer, P., Wagner, C.E., \& Wall, M. (2015). Critical care basic ultrasound learning goals for American anesthesiology critical care trainees: Recommendations from an expert group. Anesthesia Analgesia, 120(5), 1041-1053.

Ferre, Rob. (n.d.). Basic and advanced critical care echocardiography views [online video]. Retrieved from: https://vimeo.com/117873840.

Ferre, Rob. (n.d.) Introduction to doppler [online video]. Retrieved from: https://vimeo.com/137894811.

Ferre, Rob. (n.d.) Introduction to ultrasound physics [online video]. Retrieved from https://vimeo.com/99688279.

Intensive Care Medicine. (2011). International expert statement on training standards for critical care ultrasonography. Intensive Care Medicine, 37, 1077-1083. 
doi:10.1007/s00134-011-2246-9

Intensive Care Medicine. (2014). International consensus statement on training standards for advanced critical care echocardiography. Intensive Care Medicine, 40, 654-666.

Johns Hopkins Medicine Office of Human Research. (2012). Exempt Research Studies Involving Human Subjects. Retrieved from http://www.hopkinsmedicine.org/institutional_review_board/guidelines_policies/guidelines/ exempt_research.html.

Killu, K., Coba, V., Mendez, M., Reddy, S., Adrzejewski, T., Huang, Y., Ede, J., \& Horst, M. (2014). Model point-of-care ultrasound curriculum in an intensive care unit fellowship program and its impact on patient management. Critical Care Research and Practice, 2014. doi: $10.1155 / 2014 / 934796$

Kleinpell, R.M., Ely, E.W., \& Grabenkort, R. (2008). Nurse practitioners and physician assistants in the intensive care unit; An evidence-based review. Critical Care Medicine. $36,10,2888-2897$.

Kleinpell, R.M., \& Goolsby, M.J. (2004). American Academy of Nurse Practitioner national nurse practitioner sample survey; Focus on acute care. Journal of the American Academy of Nurse Practitioners, 18, 393-394.

Kleinpell, R.M., Hravnak, M., \& Werner, K.E. (2006). Skills taught in acute care NP programs: A national survey. Nurse Practitioner. 31(7), 11-13.

Kleinpell, R. M., Hudspeth, R., Scordo, K. A., \& Magdic, K. (2012). Defining NP scope of practice and associated regulations: Focus on acute care. Journal of the American Academy of Nurse Practitioners, 24(1), 11-18. doi:10.1111/j.1745-7599.2011.00683. 
Leon, A.C., Davis, L.L., Kraemer, H.C. (2011). The role of interpretation of pilot studies in clinical research. Journal of Psychiatric Research, 45(5), 626-629.

Manasia, A. R., Nagaraj, H.M., Kodali, R. B., Croft, L B., Oropello, J. M., Kohli-Seth, R., Leibowitz, A. B., DelGiudice, R., Hufanda, J. F., Benjamin, E. B., \& Goldman, M. E. (2005). Feasibility and potential clinical utility of goal-directed transthoracic echocardiography performed by noncardiologist intensivists using a small hand-held device (SonoHeart) in critically ill patients. Journal of Cardiothoracic and Vascular Anesthesia, 19(2), 155-159.

Marik, Paul E., \& Mayo, Paul. (2008). Certification and training in critical care ultrasound. Intensive Care Medicine, 34(2), 215-217.

Mayo, Paul. H. (2011). Training in critical care echocardiography. Annals of Intensive Care, 1(36). doi:10.1186/2110-5820-1-36.

Mayo, Paul.H., and Vieillard-Baron, A. (2014). International consensus statement on training standards for advanced critical care echocardiography. Intensive Care Medicine, 40(5), 654666.

Mayo, P. H., Beaulieu, Y., Doelken, P., Feller-Kopman, D., Harrod, C., Kaplan, A., Oropello, J., Vielliard-Baron, A., Lichtenstein, D., Maury, E., \& Vignon, P. (2009). American college of chest Physicians/La societe de reanimation de langue francaise statement on competence in critical care ultrasonography. Chest, 135(4), 1050-1060. doi:10.1378/chest.08-2305.

Munro, Barbara Hazard. (2005). Statistical Methods for Health Care Research. Philadelphia, PA: Lippincott Williams, \& Wilkins.

Newhouse, R., Dearholt, S., Poe, S., Pugh, L.C., \& White, K. (2005). The Johns Hopkins Nursing Evidence-based Practice Rating Scale. Baltimore, MD.: The Johns Hopkins 
University Press.

O'Connell, J., Gardner, G., \& Coyer, F. (2014). Beyond competencies: Using a capability framework in developing practice standards for advanced practice nursing. Journal of American Nursing, 70(12), 2728-2735. doi:10.1111/jan12475

Odom, Stephen. (2015). Proceedings from Ultrasonography for Intensivists and Emergency Medicine Clinicians: Ultrasound Anatomy of the Heart, Basic TTE Views and Eyeballing Principle. Boston, MA: Harvard Medical School/Beth Israel Deaconess Medical Center.

Pastores S, O’Connor M, \& Kleinpell R. (2011). The accreditation council for graduate medical education resident duty hour new standards: history, changes, and impact on staffing of intensive care units. Critical Care Medicine, 39, 2540-2549.

Price, S., Via, G., Sloth, E., Guarracino, F., Breitkreutz, R., Catena, E., \& Talmor, D. (2008). Echocardiography practice, training and accreditation in the intensive care: Document for the world interactive network focused on critical ultrasound (WINFOCUS).

Cardiovascular Ultrasound, 6, 49-7120-6-49. doi:10.1186/1476-7120-6-49 [doi]

Pustavoitau, A., Blaivas, M., Brown, S., Gutierrez, C., Kirkpatrick, A., Kohl, B., Oren-Grinberg, A., \& Frankel, H.L. (n.d.). Recommendations for achieving and maintaining competence and credentialing in critical care ultrasound with focused cardiac ultrasound and advanced critical care echocardiography. Retrieved from The Society of Critical Care Medicine website: http://journals.lww.com/ccmjournal/Documents/Critical\%20Care\%20Ultrasound.pdf

Roelandt, J. R. T. C. (2004). Ultrasound stethoscopy. European Journal of Internal Medicine, 15(6), 337-347.

Sekiguchi, H., Suzuki, J., Gharacholou, S. M., Fine, N. M., Mankad, S. V., Daniels, C. E., Gajic, 
D., \& Kashani, K. B. (2012). A novel multimedia workshop on portable cardiac critical care ultrasonography: A practical option for the busy intensivist. Anaesthesia \& Intensive Care, 40(5), 838-843.

Singh, S., \& Goyal, A. (2007). The origin of echocardiography: A tribute to Inge Edler. Texas Heart Institute Journal / from the Texas Heart Institute of St.Luke's Episcopal Hospital, Texas Children's Hospital, 34(4), 431-438.

Society of Critical Care Anesthesiologists. (2015). Critical care basic ultrasound learning goals for American anesthesiology critical care trainees: Recommendations from an expert group. Anesthesia-Analgesia, 120(5), 1041-1053.

Solis, Abbye. (2015, May). Use of Bedside Cardiac Ultrasound in the Surgical Intensive Care Unit: Potential Practice Implications for Acute Care Nurse Practitioners. Poster presentation at The Johns Hopkins Nursing Research Day, Baltimore, Maryland.

Solis, Abbye. (2015, September). Use of Bedside Cardiac Ultrasound in the Surgical Intensive Care Unit: Potential Practice Implications for Acute Care Nurse Practitioners. Poster presentation at ACNP Bootcamp at Vanderbilt University, Nashville, Tennessee.

Solis, Abbye. (2015, November). State of the Literature: Critical Care Echocardiography Education and Potential Implications for ACNPS. Poster presentation at the Washington Regional Nursing Research Consortium, $6^{\text {th }}$ Annual Doctoral Student Research Conference at The Catholic University of America in Washington, DC.

Squires, J., King, J., Wagner, C., Ashby, N., \& Parmley, C. L. (2013). ACNP intensivist: A new ICU care delivery model and its supporting educational programs. Journal of the American Association of Nurse Practitioners, 25, 119-125.

StataCorp LP. (2016). Stata/MP. College Station, TX: StataCorp LP. 
Sturgess, D., Hamilton, D., Sargsyan, A., Lumb, P., \& Karakitsos, D. (2014). Hemodynamic monitoring considerations in the intensive care unit. In P. Lumb (Ed.), Critical care ultrasound: Expert consult (193-199). Philadelphia, PA: Elsevier.

U.S. Department of Health and Human Services. (2005). Theory at a glance; A guide for health promotion. $2^{\text {nd }}$ Ed. NIH Publication No. 05-3896.

Vieillard-Baron, A., Sebastien, P., Chergui, K., Dubourg, O., \& Jardin, F. (2003). Hemodynamic instability in sepsis: Bedside assessment by doppler echocardiography. American Journal of Respiratory and Critical Care Medicine, 168, 1270-1276.

Vignon, P., Dugard, A., Abraham, J., Belcour, D., Gondran, G., Pepino, F., Marin, B., Francois, B., \& Gastinne, H. (2007). Focused training for goal-oriented hand-held echocardiography performed by noncardiologist residents in the intensive care unit. Intensive Care Medicine, 33, 1795-1799. doi:10.1007/s00134-007-0742-8

Waterman, H., Marshall, M., Noble, J., Davies, H., Walshe, K., Sheaff, R., \& Elwyn, G. (2007). The role of action research in the investigation and diffusion of innovations in health care: the PRIDE project. Qualitative Health Research, 17, 373-381. 


\section{Appendix A}

\section{Demographic Data of ACNP Participants}

Name:

Age:

Gender: Male/Female

Highest level of education completed:

Years as an ACNP:

Years as an ACNP in surgical ICU setting: 
Appendix B

Pre-educational Materials

Pre-education videos:

Vanderbilt University's Emergency Medicine Ultrasound Fellowship Training Videos:

- Introduction to Ultrasound Physics: https://vimeo.com/99688279

- Introduction to Doppler: https://vimeo.com/137894811

- Basic and Advanced CCE Views: https://vimeo.com/117873840

Written electronic permission obtained from Rob Ferre, MD on September 27, 2015.

Pre-education article:

Beaulieu, Y., \& Marik, P.E. (2005). Bedside ultrasonography in the ICU; Part I. Chest, 128(2), 881-895. 


\section{Appendix C}

Critical Care Cardiac Ultrasound Knowledge Test

Name:

Score:

I

\section{Critical Care Cardiac Ultrasound Test}

\section{Part 1}

1 This transthoracic echocardiography view is Attachments

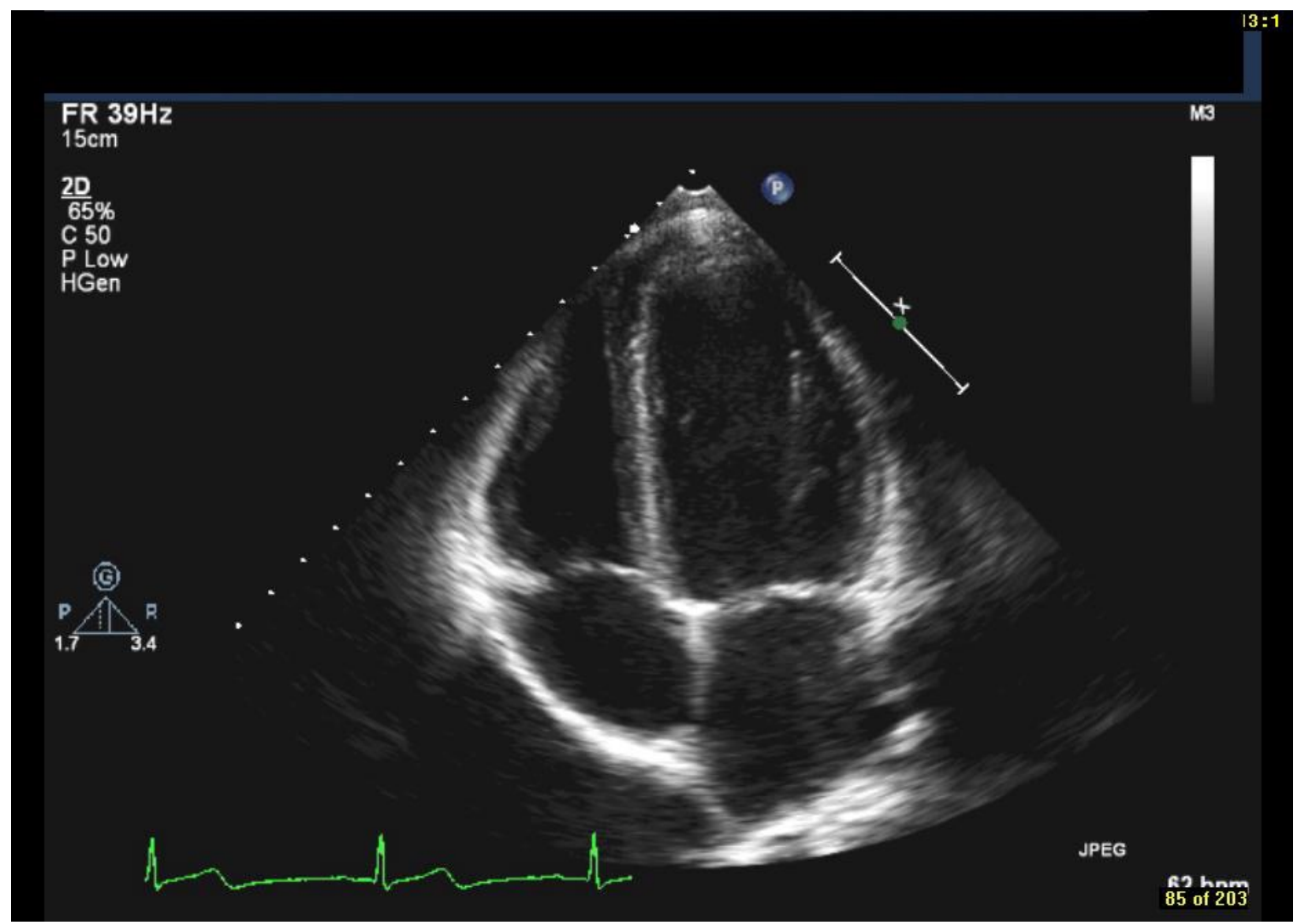
A. Parasternal long axis
B. Parasternal short axis
C. Apical 4 chamber
D. Subcostal 4 chamber

For the view displayed in the previous question, the orientation marker should be placed 


\section{Appendix C (cont.)}

Critical Care Cardiac Ultrasound Knowledge Test
A. At 3 o'clock
B. At 12 o'clock
C. At 9 o'clock
D. At 6 o'clock

This view can be used for (check all can apply)

A. Assessment of left ventricular systolic function

B. Assessment of right ventricular function

C. IVC size and respiratory variation

D. Distinction between pericardial and pleural effusion

4 This view is

Attachments

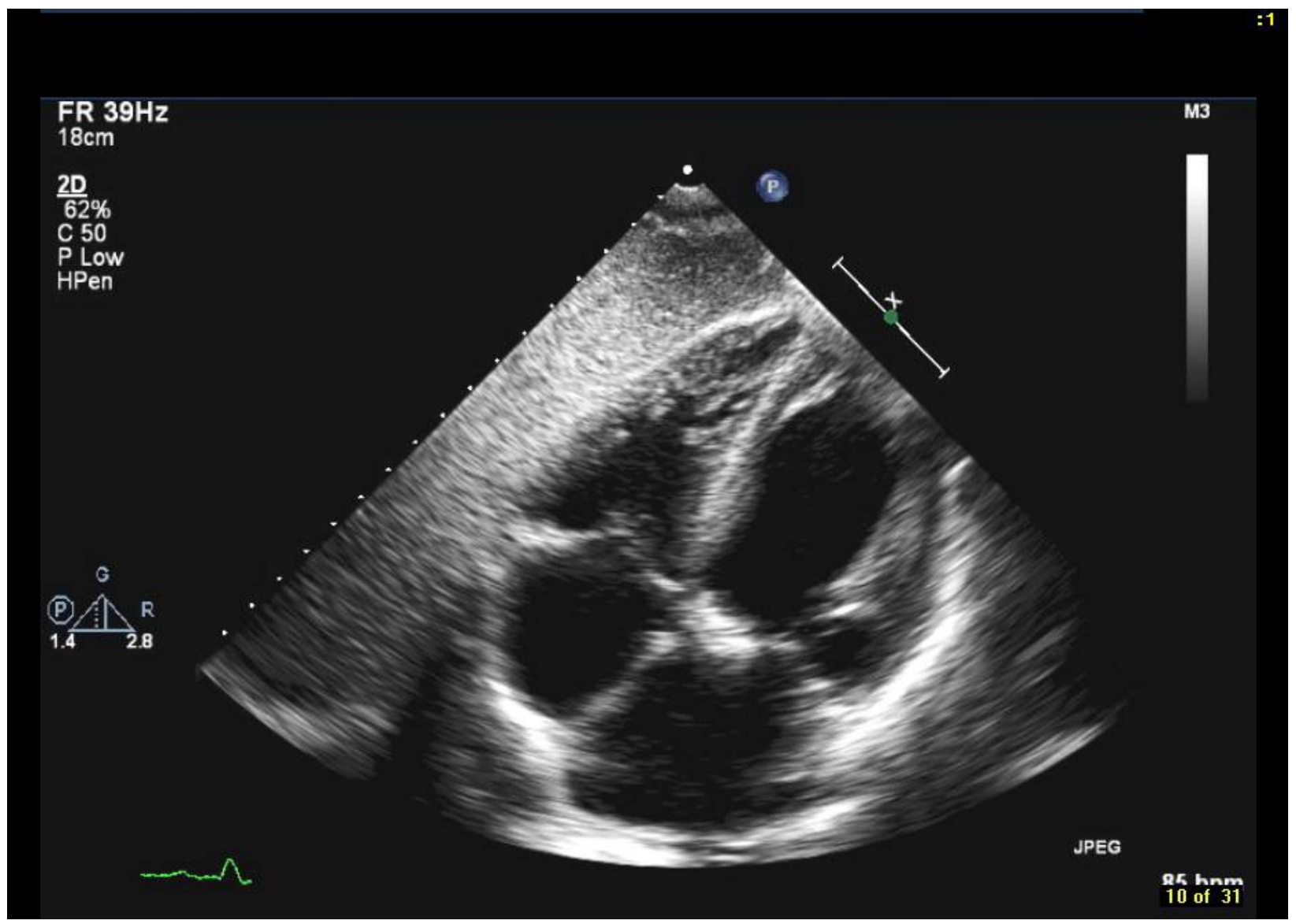




\section{Appendix C (cont.)}

\section{Critical Care Cardiac Ultrasound Knowledge Test}
A. Apical 4 chamber
B. Subcostal 4 chamber
C. Apical 5 chamber
D. Parasternal long axis
E. Parasternal short axis

What can this view be used for? (check all can apply)
A. Detection of aortic stenosis
B. Calculation of cardiac output
C. Assessment of right ventricular function
D. Detection of pericardial effusion
E. Assessment of left ventricular function

What is this transthoracic view?

\section{Attachments}

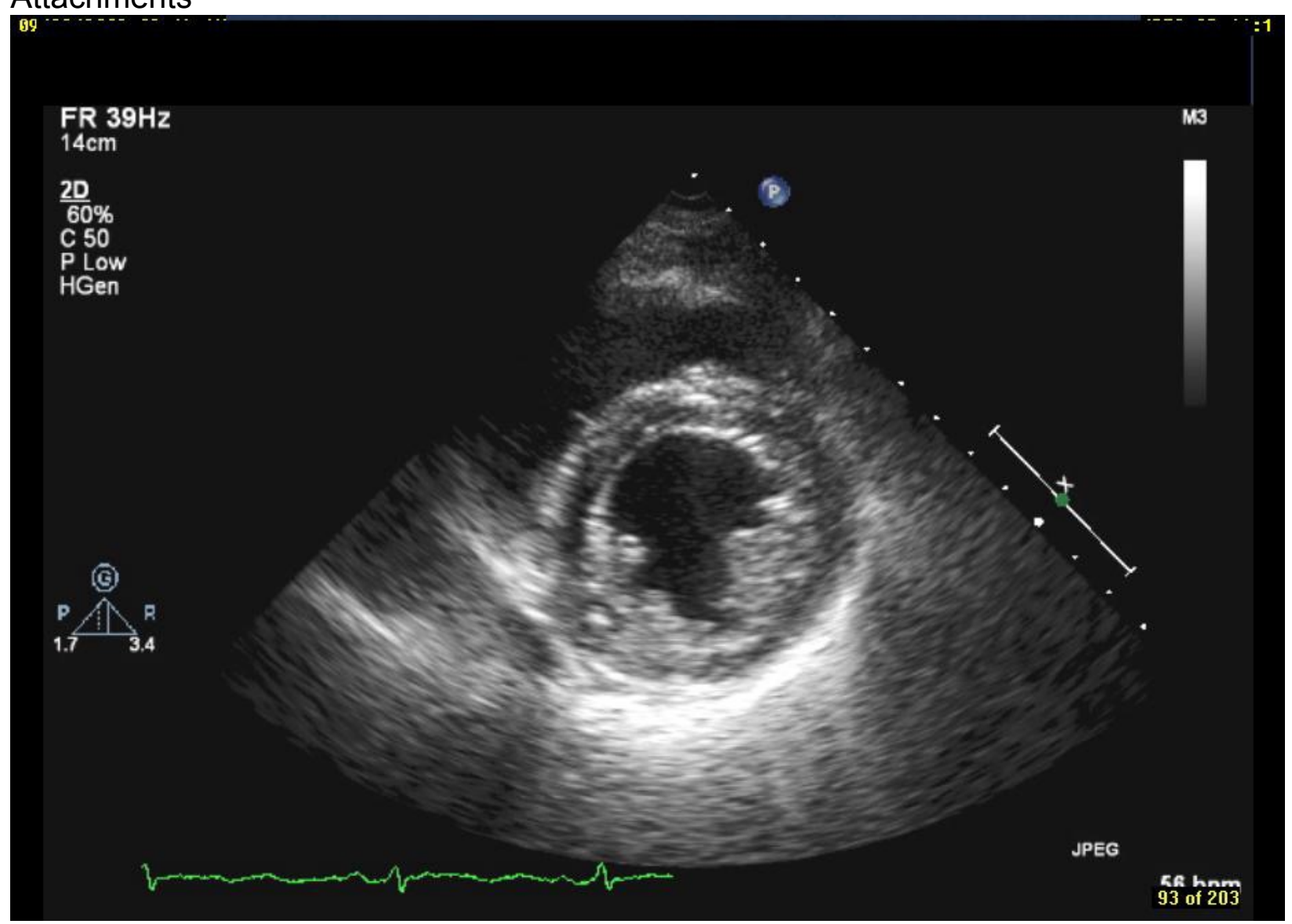


Appendix C (cont.)

\section{Critical Care Cardiac Ultrasound Knowledge Test}
A. Parasternal short axis on the aortic valve
B. Parasternal short axis on the papillary muscle
C. Subcostal 4 chamber
D. Cross-section of the IVC
E. Parasternal long axis
F. Apical 4 chamber

Where should be directed the marker on the probe for the view displayed in the previous question?
A. Toward the patient's right shoulder
B. Toward the patient's left shoulder
C. Toward the patient's left foot
D. Toward the patient's right foot

What are the criteria of quality for this view? (check all can apply)
A. You should see the apex
B. The left ventricle should be ovoid
C. The papillary muscles should be on the top of the image
D. The papillary muscles should be symmetric in the left ventricle
$E$. The left ventricle should be round

The view displayed in question 6 can be used to assess (check all can apply)
A. RV function
B. presence of pericardial effusion
C. LV function
D. size of the atria
E. aortic stenosis

The left ventricular function can be assessed from any kind of images, not necessarily from standard views
$€$ True
$€$ False

The right ventricular function can be assessed from
A. Parasternal long axis
B. Parasternal short axis 


\section{Appendix C (cont.)}

\section{Critical Care Cardiac Ultrasound Knowledge Test}

C. Apical 4 chamber

D. Subcostal 4 chamber

E. All are true but I need at least 2 different views

\section{Left pleural effusion is located in space}

Attachments

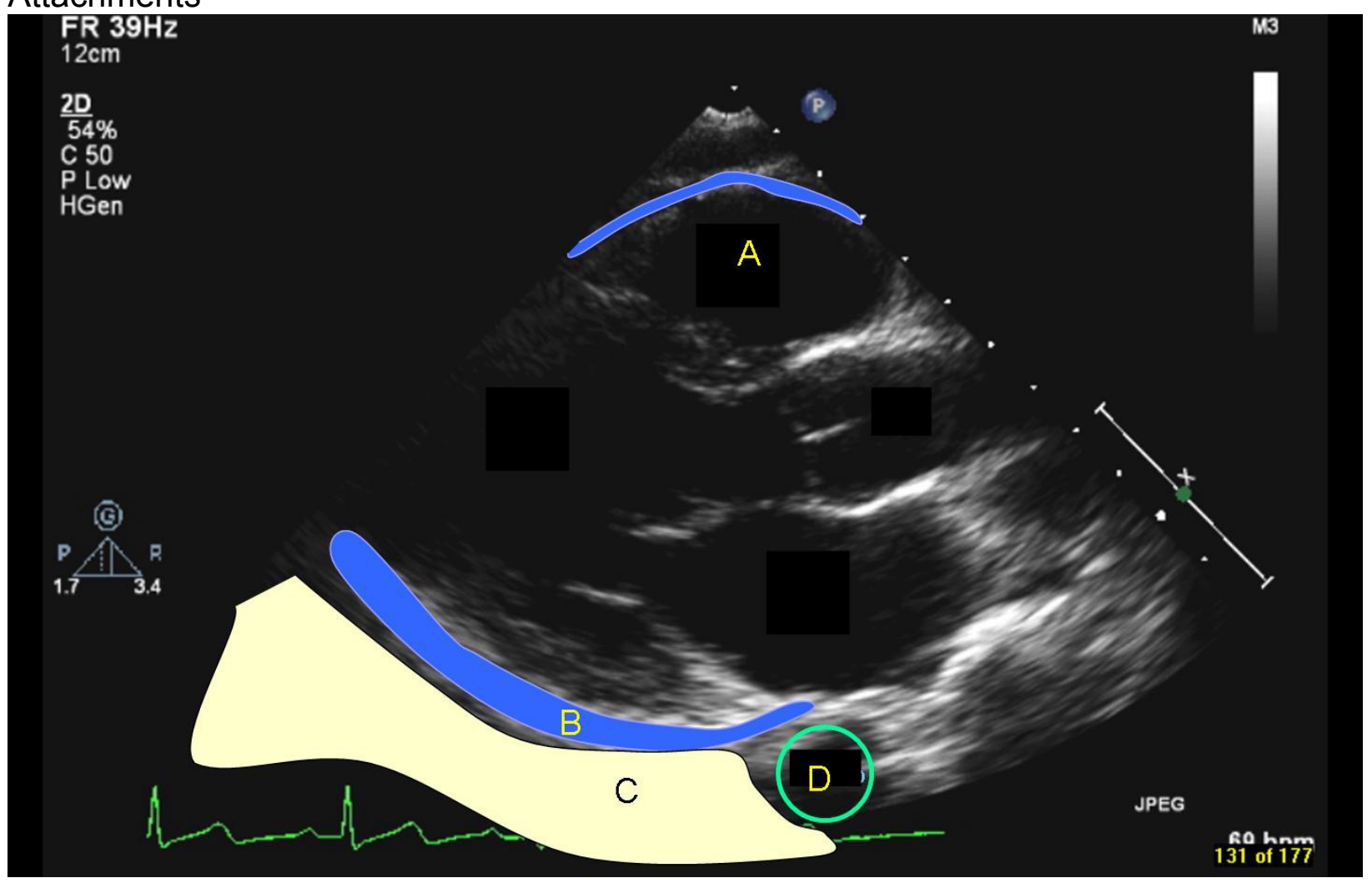
A. A
B. B
C. C
D. D

The most important indice to differentiate the IVC from the abdominal aorta is
A. the IVC is smaller
$B$. the aorta does not have respiratory variations
C. the IVC is not pulsatile
$D$. the IVC is merging into the right atrium
$E$. their direction is different 
Appendix C (cont.)

Critical Care Cardiac Ultrasound Knowledge Test

14 The IVC should be measured at location Attachments

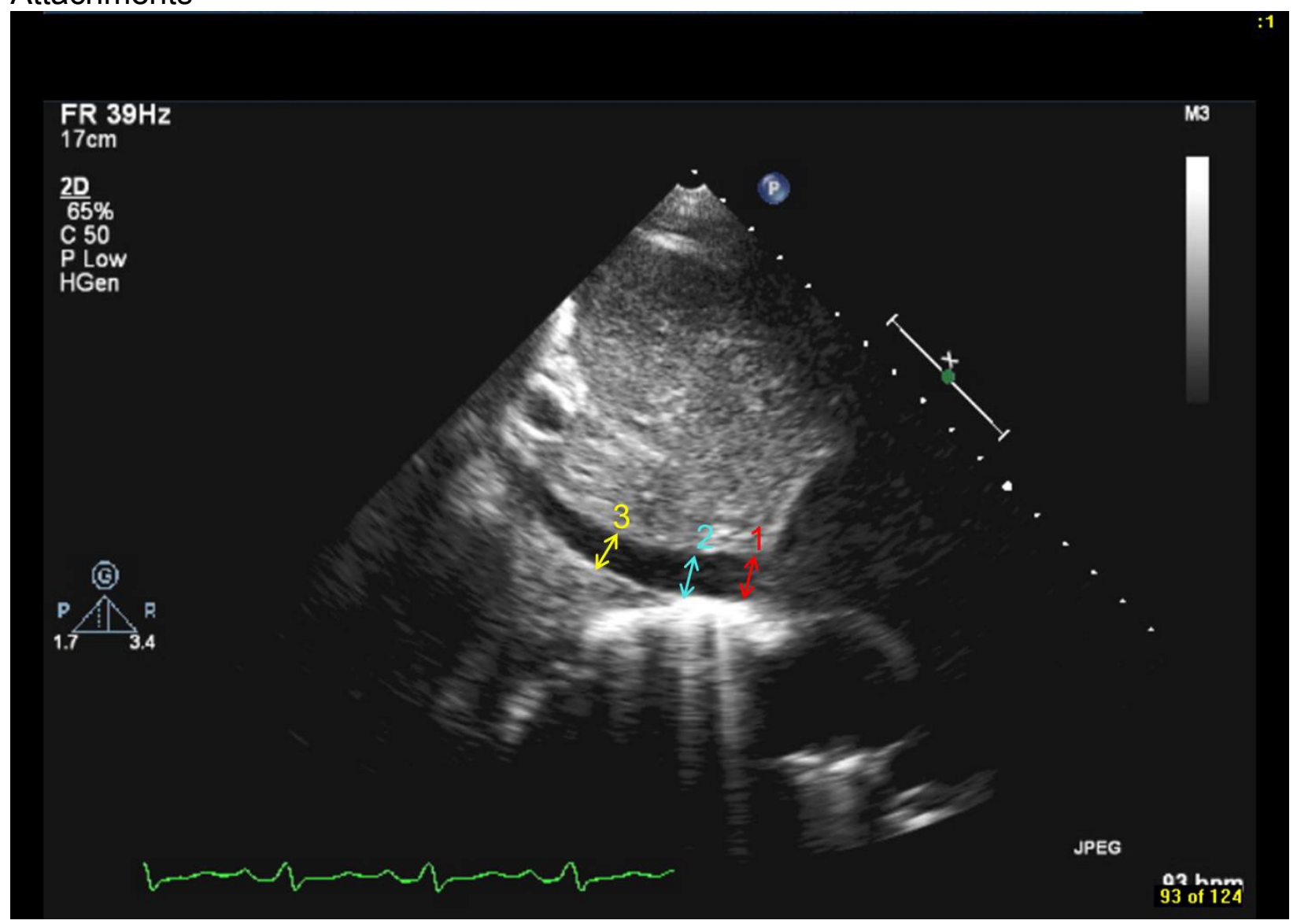
A. 1
B. 2
C. 3

In normal right ventricle

A. The size of the right ventricle is bigger than the size of the left ventricle

$B$. The size of the right ventricle is less than $2 / 3$ of the size of the left ventricle 


\section{Appendix C (cont.)}

\section{Critical Care Cardiac Ultrasound Knowledge Test}

16 In this view, can you recognize the heart structures?

\section{Attachments}

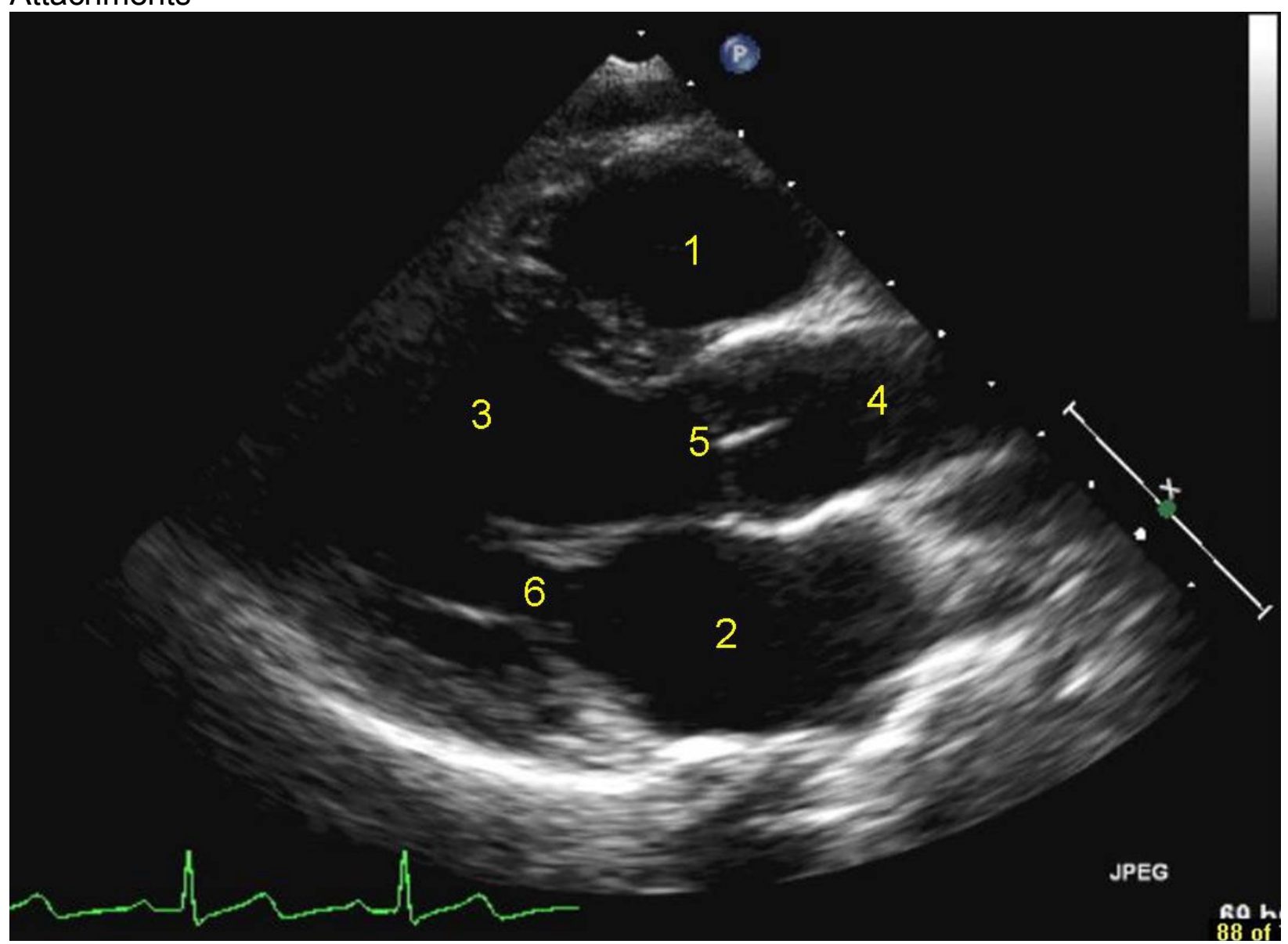

1. 1 A. Mitral valve

2. 2 B. Aortic valve

3. 3 C. Ascending aorta

4. 4 D. Right ventricle

5. $5 \mathrm{E}$. Left ventricle

6. $6 \mathrm{~F}$. Left atrium 


\section{Appendix D}

Introduction to Critical Care Echocardiography Lecture

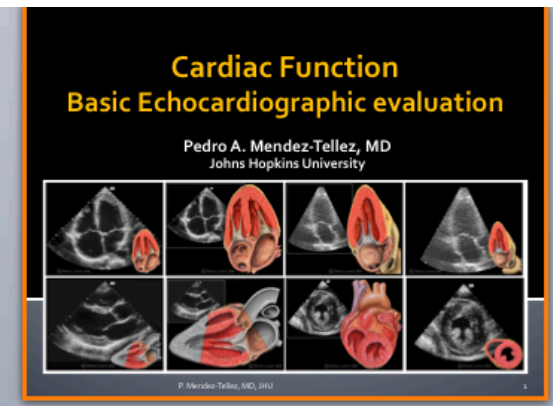

Standard Apical 4 Chamber View

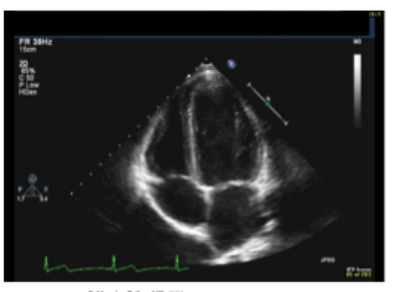

Standaard Apical 5 Chamber View

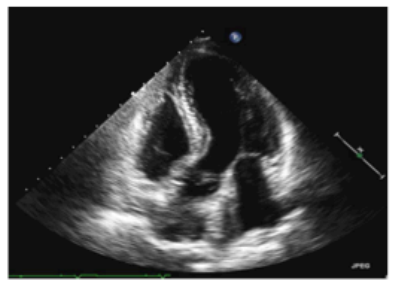

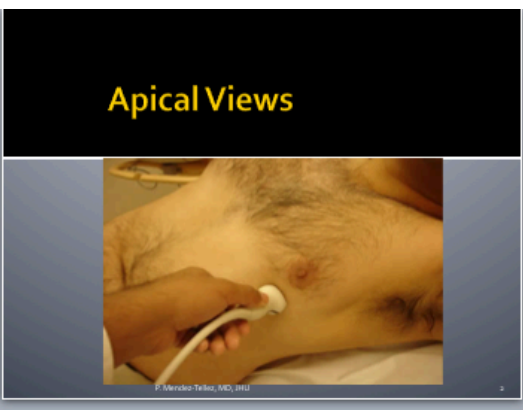

Standard Apical 5 Chamber View

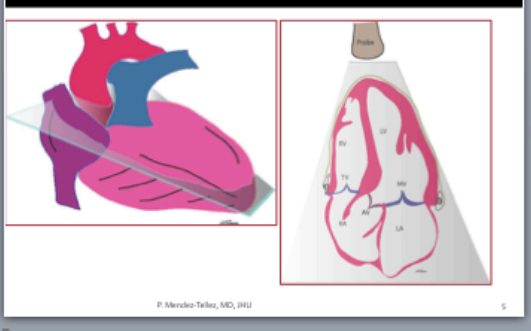

Standard Apical 2 Chamber View

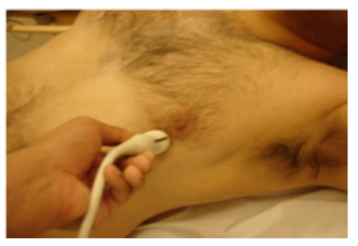

Standard Apical 4 Chamber View

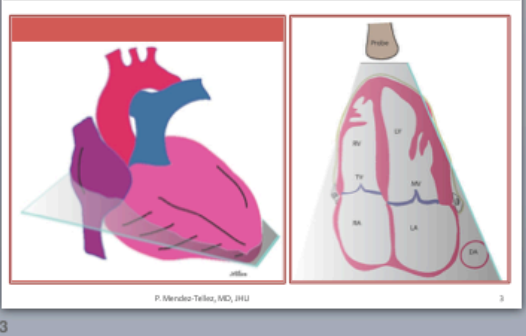

Standard Apical 4 \& 5-Chamber Views

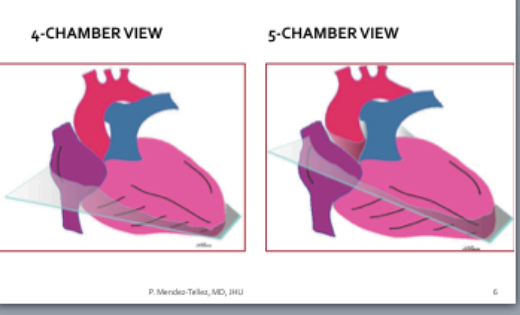

Standard Apical 2 Chamber View

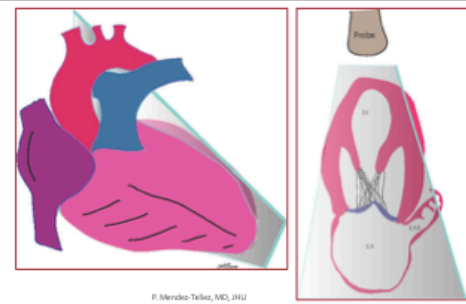


Appendix D (cont.)

Introduction to Critical Care Echocardiography Lecture

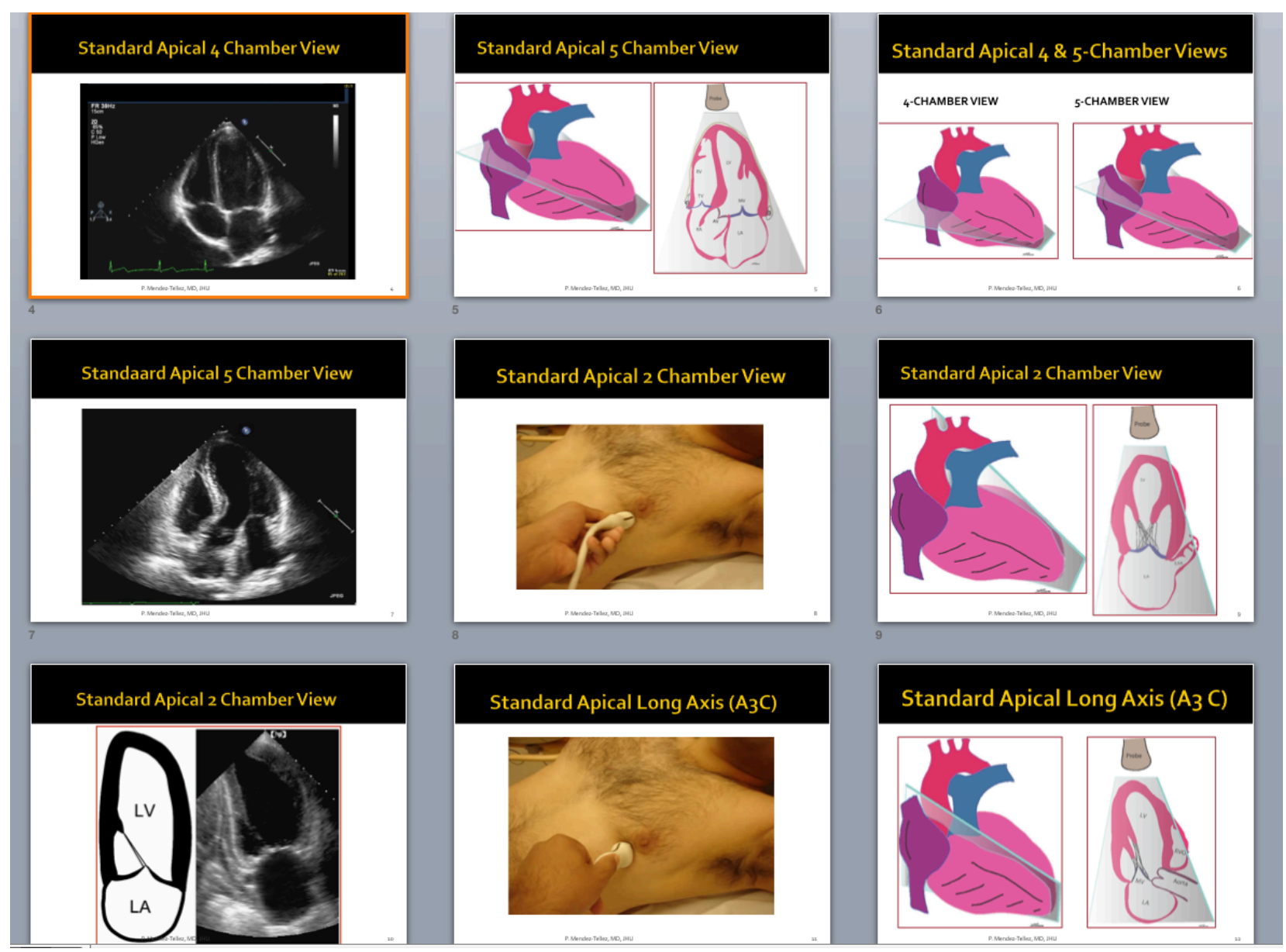


Appendix D (cont.)

Introduction to Critical Care Echocardiography Lecture

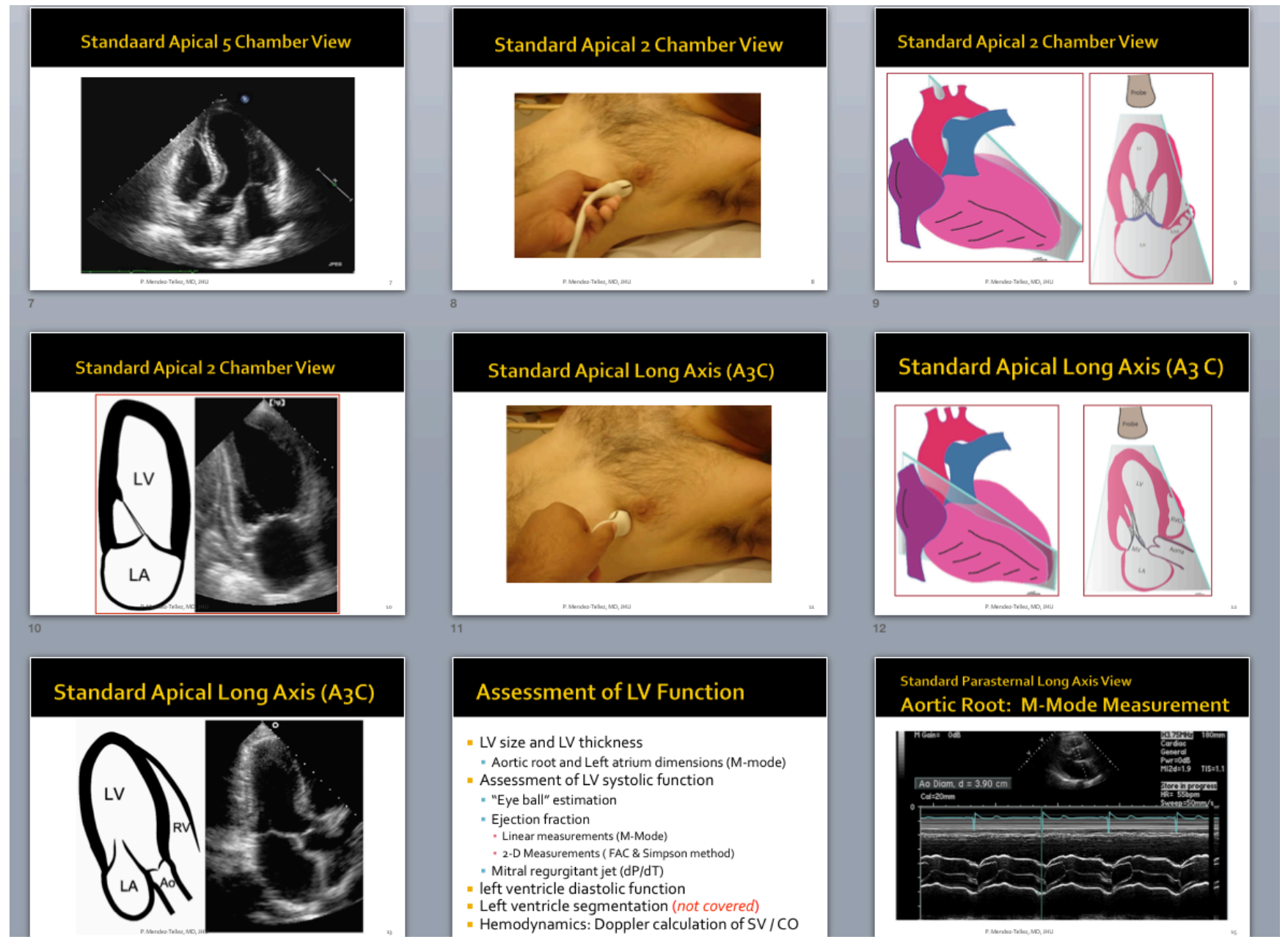


Appendix D (cont.)

Introduction to Critical Care Echocardiography Lecture

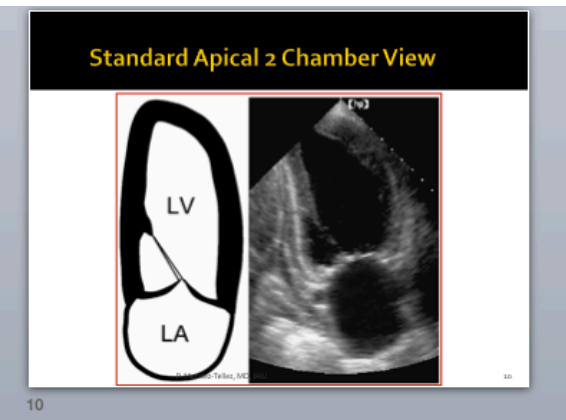

Standard Apical Long Axis $\left(\mathrm{A}_{3} \mathrm{C}\right)$

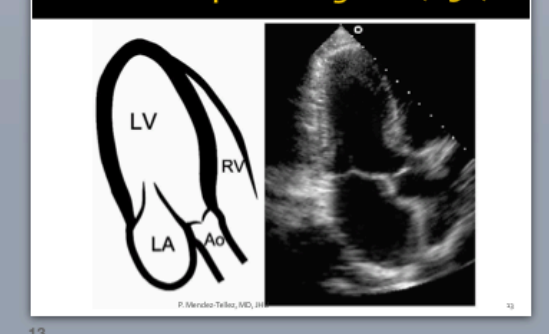

Standard Parasternal Long Axis View LA diameter M-Mode measurement

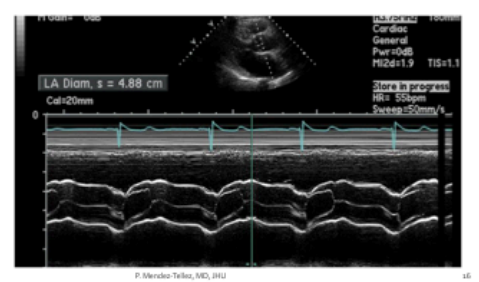

Standard Apical Long Axis $\left(\mathrm{A}_{3} \mathrm{C}\right)$

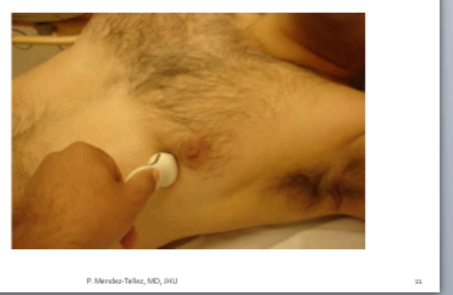

\section{Assessment of LV Function}

- LV size and LV thickness

- Aortic root and Left atrium dimensions (M-mode)

- Assessment of LV systolic function

- "Eye ball" estimation

- Ejection fraction

- Linear measurements (M-Mode)

2-D Measurements (FAC \& Simpson method)

Mitral regurgitant jet (dP/dT)

- left ventricle diastolic function

- Left ventricle segmentation (not covered)

- Hemodynamics: Doppler calculation of SV / CO

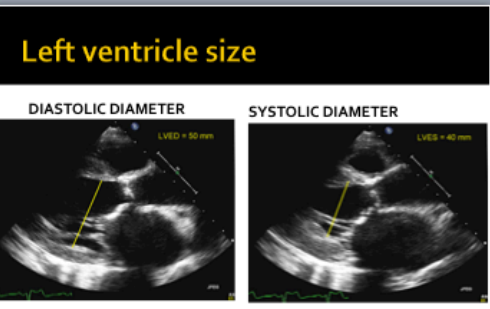

The LV diameter is measured in PLAX, at the tip of the mitral leaflets, at the interface blood-internal wall
Standard Apical Long Axis $\left(\mathrm{A}_{3} \mathrm{C}\right)$
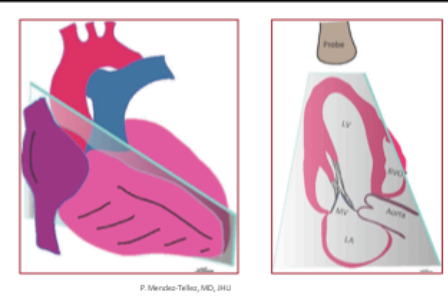

Standard Parasternal Long Axis View Aortic Root: M-Mode Measurement
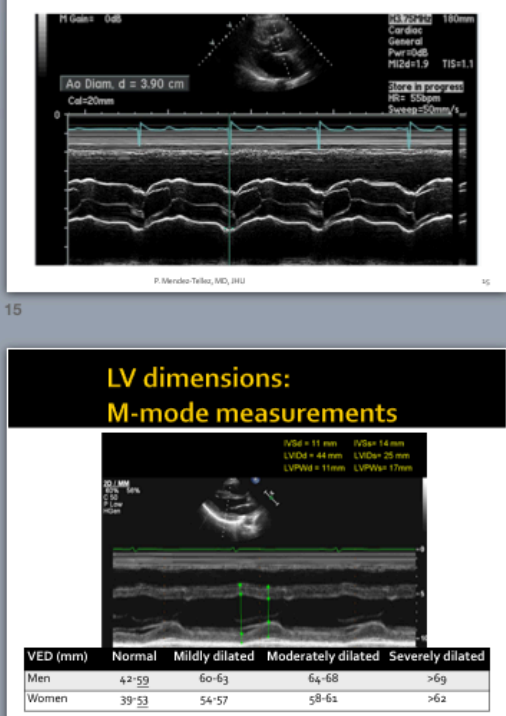


\section{Appendix D (cont.)}

Introduction to Critical Care Echocardiography Lecture

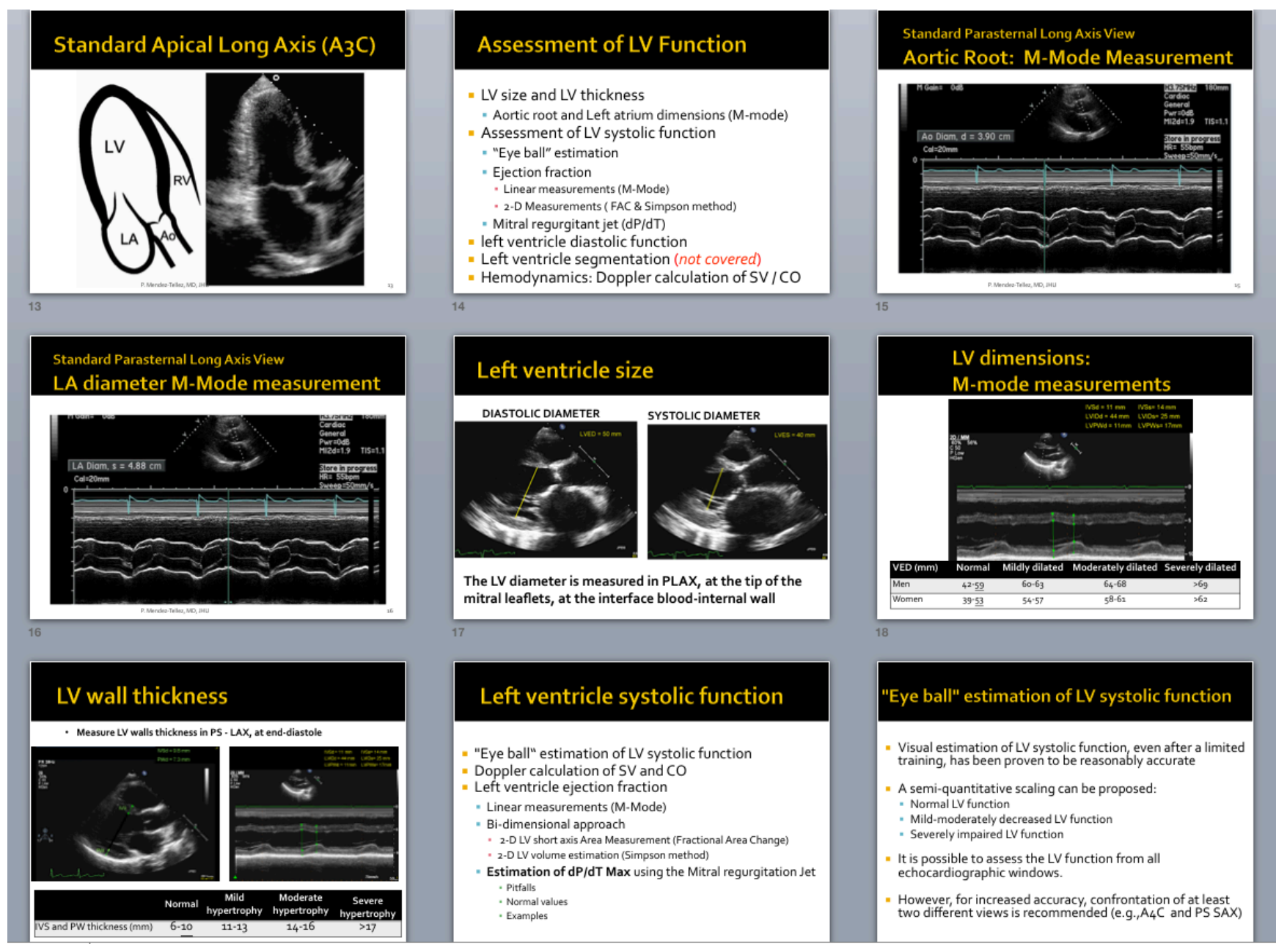


Appendix D (cont.)

Introduction to Critical Care Echocardiography Lecture

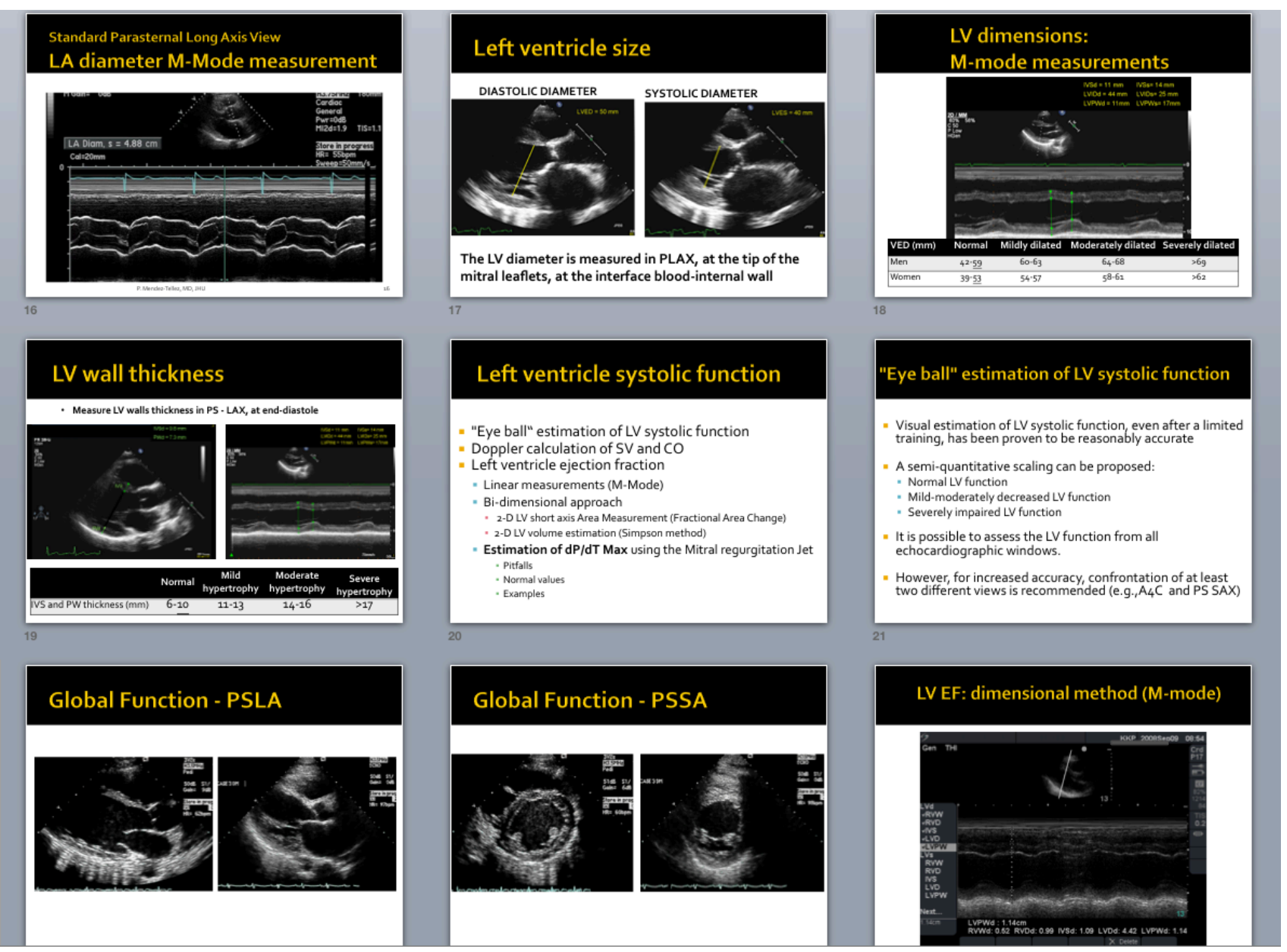




\section{Appendix D (cont.)}

\section{Introduction to Critical Care Echocardiography Lecture}

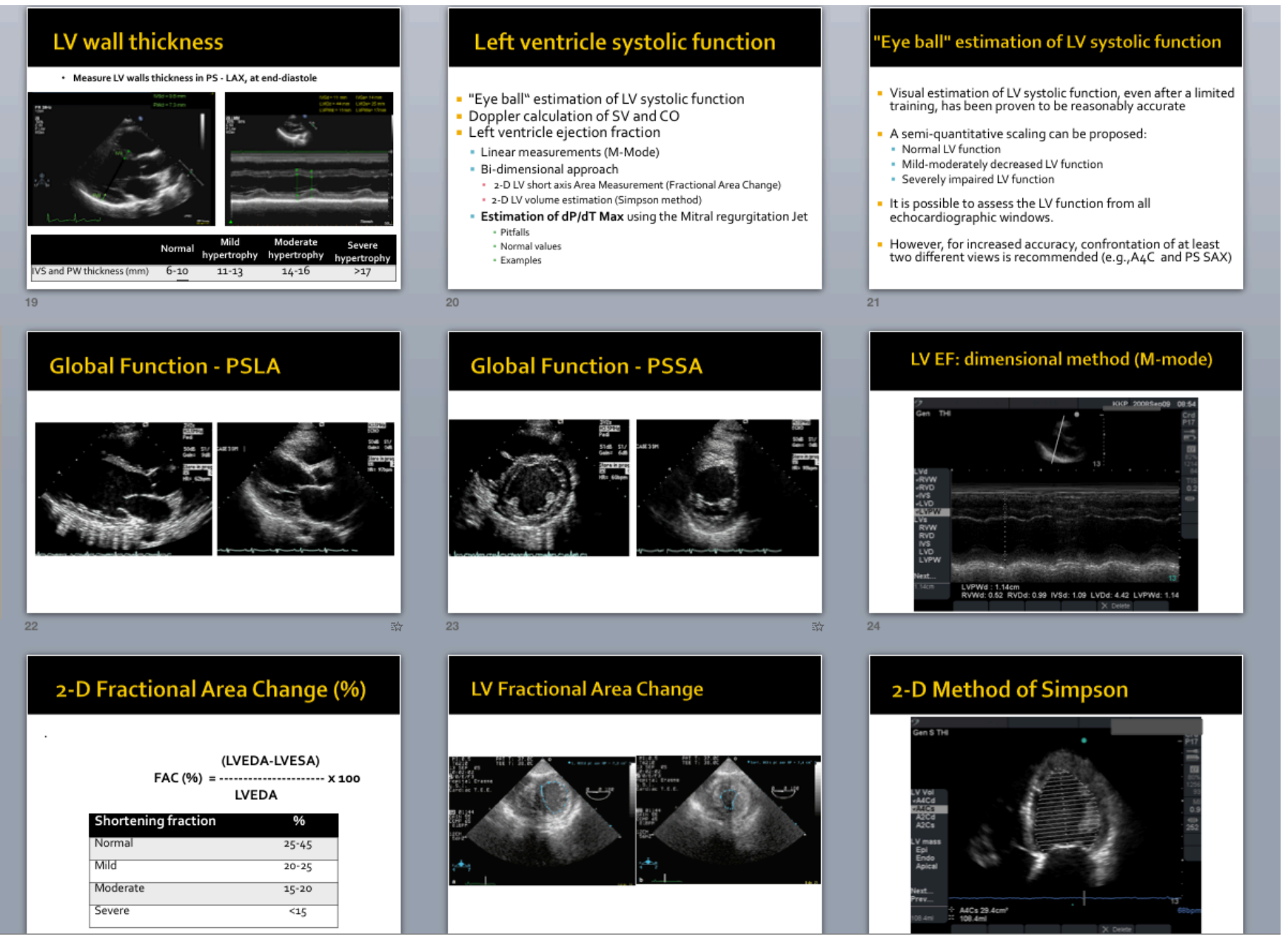


Appendix D (cont.)

Introduction to Critical Care Echocardiography Lecture

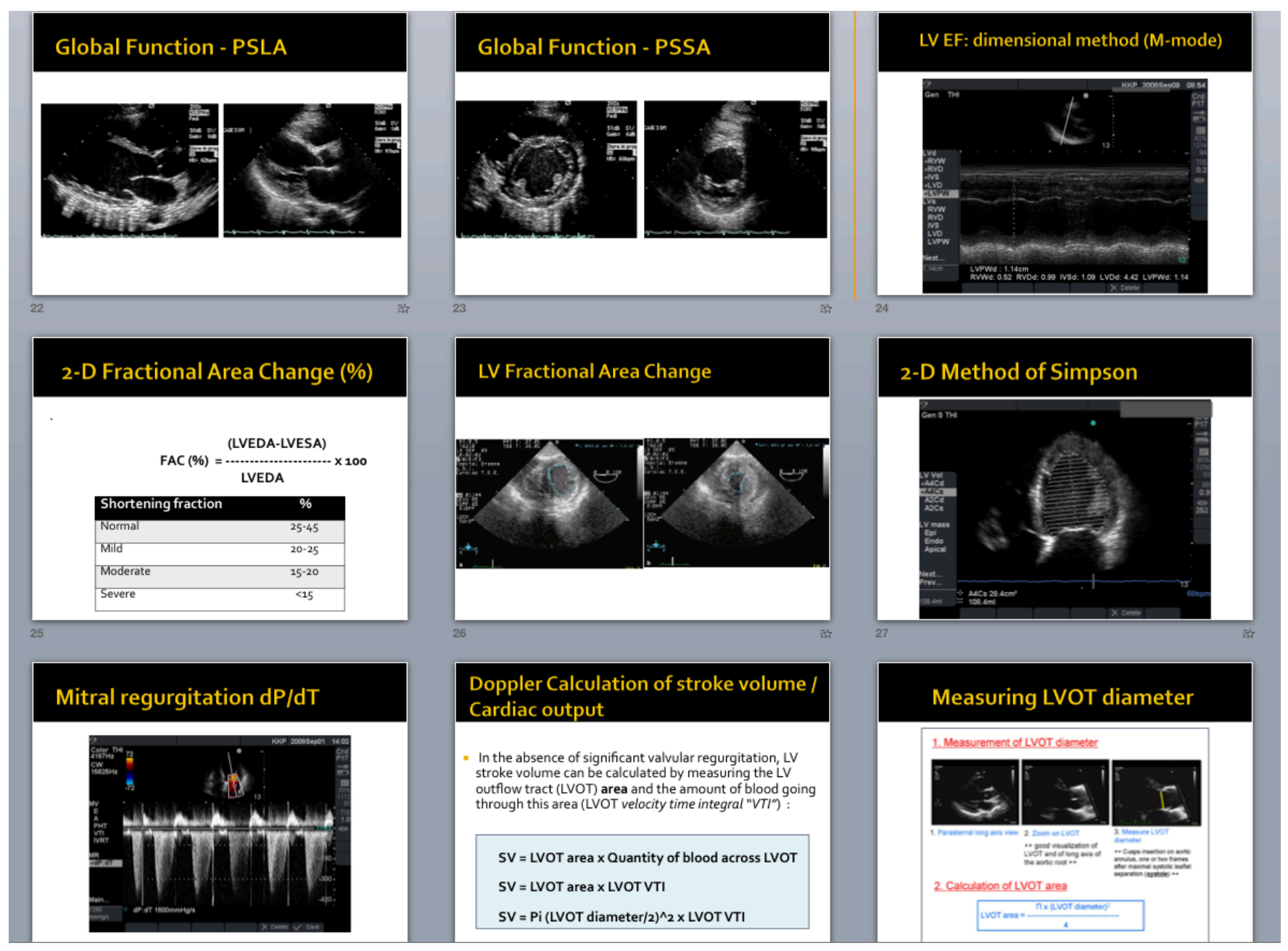




\section{Appendix D (cont.)}

\section{Introduction to Critical Care Echocardiography Lecture}

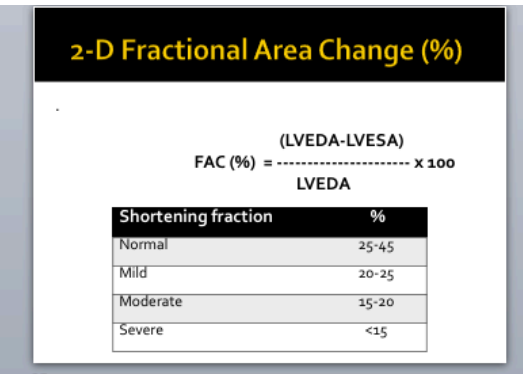

\section{Mitral regurgitation $\mathrm{dP} / \mathrm{dT}$}

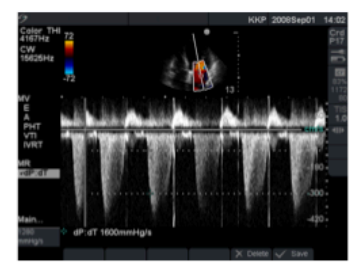

\section{Measuring LVOT diameter}

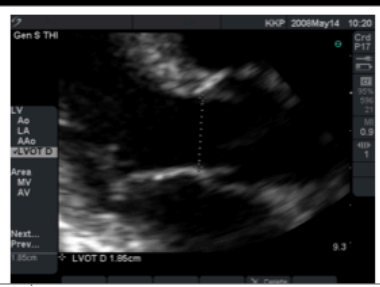

\section{Fractional Area Change}

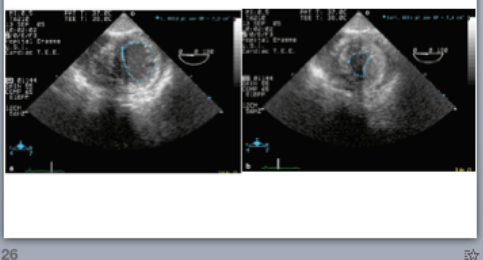

Doppler Calculation of stroke volume / Cardiac output

- In the absence of significant valvular regurgitation, LV outflow tract (LVOT) area and the amount of bhe through this area (LVOT velocity time integral "VTI") :

SV = LVOT area $x$ Quantity of blood across LVOT $S V=L V O T$ area $x$ LVOT VTI

$\mathrm{SV}=\mathrm{Pi}($ LVOT diameter/2)^^2 $\times$ LVOT VTI

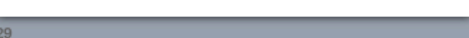

\section{Measuring LVOT VTI}

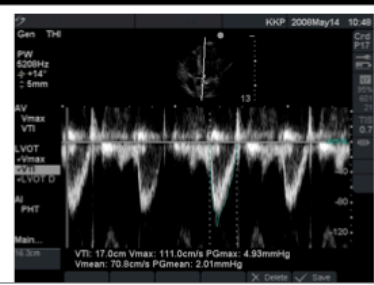

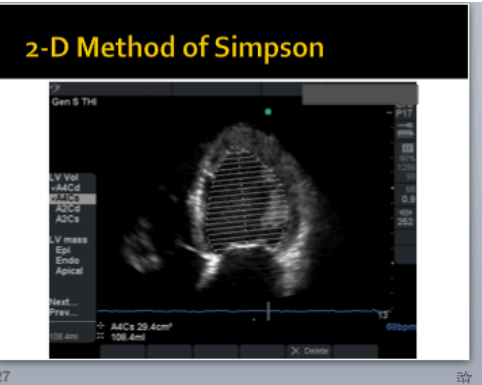

Measuring LVOT diameter

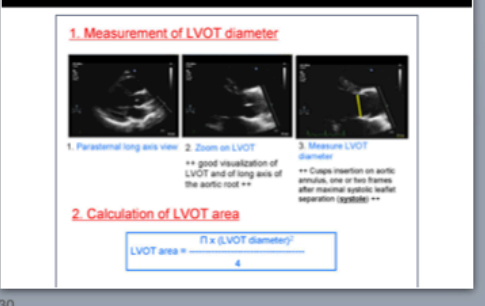

Stroke volume / CO calculation

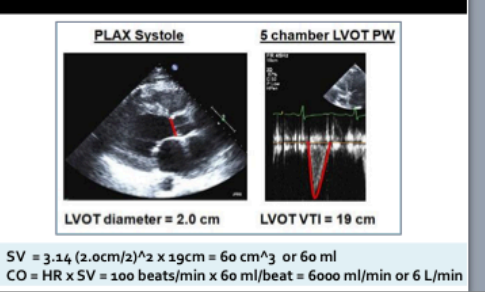




\section{Appendix D (cont.)}

\section{Introduction to Critical Care Echocardiography Lecture}
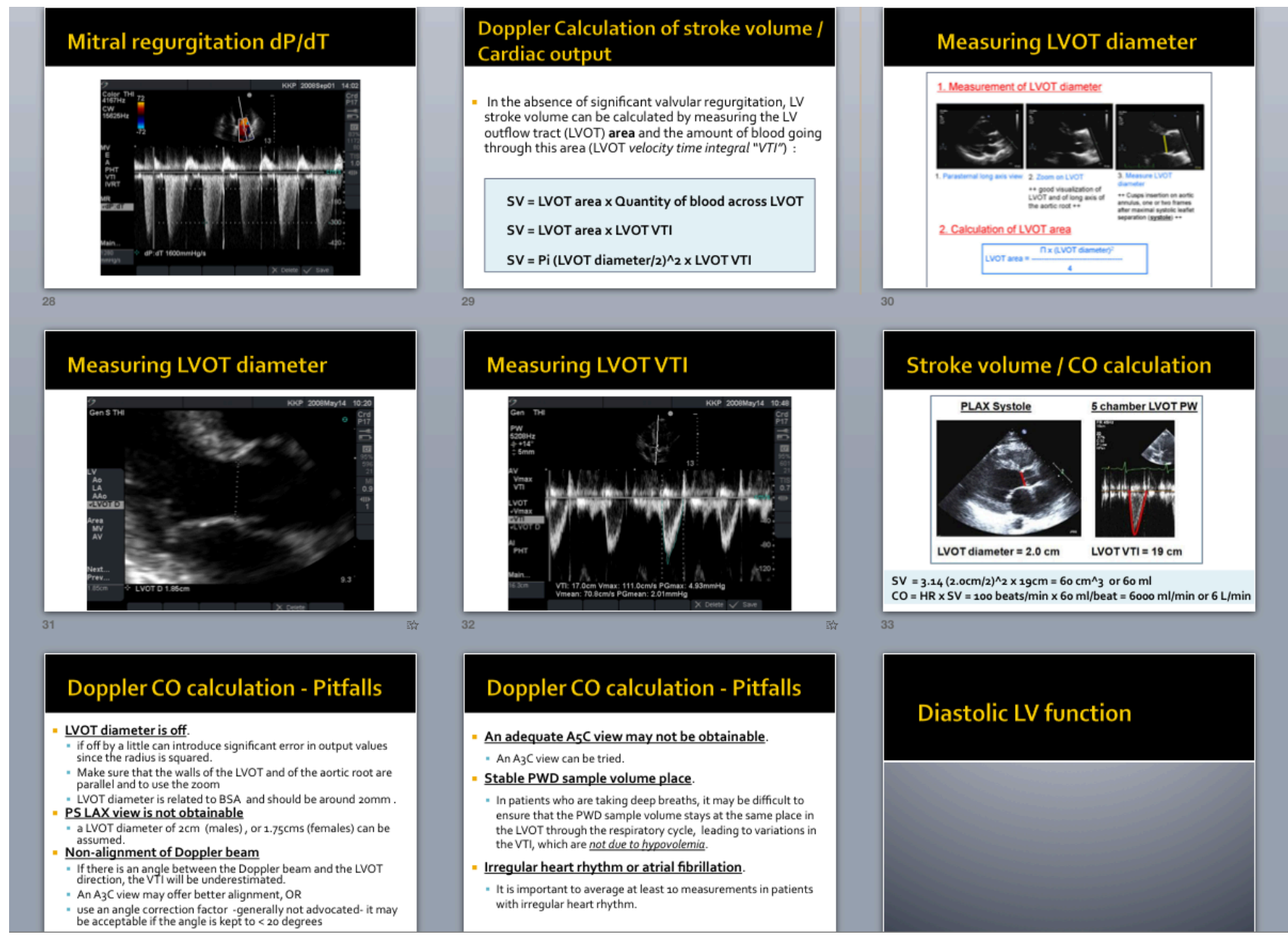

$\mathrm{SV}=3.14\left(2.0 \mathrm{~cm} / 2 \wedge^{\wedge} \times 19 \mathrm{~cm}=60 \mathrm{~cm}^{\wedge} 3\right.$ or $60 \mathrm{ml}$
$\mathrm{CO}=\mathrm{HR} \times \mathrm{SVV}=100$ beats $/ \mathrm{min} \times 60 \mathrm{~m} / / \mathrm{beat}=6000 \mathrm{ml} / \mathrm{min}$ or $6 \mathrm{~L} / \mathrm{min}$

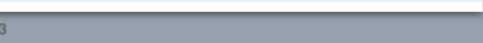

Diastolic LV function 


\section{Appendix D (cont.)}

\section{Introduction to Critical Care Echocardiography Lecture}

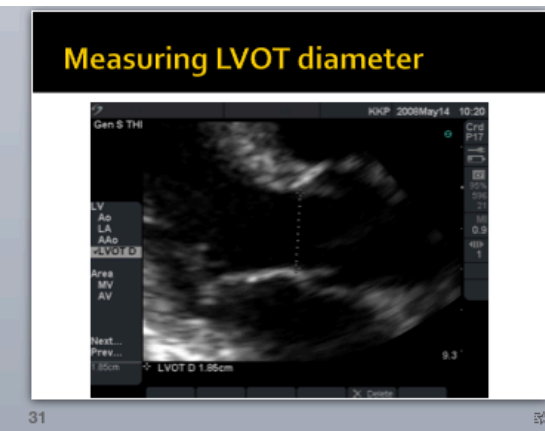

\section{Doppler CO calculation - Pitfalls}

" LVOT diameter is off.

If off by a little can introduce significant error in output values
since the radius is squared.

Make sure that the walls of th

LVOT and of the aortic root are

LVOT diameter is related to BSA and should be around $20 \mathrm{~mm}$.

PS LAX view is not obtainable

a LVOT diameter of $2 \mathrm{~cm}$ (males), or $1.75 \mathrm{cms}$ (females) can be

Non-alignment of Doppler beam

" If there is an angle between the Doppler beam and the LVOT
direction, the VII will be underestimated.

$\mathrm{An}_{\mathrm{A}} \mathrm{A}_{3} \mathrm{C}$ view may offer better alignment, $O R$

use an angle correction factor -generally not advocated-it may

be acceptable if the angle is kept to $<20$ degrees

\section{Diastolic LV function}

- Mitral annular velocities

" Pulmonary veins blood flow

" Velocity of flow progression (Vp)

\section{Measuring LVOTVTI}

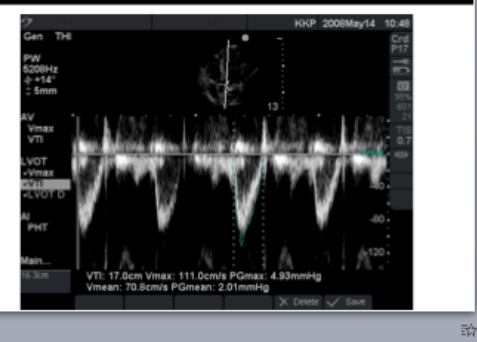

\section{Doppler CO calculation - Pitfalls}

- An adequate $\mathrm{A}_{5} \mathrm{C}$ view may not be obtainable.

- An $\mathrm{A}_{3} \mathrm{C}$ view can be tried.

- Stable PWD sample volume place.

In patients who are taking deep breaths, it may be difficult to ensure that the PWD sample volume stays at the same place in the LVOT through the respiratory cycle, leading to variations in

the VTI, which are not due to hypovolemia.

- Irregular heart rhythm or atrial fibrillation

It is important to average at least 10 measurements in patients with irregular heart rhythm

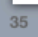

\section{Mitral inflow velocities examination}
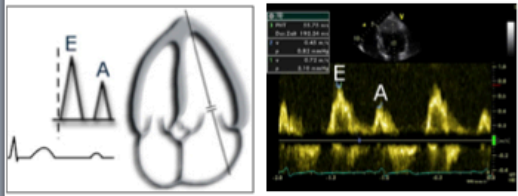

Stroke volume / CO calculation

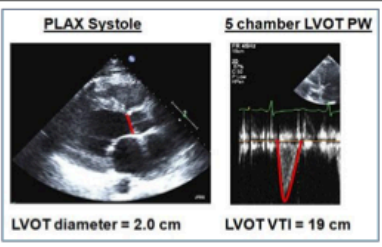

$\mathrm{SV}=3.14(2.0 \mathrm{~cm} / 2)^{\wedge} 2 \times 19 \mathrm{~cm}=60 \mathrm{~cm}^{\wedge} 3$ or $60 \mathrm{ml}$ $\mathrm{CO}=\mathrm{HR} \times \mathrm{SV}=100$ beats $/ \mathrm{min} \times 60 \mathrm{ml} / \mathrm{beat}=6000 \mathrm{ml} / \mathrm{min}$ or $6 \mathrm{~L} / \mathrm{min}$

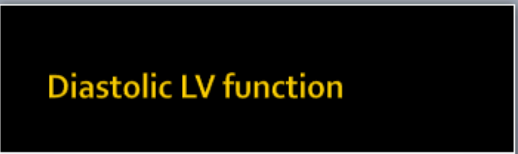

Mitral inflow velocities examination
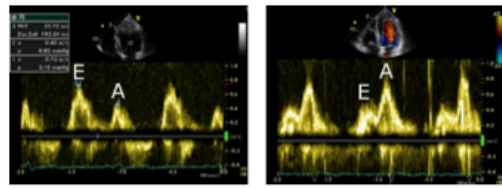


\section{Appendix D (cont.)}

Introduction to Critical Care Echocardiography Lecture

\section{Doppler CO calculation - Pitfalls}

\section{Doppler CO calculation - Pitfalls}

" LVOT diameter is off.

if off by a little can introduce significant error in output values since the radius is squared.

- Make sure that the walls of the LVOT and of the aortic root are parallel and to use the zoom

LVOT diameter is related to BSA and should be around $20 \mathrm{~mm}$.

" PS LAX view is not obtainable a LVOT diameter of $2 \mathrm{~cm}$ (males), or $1.75 \mathrm{cms}$ (females) can be
assumed.

- Non-alignment of Doppler beam

If there is an angle between the Doppler beam and the LVOT

- direction, the VTl betweenderestimated.

- An $\mathrm{A}_{3} \mathrm{C}$ view may offer better alignment, $O R$

use an angle correction factor -generally not advocated-it may be acceptable if the angle is kept to < 20 degrees
An adequate $\mathrm{A}_{5} \mathrm{C}$ view may not be obtainable.

- An $\mathrm{A}_{3} \mathrm{C}$ view can be tried.

\section{= Stable PWD sample volume place.}

- In patients who are taking deep breaths, it may be difficult to ensure that the PWD sample volume stays at the same place in the LVOT through the respiratory cycle, leading to variations in the VTI, which are not due to hypovolemia.

= Irregular heart rhythm or atrial fibrillation.

- It is important to average at least 10 measurements in patients with irregular heart rhythm. 
Appendix E

Introduction to Doppler PowerPoint

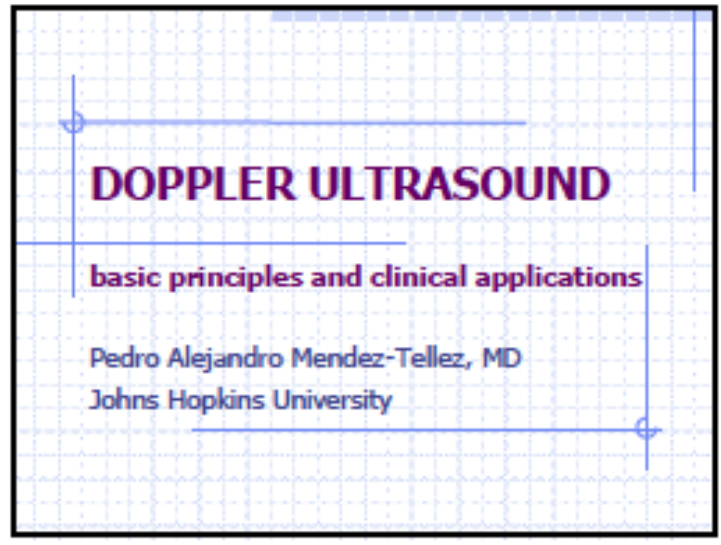

\section{Outline}

+ Doppler Principles

- Doppler Effect

- Doppler equation:

- (Dopoler) Frequency shirt a Flow velocty calculation

- The effect of the Doppler angle beam

- Doppler display

+ Spectral Doppler

- Continuous (CW) \& Pulsed (PW) wave Doppler

- Sample volume

- Alasing / Nyquist limt

- Cortrol of alasing

+ Clinical applications / Examples

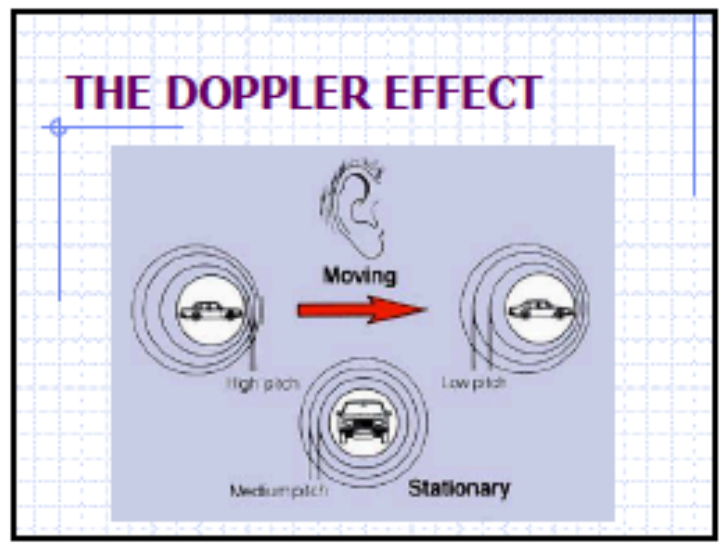

DOPPLER SHIFT:

SIGNAL FREQUENCY AND BLOOD FLOW DIRECTION

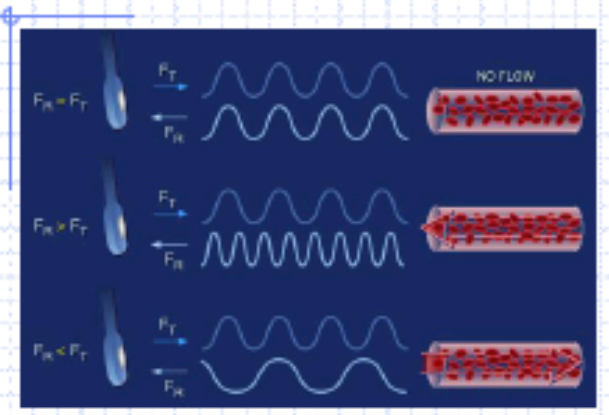


Appendix E (cont.)

Introduction to Doppler PowerPoint
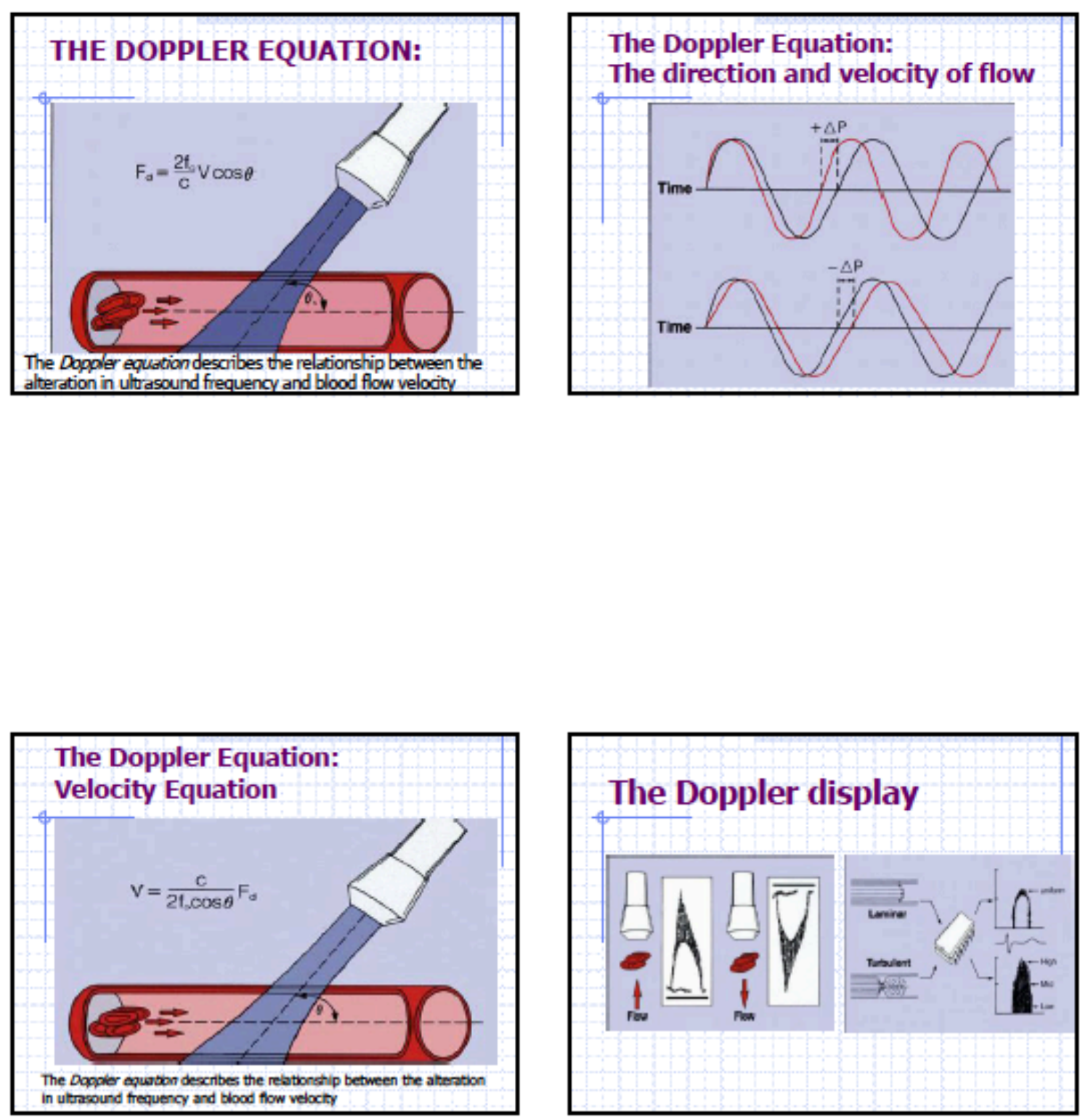
Appendix E (cont.)

Introduction to Doppler PowerPoint
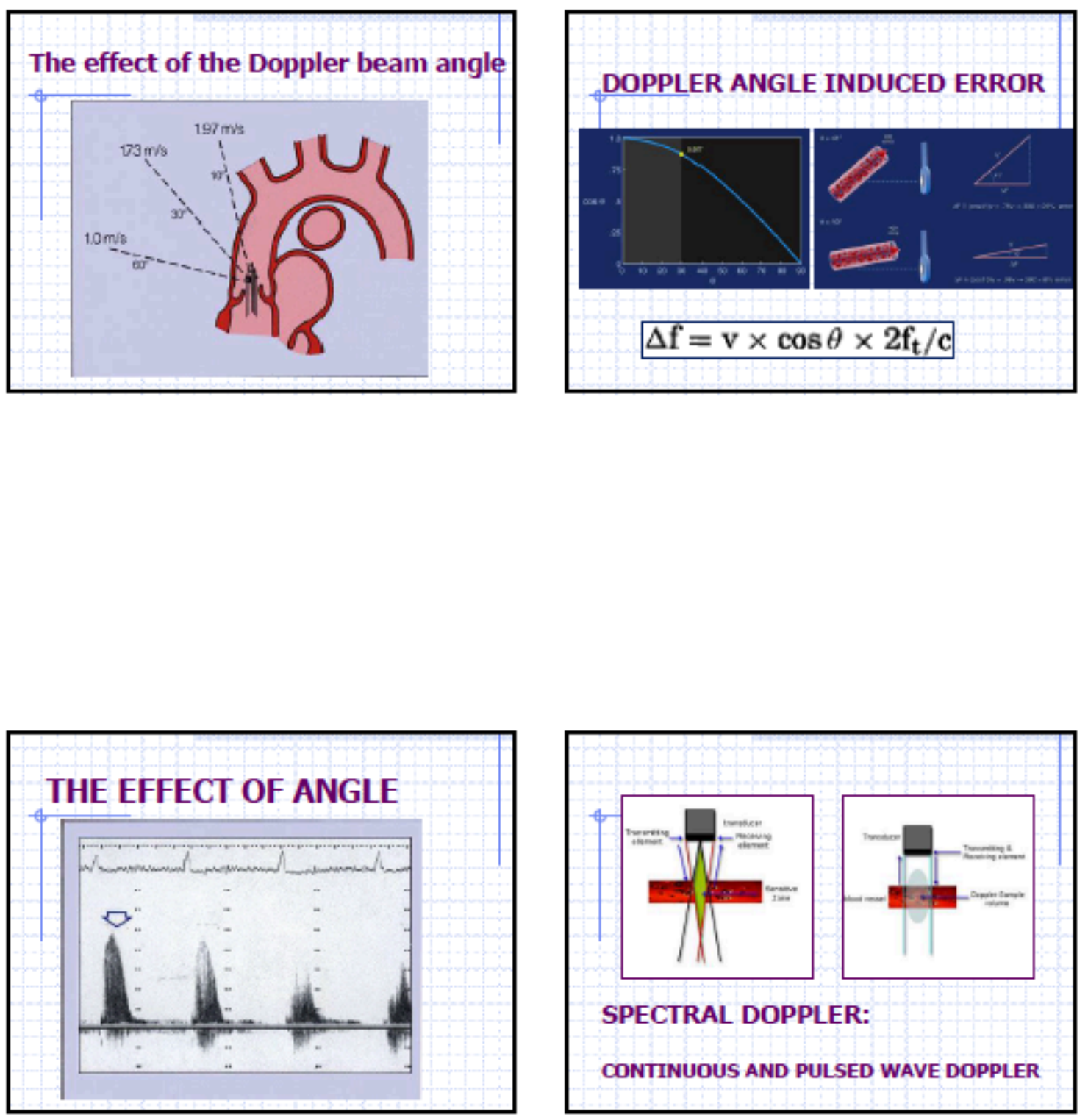
Appendix E (cont.)

Introduction to Doppler PowerPoint
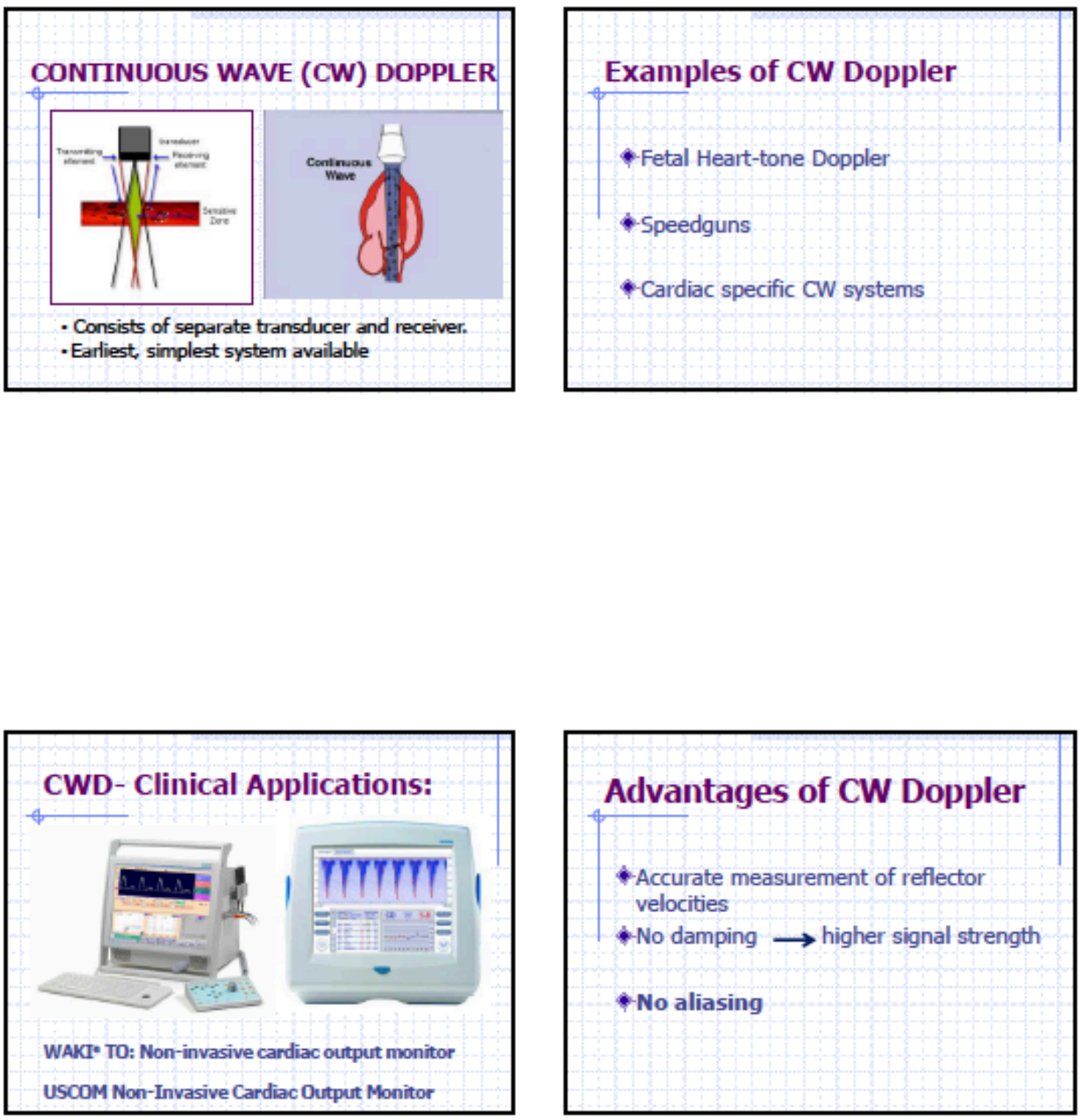
Appendix E (cont.)

Introduction to Doppler PowerPoint
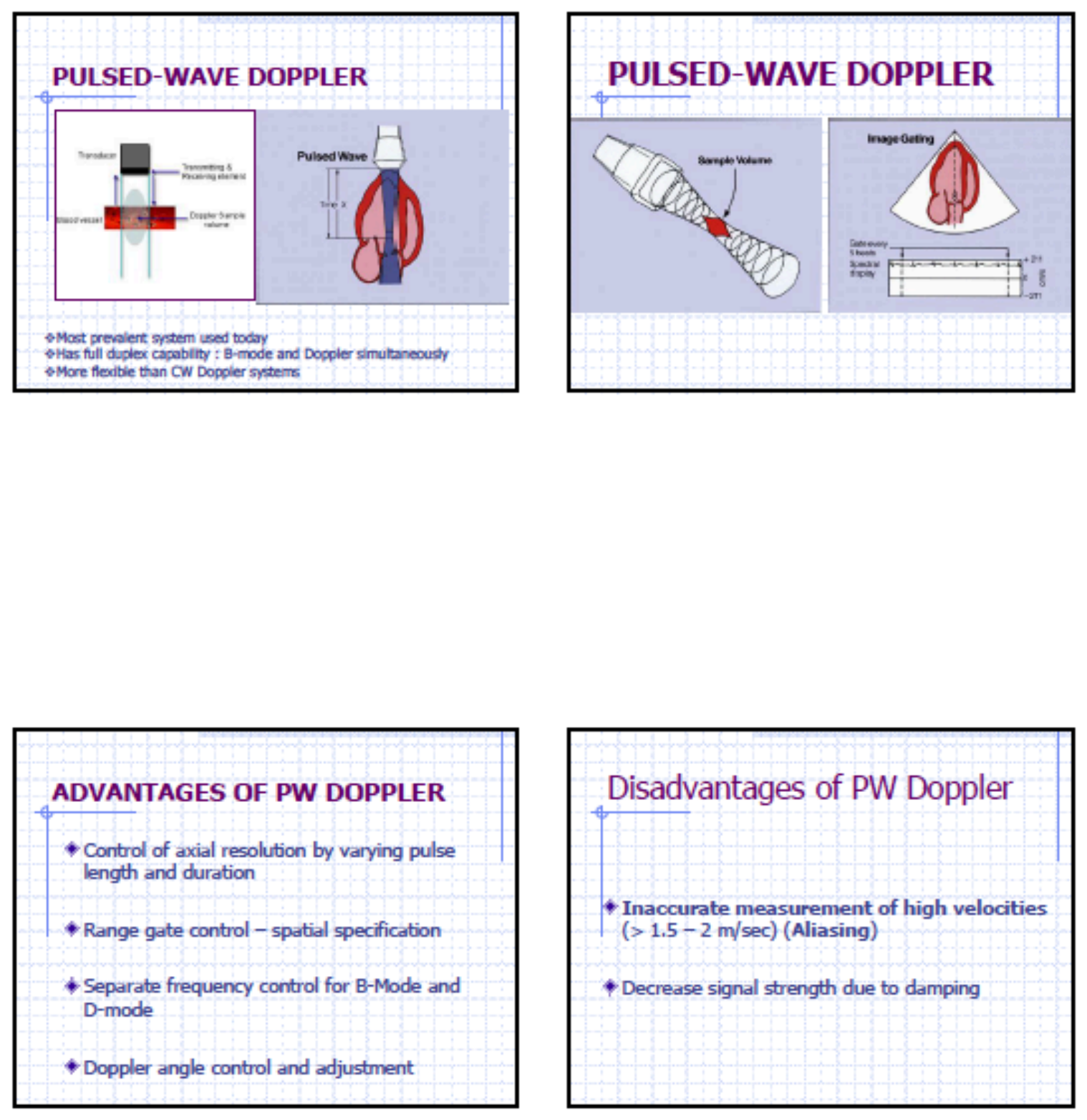
Appendix E (cont.)

Introduction to Doppler PowerPoint
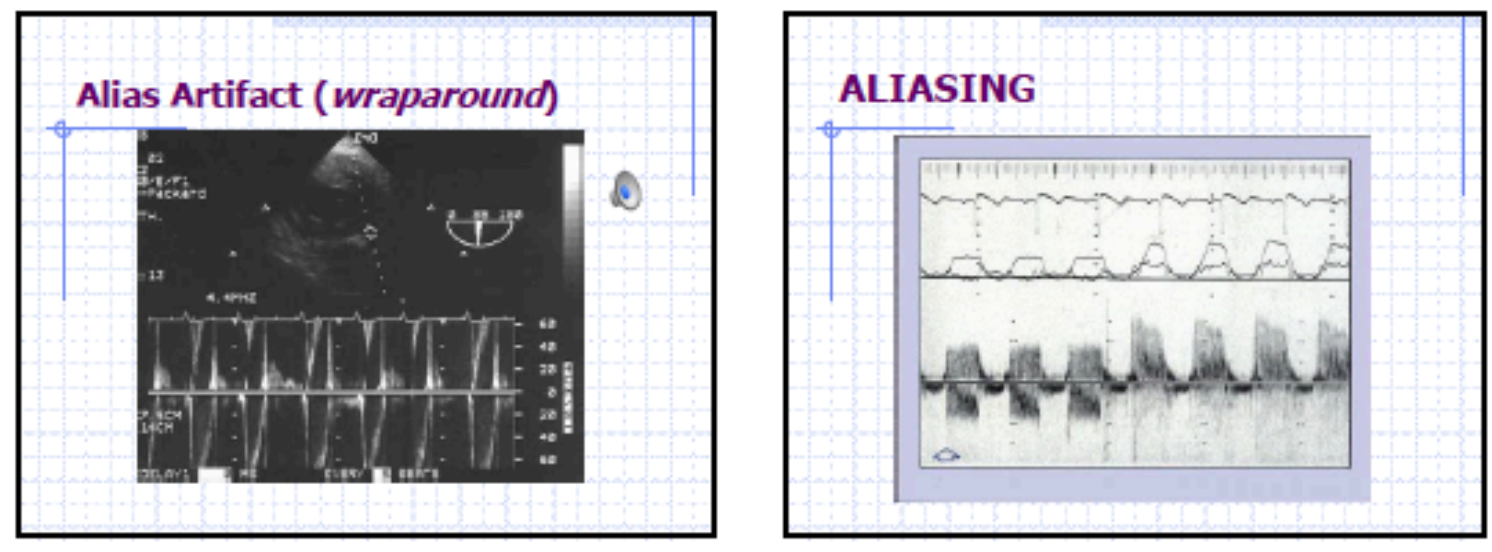

LIMITATIONS OF PW DOPPLER The Nyquist Limit
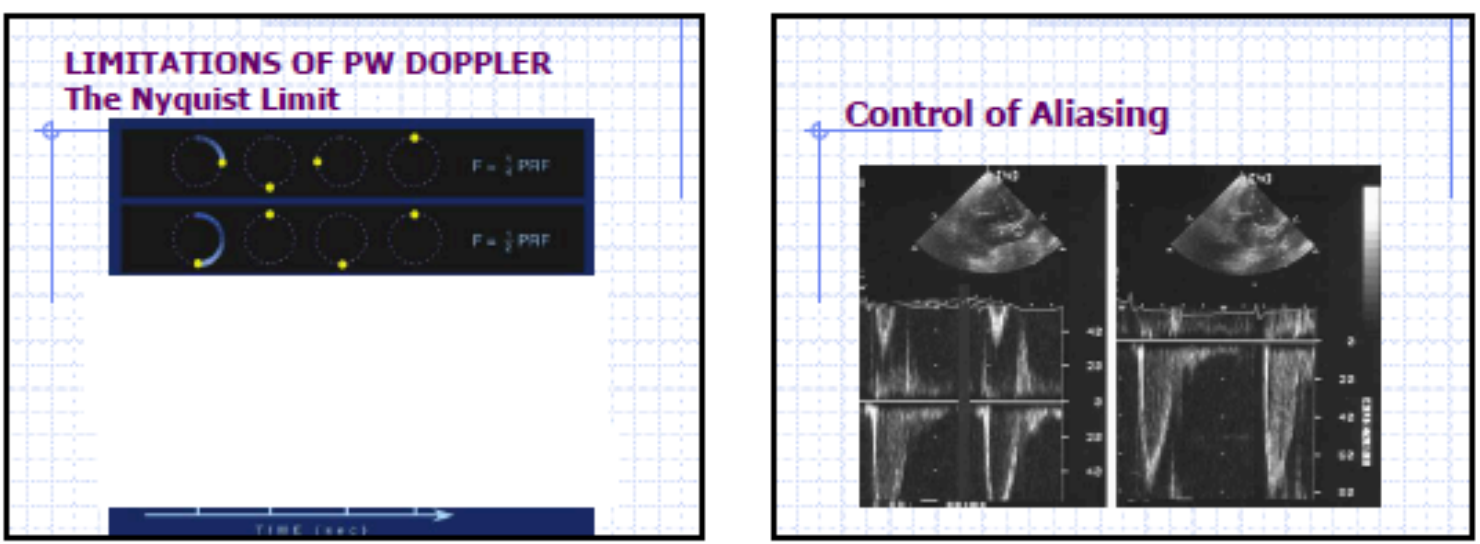
Appendix E (cont.)

Introduction to Doppler PowerPoint
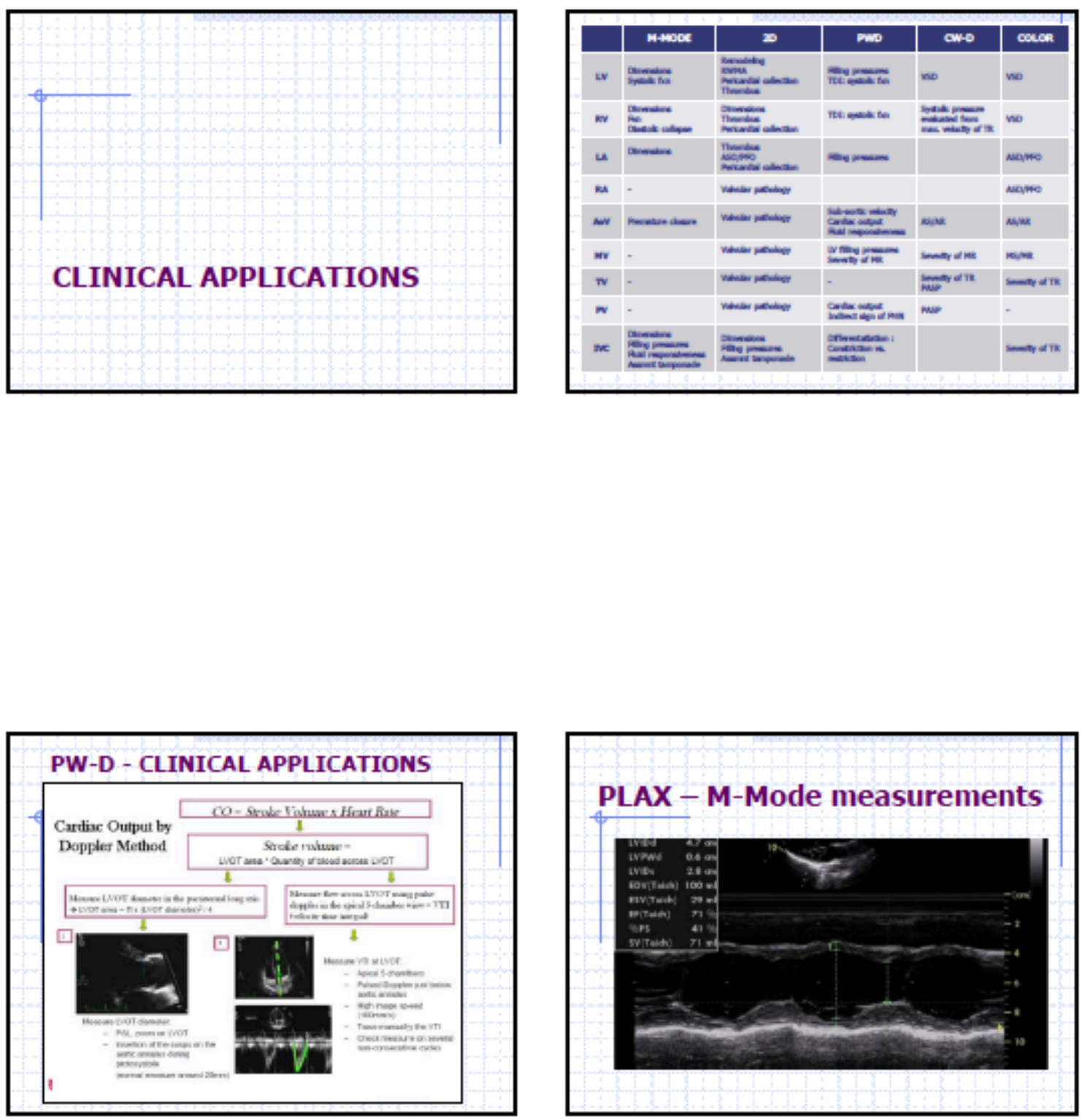

PLAX - M-Mode measurements

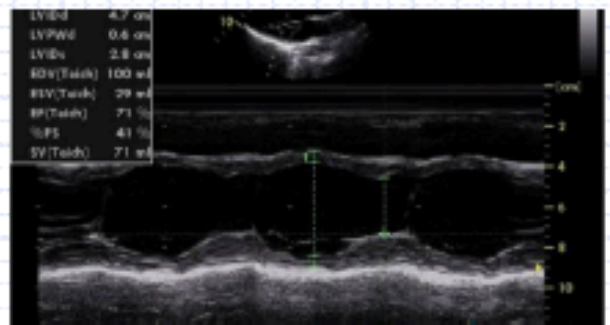


Appendix E (cont.)

Introduction to Doppler PowerPoint
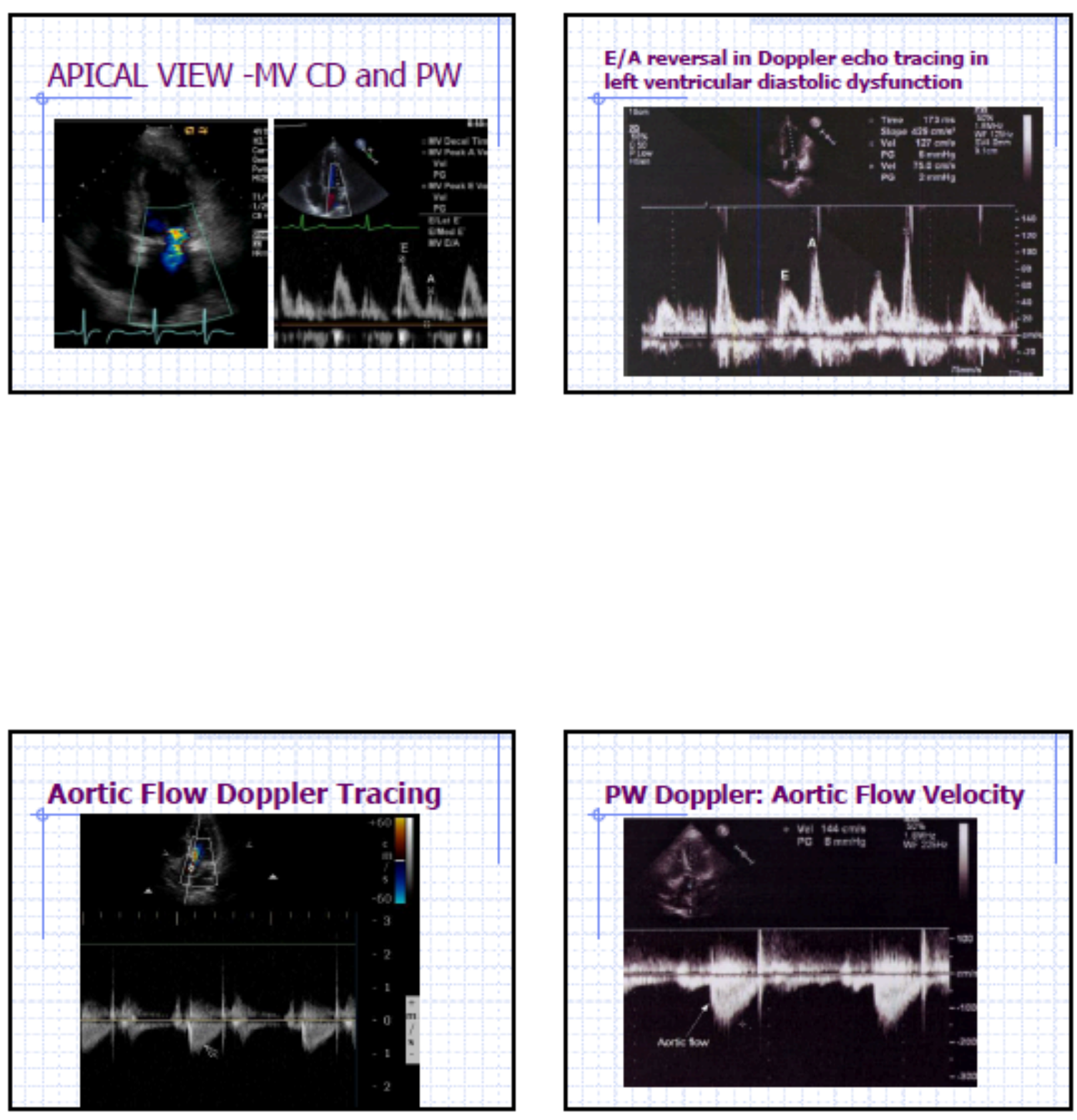
Appendix E (cont.)

Introduction to Doppler PowerPoint
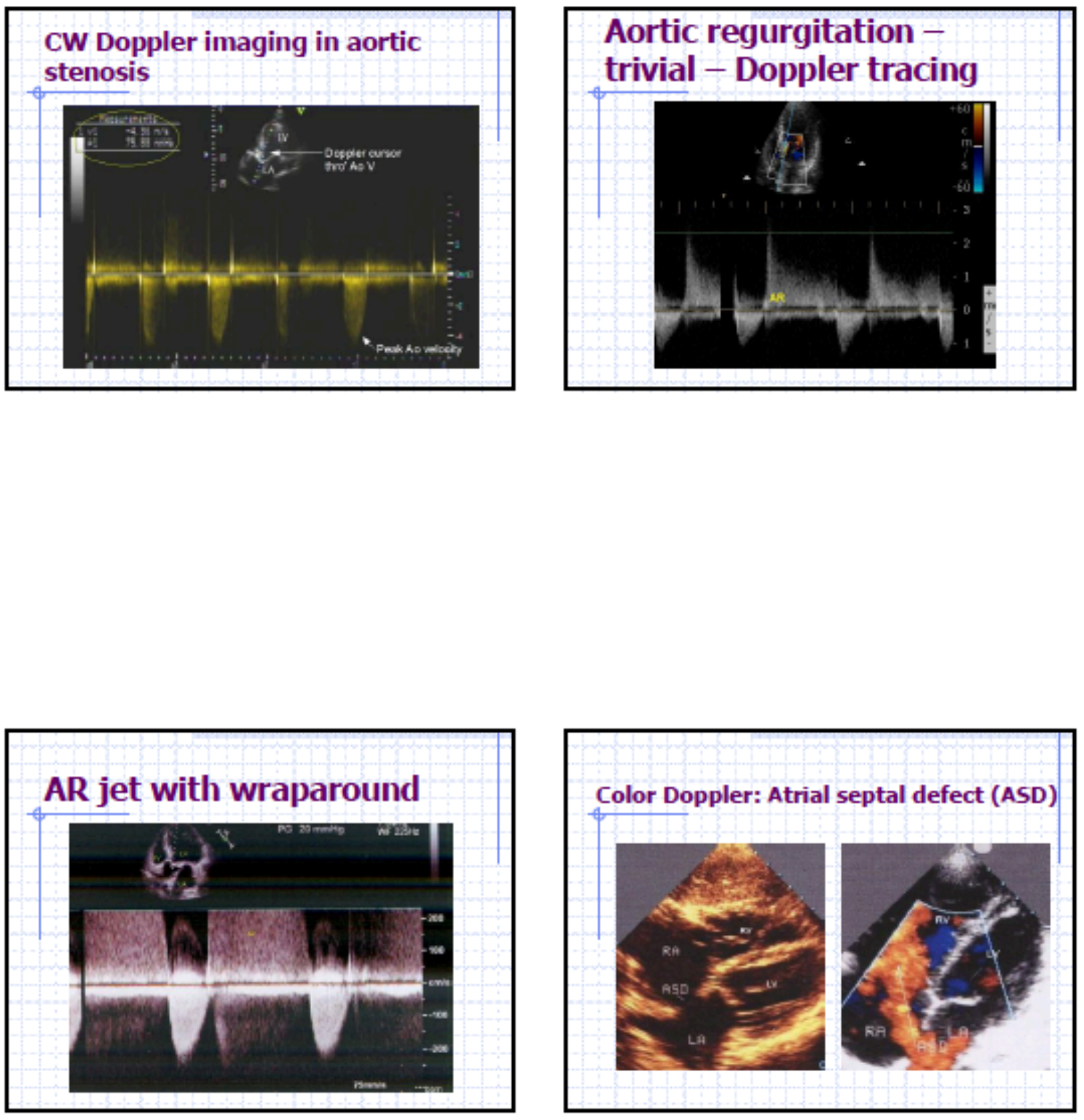
Appendix E (cont.)

Introduction to Doppler PowerPoint
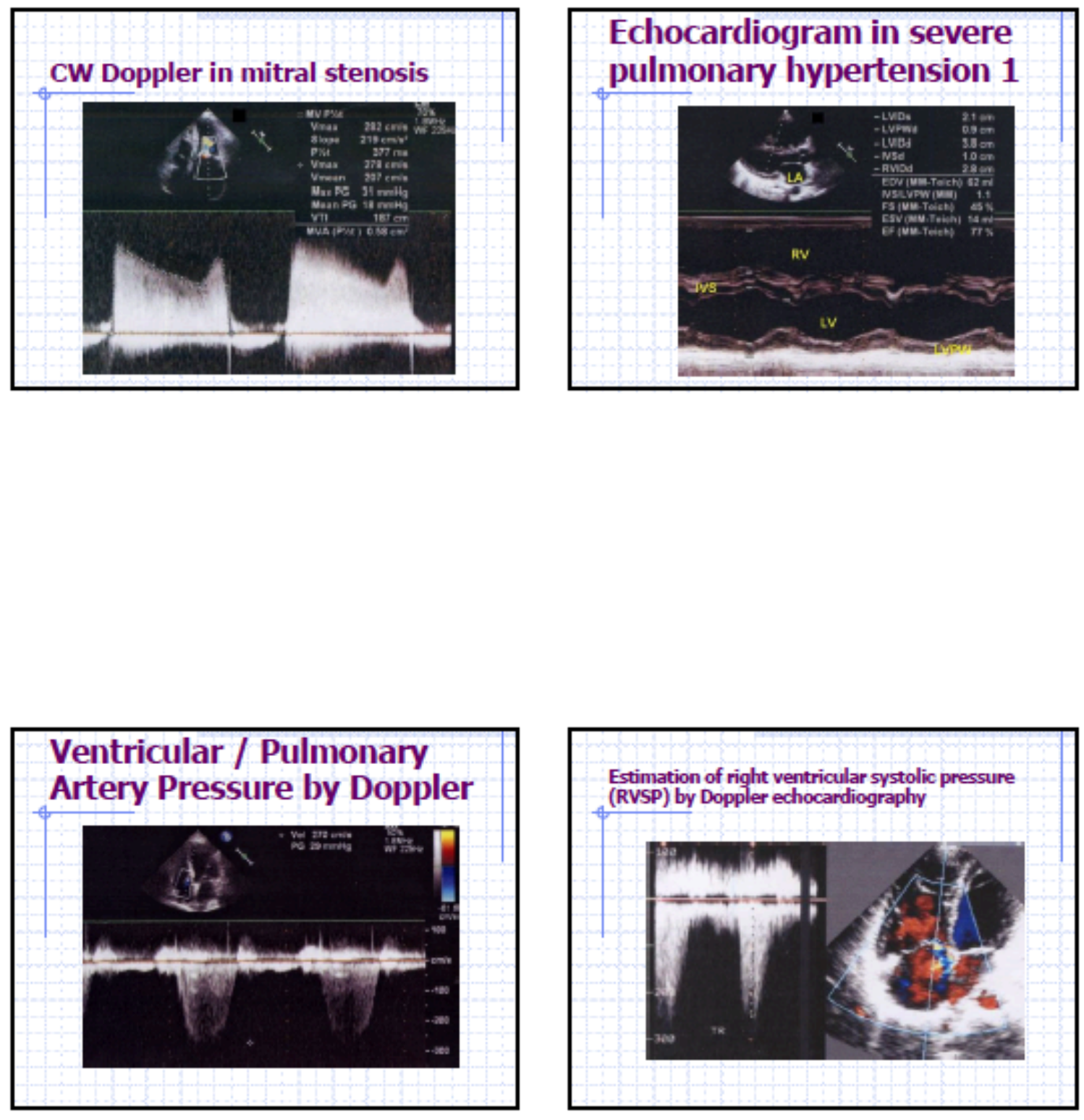
Appendix E (cont.)

Introduction to Doppler PowerPoint
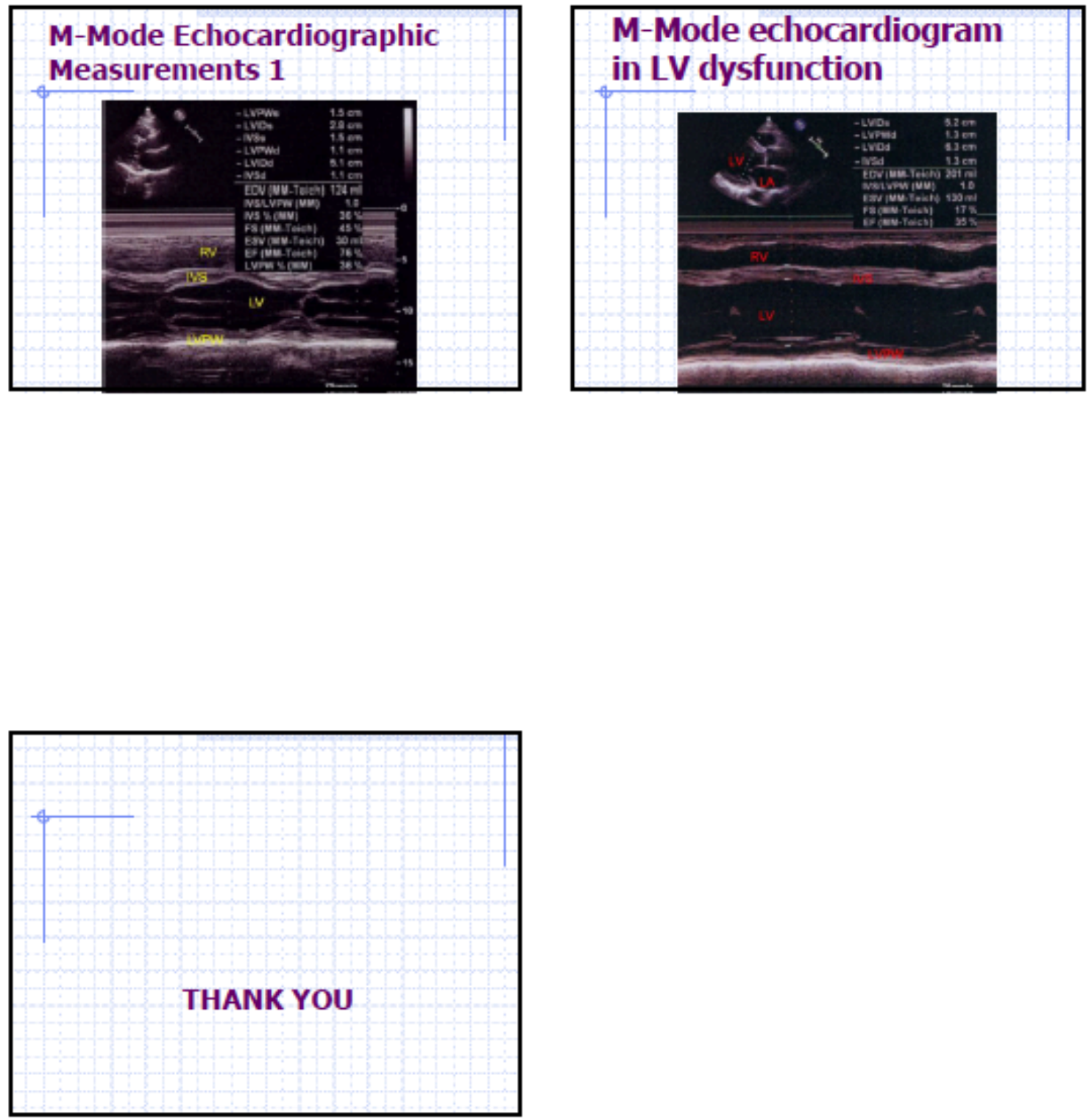


\author{
Appendix F \\ Limited Critical Care Echocardiography Views Clinical Ability Test
}

Participant Name:

Reviewer:

Did the participant adequately obtain the view of (check one):

\begin{tabular}{|c|c|c|c|}
\hline 1) Parasternal long axis & YES & $\mathrm{NO}$ & Unable to determine \\
\hline 2) Parasternal short axis & YES & $\mathrm{NO}$ & Unable to determine \\
\hline 3) Apical four chamber & YES & $\mathrm{NO}$ & Unable to determine \\
\hline Apical five chamber & YES & $\mathrm{NO}$ & Unable to determine \\
\hline
\end{tabular}




\section{Appendix G}

Stroke Volume/Cardiac Output Clinical Ability Test

Participant Name:

Reviewer:

For this simulation case of John Jones, calculate stroke volume/cardiac output* using:

1) Biplane method of disks: Stroke Volume = Cardiac Output $=$

2) Fractional area change: Stroke Volume $=$

Cardiac Output $=$
a. RVEDA:
b. RVESA:

$$
\mathrm{FAC}(\%)=[(\mathrm{RVEDA}-\mathrm{RVESA}) / \mathrm{RVEDA}] \times 100
$$

3) Cardiac Output
a. VTI:
b. LVOT diameter:
c. HR:

Stroke Volume: LVOT $\operatorname{area}^{2}$ x VTI; CO $=\mathrm{HR}$ x SV

$\mathrm{CO}$ : 


\section{Appendix H}

Johns Hopkins Medicine Institutional Review Board Form

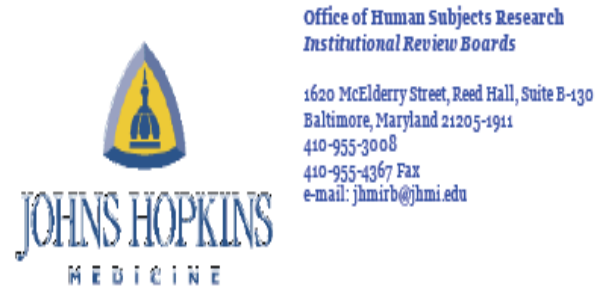

Date: January 7,2016

\section{ACKNOWLEDGEMENT}

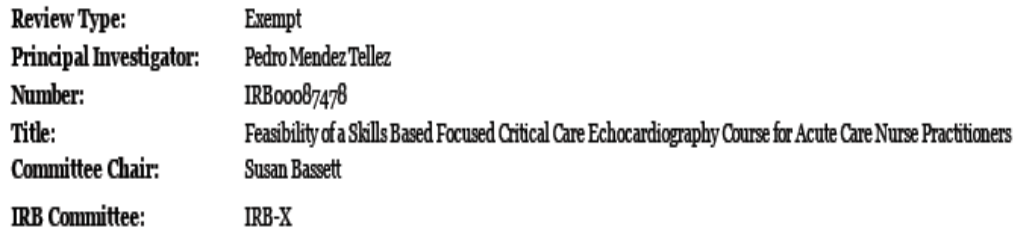

Date of acknowledgement: January 7,2016

Date of expiration: January 7,2019

The JHMIRB has determined that the above-referenced new application qualifies as exemptresearch under the DHHS regulations.

You may proceed with this project without further interaction with the JHMIRB. If there are changes in this project thatmay affect this determination, you should consult with the JHMIRB before making those changes.

45 CFR 46.101 (b)(1): Research conducted in established or commonly accepted educational settings, involving normal educational practices, such as (i) research on regular and special education instructional strategies, or (ii) research on the effectiveness of or the comparison among instructional techniques, curricula, or classroom managementmethods.

Tokeep the JHMIRB files current, we are assigning a 3-year expiration date toprojects that qualify as exemptor nothuman subjects research. You will receive an email notification prior to the expiration date, allowing you to extend this project by completing an 'Extend Approval' activity (a continuing review application is notrequired).

IRB revievincluded the following:

Use of an oral consentprocess.

Study Team Members:

AbbyeSolis

The Johns Hoplins Institutions operates under multiple Federal-Wide Assurances: The Johns Hopkins University School ofMedicine- FWA00005752, The Johns Hopkins University School of Nursing - FWA00006088, The Johns Hoplins Hospital and Johns Hoplins Headth Systems - FWA00006087, Johns Hopkins Bayview Medical Center- FWA00006089, Howard County General Hospital - FWA00005743, Hugo W. Moser Research Institute at Kennedy Krieger, Inc. - FWA00005719, Johns Hopkins Community Physicians - FWA00002251, Suburban Hospital and Health System - FWA00005924 


\section{Appendix I}

UVa IRB: Determination of UVa Agent Form

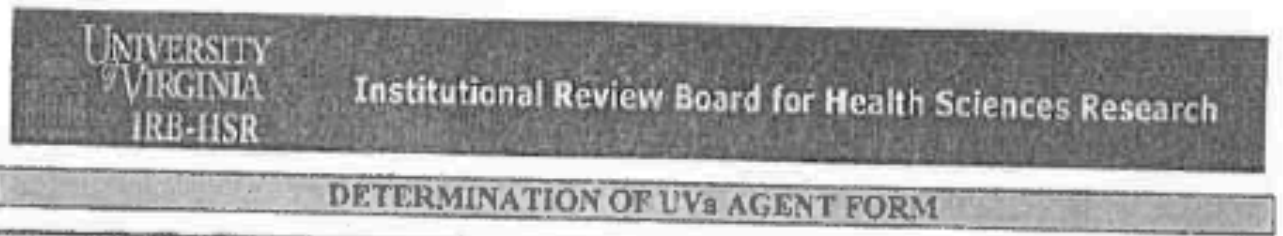

\section{INFORMATION ABOUT THIS FOKM} - This form is to determine if UVa pursonnel are er are not considered to be working as an Agent' for
UVa on this project.

- If it is deteimined that UVa personnol are considered to be working as an Agant' for UVa the stidy tearn will be recuired to submit an additional submission to the IRB-HSR, unless the project is

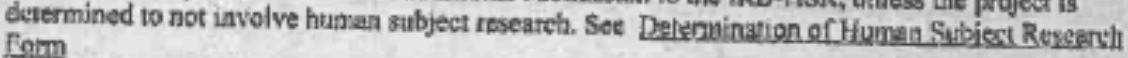

Agent- all hadividwals (inctuding students) performing instinutionally designated activities or exercising thstiantionally dologated authoricy or responstbility.

Enter ropponses electronicully. Prior to abluining stgnatures, email the completed form to IRBHSRgavirginia edu for pre-review. An IRE stuff mamber will reply with any changes to be made.

\begin{tabular}{|c|c|}
\hline Name of lndividual to be Working on Project: & Abbye Solis \\
\hline Email: & Ars9uy @irginia.edu \\
\hline Phone: & $931-239-2434$ \\
\hline \multicolumn{2}{|l|}{ UVa Mossenger Mail Box } \\
\hline Iroject/Protocol Title if Known: & $\begin{array}{l}\text { Feasibility of a Skills Based Focused Critical Caro } \\
\text { Echocardiography Course for Acute Care Nuse } \\
\text { Practitiontss }\end{array}$ \\
\hline $\begin{array}{l}\text { Explain your role in the project: } \\
\text { (200 wonds or less) }\end{array}$ & $\begin{array}{l}\text { This study will examine the feasibility of a one-day } \\
\text { educational program to teach goal-dlrected critical care } \\
\text { echocardiography for the assessment of cardiac output to } \\
\text { acute care nurse practitioners who currently work in a } \\
\text { surgical ICU (study participants). The education sesslon wili } \\
\text { take place in a classtoom at The Johns Hopkins University } \\
\text { School of Nursing. The educatlonal design will mimic recent } \\
\text { studies with physicians, which includes a four hour didactic } \\
\text { session followed by four hours of hands an training. } \\
\text { Demographit data about the particlpants will be collected. } \\
\text { The particlpants will be asked te complete a knowledge test } \\
\text { at thrte different time intervals. The particlpants will also } \\
\text { be askeo to complate two skills tests to evaluate } \\
\text { effectiveness of (1) obtaining adequate ultrasound views } \\
\text { and; (2) calculating cardiac output from a standardized } \\
\text { computer case study. }\end{array}$ \\
\hline
\end{tabular}


Appendix I (cont.)

UVa IRB: Determination of UVa Agent Form

Explain the reason for traveling to the outside Study site is primary site of employment for investigator
institution.


Appendix I (cont.)

UVa IRB: Determination of UVa Agent Form

1. Answer the following questions:

$\square$ Yes $\square$ No I was involved in the design of this research project.

Yes. $\mathrm{No}$ A UVa IRB has apptoved this research. IRB-HSR \#

$\square$ Yes $\square_{\text {No }}$ Punding to conduct this research will come from UVa.

Yes No Working on this I and traveligg to this outside institution is to work on this research.

2. I confirm that

$\square$ Yes $\square$ No I am a student, employee and/or faculty member of the University of Virginia. My work oa this project will be overseen by the Principal Investigator and the IRB at the
outside institurion. This ineludes completing any training in human subject research
protection as required by the outside

$\square$ Yes $\square N_{0}$ protection as required by the outside $1 R B$.

I will communicate with the IRB and the Contracts Office, to determine what approvals may be needed, prior to recaiving any data from the outside institution.

\section{OR}

3. I coafirm that :

Xes ${ }^{2}$ Ne I designed this reseerch.

XYes $\square$ Ye l am a student at UVa but am employed by another institution.

XYes $\square$ Y $\mathrm{All}$ subjects will be enrolled at this outside institution

Board. This includes completing their IRB and, if applicable, their HIPAA Privacy required by the outsids IRB.

$X$ Ye $\square$ There is no funding for this study.

QYes $\square$ No I have notified the outside study,

ATTACII COPY OF OUTSIDE

Abbre Solis

Printed Name of Person Completing this Form

$\begin{array}{r}\frac{1 / 7 / 16}{\text { Dale }} \\ 1 / 7 / 16 \\ \hline \text { Dale }\end{array}$

Signature of Rerson Completing this Form

FOR IRB-HSR OFFICE USE ONLY
No hyparoversonals are not coasiderod to be working as an Agent for UVa on this project.

No happrovals from the UVa IRB-HSR are required.

YVa personal are considered to be working as an Ayent for UVa on this project. submit ahesearch application to the UVa IRB-HSR.

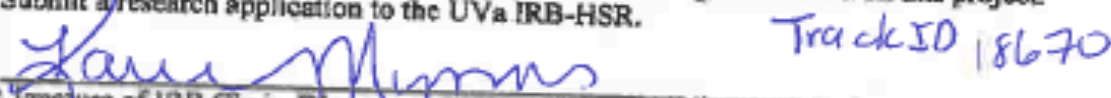

1. genequre of IRB Chair, Director or Designee Dete $01-08-16$

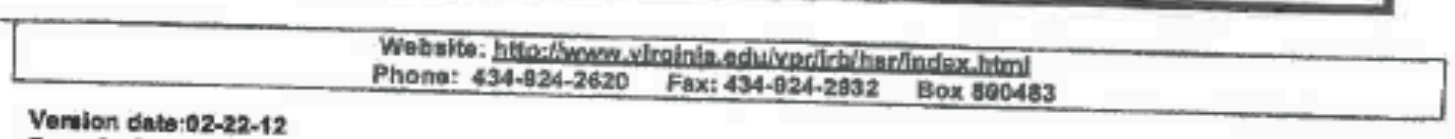

$02-22-12$

Page 2 of 2 
Appendix $\mathbf{J}$

Participant Oral Consent Script

Protocol Title: Feasibility of a Skills Based Critical Care Echocardiography Course for Acute Care Nurse Practitioners

Purpose: You are being asked to take part in a research study because you are an acute care nurse practitioner who works in a surgical intensive care unit. The purpose of this study is to evaluate the effectiveness of a skills based critical care echocardiography short course for acute care nurse practitioners who already work in a surgical intensive care unit. You are being asked to participate because you are an acute care nurse practitioner who works in a surgical intensive care unit.

Procedures: There are three parts to this study. The first part is completing a test before the education course. The test will be emailed to you three weeks before the course and has multiple choice answers. You will be asked to email this test back to the co-investigator. Two weeks before the course, you will be emailed three educational videos and one article to review prior to the educational course.

The second part of the study is the one day education course. The course will be eight hours in length and will include a one hour lunch break. After four hours of lecture, you will be asked to repeat the same multiple choice test that you completed prior to the course. After the lecture portion of the course, you will be asked to participate in hands-on-training where you will practice obtaining ultrasound views of the heart on two live/in-person medical models. You will then be asked to participate in two practical tests. For the first test, you will be asked to obtain four standard ultrasound views of the heart on one of the two live models. Two board certified anesthesiologists who have training in critical care echocardiography will grade you on obtaining these views. For the second test, you will be asked to calculate standard measurements of cardiac output using a standardized case (not on the live models) on the ultrasound machine, writing down your answers on a piece of paper.

The third part of the study will take place one week after the education course. You will be emailed the same multiple choice test, asked to complete the test, and asked to return your completed test to the co-investigator. You will also be asked to calculate standard measurements of cardiac output using the same standardized case on the ultrasound machine.

After all tests (both the multiple choice test and the measurements of cardiac output) are returned to the co-investigator, you will be emailed back the results of the multiple choice test with the correct answers. The practical test answers will also be emailed to you.

You may request additional education from either the principal investigator or the co-investigator at any time during the course or after the course.

At any time during this study, you have the right to refuse to answer any of the multiple choice test questions or perform any aspect of the practical tests. 


\author{
Appendix J (cont.) \\ Participant Oral Consent Script
}

Risk/Discomforts: All research studies have some degree of risk or discomfort. Time involved in completing and reviewing the pre-education materials, attending the one day education course, and completing the post-educational tests could be burdensome. The discomfort of sitting for the four hour lecture plus completing hands-on-training using an ultrasound could cause some physical discomfort. However, it is anticipated that these risks are minimal.

Benefits: There is a benefit to you to completing this research study. The primary benefit is obtaining a new job skill. You will not be paid or compensated for your time by the investigators.

Voluntary Participation: Your participation in this study is voluntary, meaning you do not have to agree to be in this study. If you do not want to join the study, it will not affect your job at The Johns Hopkins Hospital.

If you have any questions about your rights as a research participant, or if you think you have not been treated fairly, you may call the Johns Hopkins Institutional Review Board (IRB) at 410955-3008.

We will not collect personal health information about you in this study. We will collect information about you in this study. We will ask you to complete basic demographic information about yourself that could include: age, gender, number of years as a nurse, number of years as a nurse practitioner, etc.

People at Johns Hopkins who are involved in the study or who need to make sure the study is being done correctly will see the information.

People at Johns Hopkins may need to send your information to people outside of Johns Hopkins (for example, government groups like the Food and Drug Administration) who need to make sure the study is being done correctly.

These people will use your information for the purpose of the study.

We will continue to collect information about you until the end of the study unless you tell us that you have changed your mind. If you change your mind and don't want your information used for the study anymore, you can call The Johns Hopkins Institutional Review Board at 410955-3008. Just remember, if we have already used your information for the study, the use of that information cannot be cancelled.

We try to make sure that everyone who needs to see your information uses it only for the study and keeps it confidential - but, we cannot guarantee this. 
Appendix K

\section{Volunteer Oral Consent Script}

Protocol Title: Feasibility of a Skills Based Focused Critical Care Echocardiography Course for Acute Care Nurse Practitioners

Purpose: You are being asked to take part in a research study because you have volunteered to be a healthy subject who is willing to have ultrasounds of the heart performed on you. The purpose of this study is to evaluate the feasibility of a skills based focused critical care echocardiography short course for acute care nurse practitioners who already work in a surgical intensive care unit.

Procedures: For you as the participant, there is only one part to this study. You will be asked to participate one afternoon for approximately five hours. Participation will require that you be willing to expose your upper chest in order that nurse practitioners can practice obtaining heart ultrasounds on live humans. The heart ultrasounds performed on you are not comprehensive exams of your heart and should not be interpreted as formal echocardiograms that a cardiologist would perform.

Risk/Discomforts: All research studies have some degree of risk or discomfort. There is a possibility that while reviewing your ultrasound images we may see an abnormality that we did not expect to see in this study. This is what is called an "incidental finding." This is the main risk to you as a medical volunteer. An incidental finding may cause you to feel anxious.

If an incidental finding is seen, you will be immediately informed verbally by the Principal Investigator of this study, a board certified anesthesiologist who has extensive training and credentialing in cardiac echocardiography, Dr. Pedro Mendez-Tellez. You do not have an option to decline information about an incidental finding. We will advise you to be seen by your primary care provider. A letter stating the finding or abnormality will be written for you to provide to your primary care provider. If you do not have a primary care provider or would like to be evaluated by someone at The Johns Hopkins Hospital (JHH), you can request that we contact the Physician Access Line at JHH for an appointment. However, all initial and follow-up costs for any incidental finding is your responsibility. The costs for any care that will be needed to diagnose or treat an incidental finding would not be paid for by this research study. These costs would be your responsibility.

Some discomfort during the practice ultrasounds could be experienced. You could feel some pressure of the ultrasound probe on your chest. You might also become cold from the ultrasound gel applied to your chest. Blankets will be provided for your comfort to drape across your chest to maintain privacy.

If you feel any discomfort at any time, you can ask that the reason for the discomfort be eliminated. If you do not longer want to be a volunteer for the study you can, at any time, choose to stop.

Benefits: There is a benefit to you for being a volunteer for this study. You will be paid $\$ 100$ in the form of a gift card upon completion of the five hour session. 


\author{
Appendix K (cont.) \\ Volunteer Oral Consent Script
}

Voluntary Participation: Your participation in this study is voluntary, meaning you do not have to agree to be in this study. If you do not want to join the study, it will not affect your care at Johns Hopkins.

If you have any questions about your rights as a research participant, or if you think you have not been treated fairly, you may call the Johns Hopkins Institutional Review Board (IRB) at 410955-3008.

We will not collect personal health information about you in this study. The images obtained by the ultrasounds will not be stored on a computer to be viewed by others.

People at Johns Hopkins who are involved in the study or who need to make sure the study is being done correctly will see the information.

People at Johns Hopkins may need to send your information to people outside of Johns Hopkins (for example, government groups like the Food and Drug Administration) who need to make sure the study is being done correctly.

These people will use your information for the purpose of the study.

We will continue to collect information about you until the end of the study unless you tell us that you have changed your mind. If you change your mind and don't want your information used for the study anymore, you can call The Johns Hopkins Institutional Review Board at 410955-3008. Just remember, if we have already used your information for the study, the use of that information cannot be cancelled.

We try to make sure that everyone who needs to see your information uses it only for the study and keeps it confidential - but, we cannot guarantee this. 


\section{Appendix L}

Tables and Graphs of Results

Table 1

ACNPs and Raw Score of Knowledge Test, out of 16

\begin{tabular}{cccc}
\hline ACNP & Pre-test & Day-test & Post-test \\
\hline 1 & 6 & 10 & 12 \\
2 & 6 & 12 & 10 \\
3 & 10 & 10 & 10 \\
4 & 7 & 7 & 14 \\
5 & 6 & 7 & 4 \\
\hline
\end{tabular}

Table 2

Mean Scores of Knowledge Test with Standard Deviation

\begin{tabular}{lc}
\hline & $\begin{array}{c}\text { Mean Scores } \\
(\mathrm{SD})\end{array}$ \\
\hline Pre-Test & $7(1.73)$ \\
Day-Test & $9.2(2.16)$ \\
Post-Test & $10(3.74)$ \\
\hline
\end{tabular}


Appendix L (cont.)

Tables and Graphs of Results

Graph 1

Comparison of Raw Scores of Knowledge Test Over Time

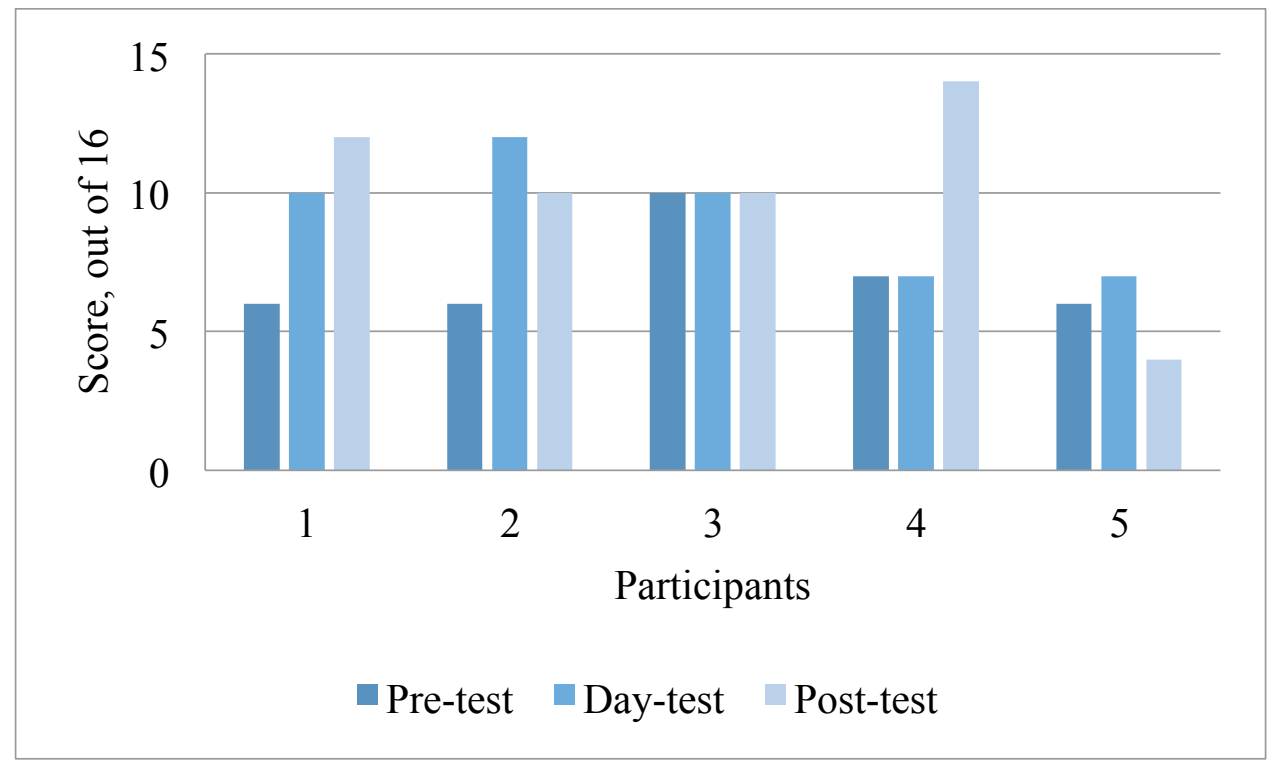


Appendix L (cont.)

Tables and Graphs of Results

Graph 2

ACNPs and Raw Score of Knowledge Test, out of 16, with Standard Deviations of Scores

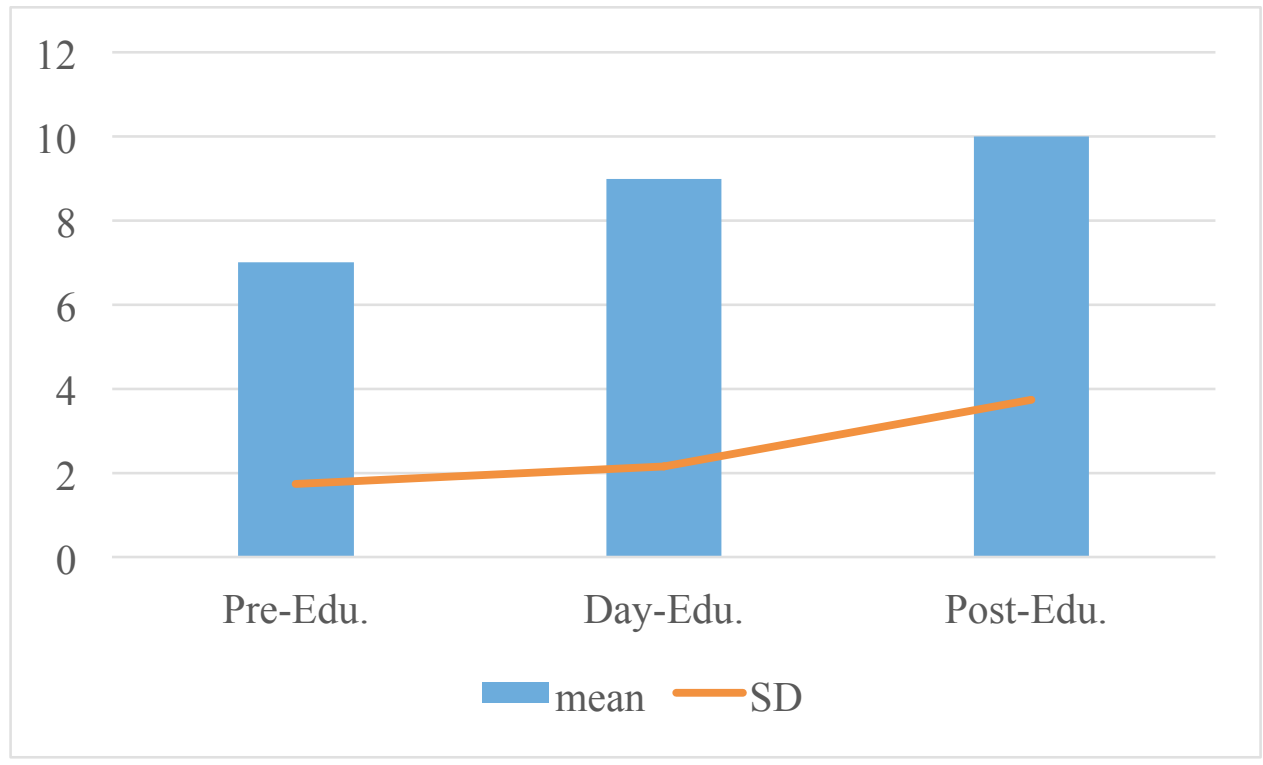


Appendix L (cont.)

Tables and Graphs of Results

Graph 3

Limited Critical Care Cardiac Ultrasound Views Clinical Ability Test Results

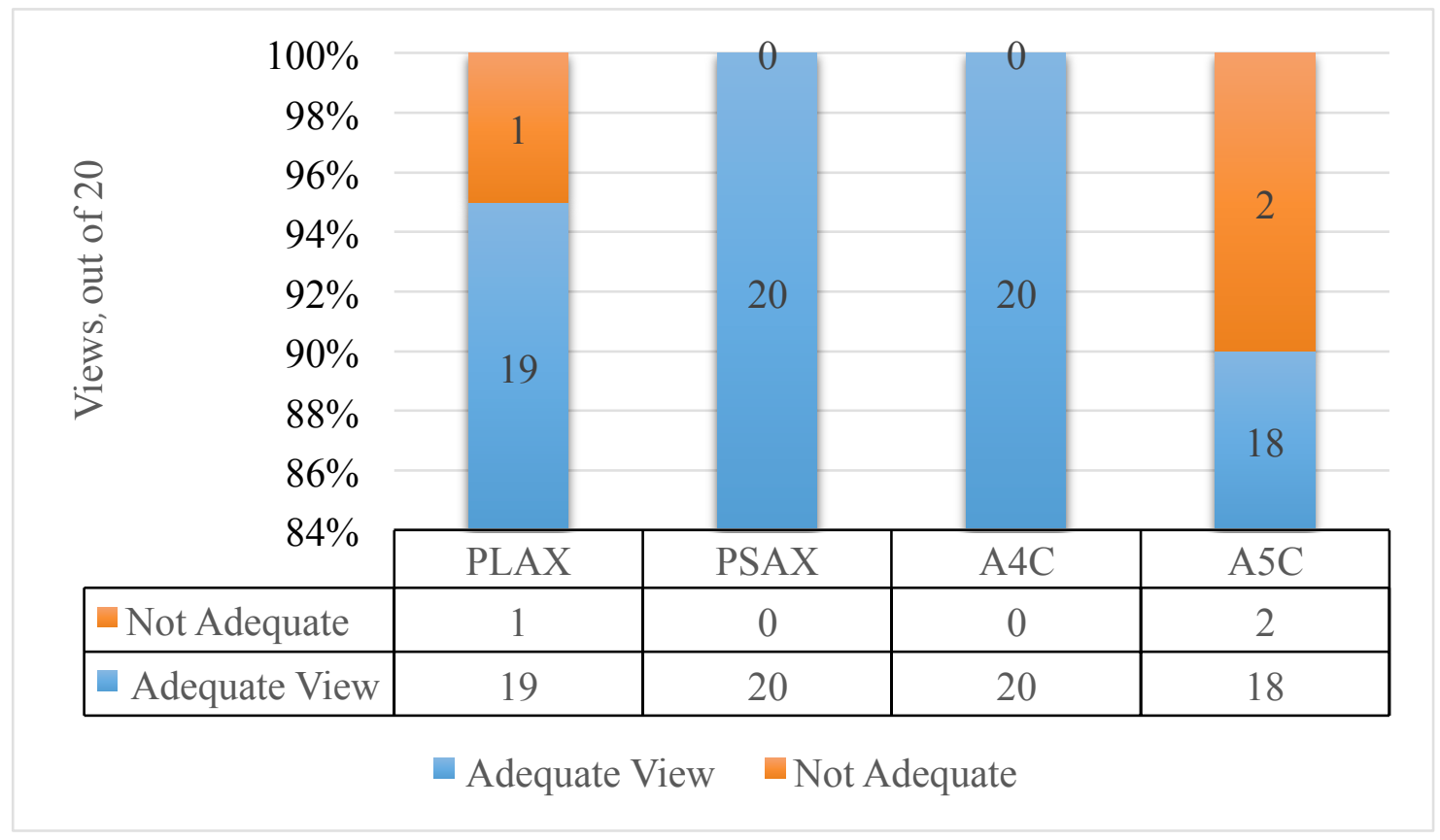

*PLAX $=$ Parasternal long axis; PSAX = Parasternal short axis; A4C $=$ Apical four chamber;

$\mathrm{A} 5 \mathrm{C}=$ Apical five chamber 
Appendix L (cont.)

Tables and Graphs of Results

Table 3

Fractional Area Change and Cardiac Output by Participant

\begin{tabular}{ccccc}
\hline ACNP & $\begin{array}{l}\text { Time 1: } \\
\text { FAC* }\end{array}$ & $\begin{array}{l}\text { Time 2: } \\
\text { FAC* }\end{array}$ & $\begin{array}{l}\text { Time 1: } \\
\text { CO* }\end{array}$ & $\begin{array}{l}\text { Time 2: } \\
\text { CO* }\end{array}$ \\
\hline 1 & 75.8 & 70 & 4.53 & 3.6 \\
2 & 58 & 71 & 4.5 & 5.4 \\
3 & 83 & 70 & 3.2 & 3.6 \\
4 & 59.9 & 81.6 & 5.3 & 3.6 \\
5 & 40.5 & 21.3 & 4.1 & 3.01 \\
\hline
\end{tabular}

$* \mathrm{FAC}=$ Fractional Area Change; $\mathrm{CO}=$ Cardiac Output

Table 4

Fractional Area Change and Cardiac Output Mean Scores and Standard Deviation

\begin{tabular}{lcccc}
\hline & FAC*, Time 1 & FAC*, Time 2 & CO*, Time 1 & CO*, Time 2 \\
\hline Mean Score (SD) & $63.44(16.6)$ & $62.78(10.59)$ & $4.3(0.76)$ & $3.8(0.91)$ \\
\hline
\end{tabular}

$*$ FAC $=$ Fractional Area Change; $\mathrm{CO}=$ Cardiac Output 
Appendix L (cont.)

Tables and Graphs of Results

Graph 4

Comparison of Fractional Area Change Answers (in percentage)

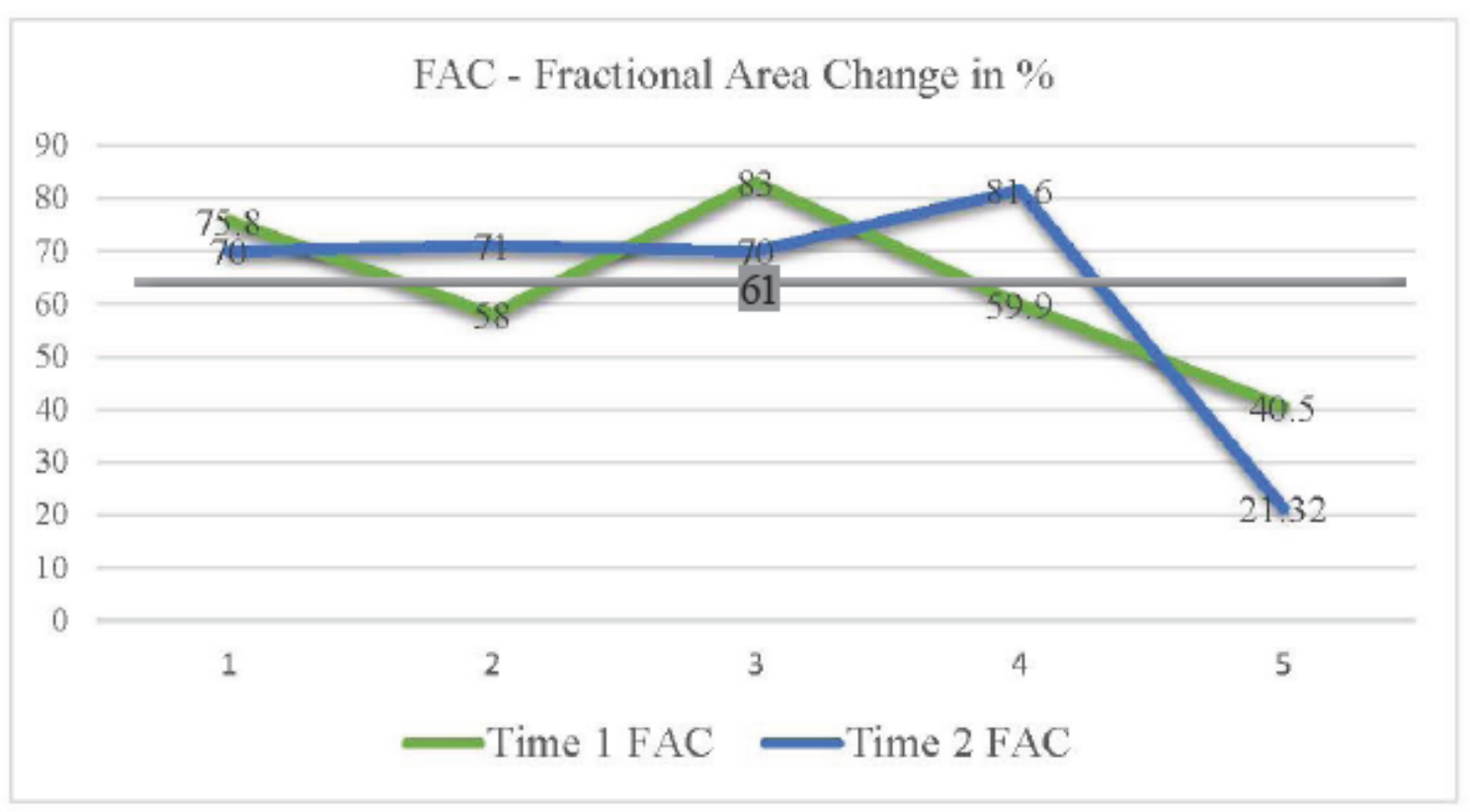

Note: Accepted range for answer $=54.9-67.1$ 
Appendix L (cont.)

Tables and Graphs of Results

\section{Graph 5}

Comparison of Cardiac Output Answers (in liters)

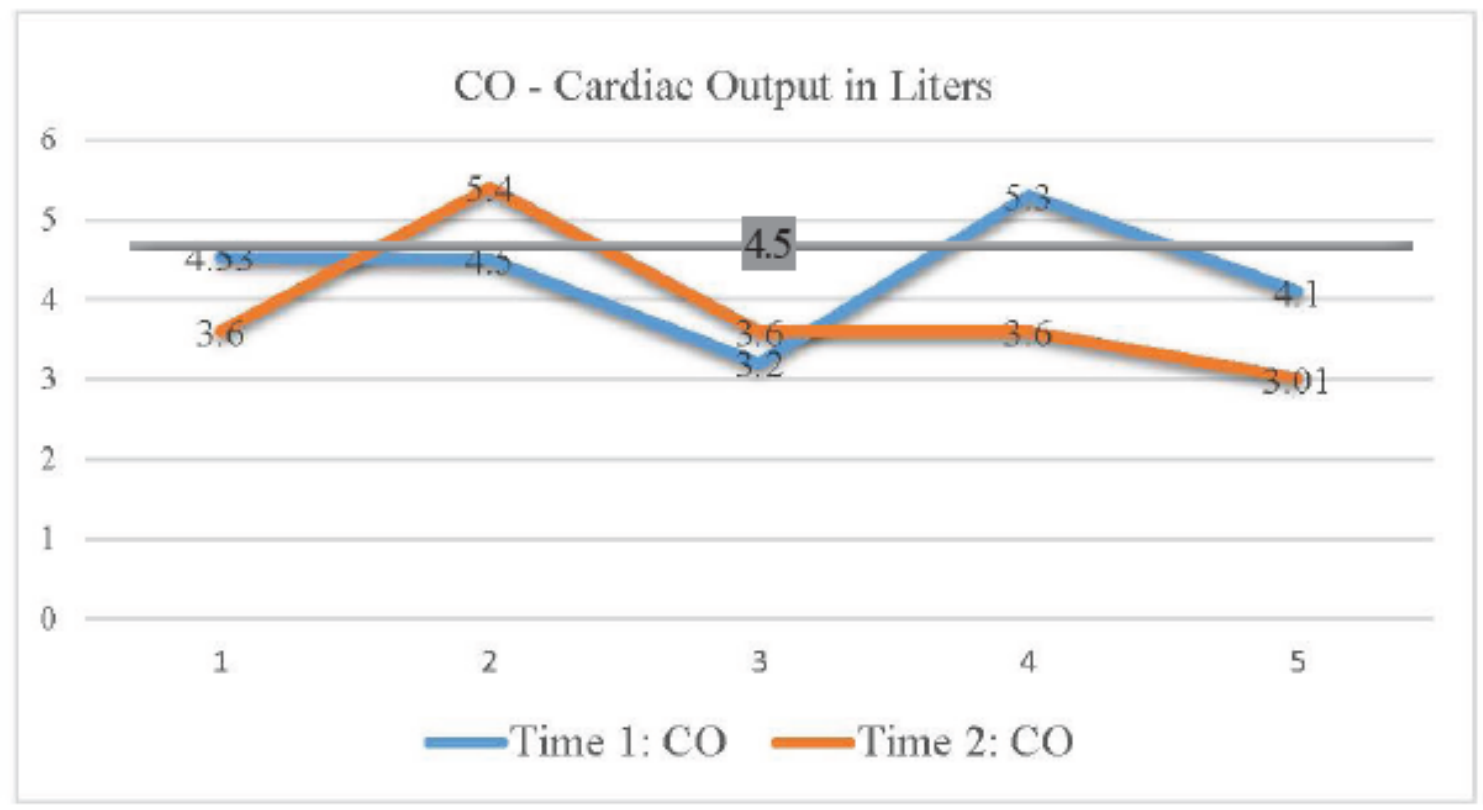

Note: Accepted range for answer $=4.05-4.95$ 


\section{Appendix M}

Journal of the American Association of Nurse Practitioners Author's Guidelines for Authors

Table of contents

Section 1: Overview and General Information

1.1 - Aims and Scope

1.2 - Correspondence

1.3 - Review and Response

Section 2: Manuscript Submission Criteria

2.1 - Publication Ethics

2.2 - Manuscript Files and Format

2.3 - Categories of Articles

2.4 - Size / Length / Fonts

2.5 - Style and References

2.6 - Footnotes

Section 3: Additional Guidelines

3.1 - Title Page

3.2 - Cover Letter

3.3 - Abstract

3.4 - Acknowledgements

3.5 - Electronic File Formats

3.6 - Tables, Figures and Graphics

3.7 - Permissions

3.8 - Copyright Transfer Agreement (CTA)

Section 4: Guidelines for the online submission process

4.1- Prior to LOGIN

4.2 - Be Prepared

4.3 - After You Have Logged In

4.4 - Keyword Tips

4.5 - Manuscript File Naming for Submission

4.6 After Your Submission is Complete

Section 5: Manuscript Submission Checklist 
Appendix M (cont.)

Journal of the American Association of Nurse Practitioners Author's Guidelines for Authors

\section{Section 1: Overview and General Information}

\section{1 - Aims and Scope}

The Joumal of the American Association of Nurse Practitioners (JAANP) is a monthly scholarly, peer-reviewed journal for Advanced Practice Registered Nurses (APRNs) and is the official journal for all members of the American Association of Nurse Practitioners (AANP; see www.aanp.org for more information). Formed in 1985, the AANP is the largest and only full-service professional membership organization in the United States for NPs of all specialties. The JAANP supports the mission of AANP to lead NPs in transforming patient-centered health care with a vision of high quality health care for all by the patient's provider of choice.

The mission of the JAANP is to help serve the information needs of nurse practitioners (NPs) and others with an interest in advanced practice nursing and patient-centered health care. Our collective vision is high quality health care for all by the patient's provider of choice. The readers of the JAANP are mostly primary care NPs and other advanced practice registered nurses (APRNs), who provide care in domestic and international settings where they serve clients of all ages, manage a broad spectrum of acute and chronic conditions, prescribe a variety of medications and treatments, and function to the full scope of advanced practice nursing in their respective states and countries. Our organizational core values promote integrity, excellence, professionalism, leadership, and service, which is reflected in the way our members have embraced advanced education, lifelong learning, and the continued evolution of advanced practice nursing.

The JAANP encourages submission of scholarly articles addressing a broad range of topics appropriate to advanced practice nursing in the United States and internationally. Of particular interest in the current evolving health care delivery system are quantitative, qualitative, and mixed methods research studies answering new and novel problems; outcomes research addressing in particular outcomes directly affected by APRNs/NPs; cost-effectiveness or economic analysis of health care interventions used by APRNs/NPs; systematic reviews and meta-analyses of scientific literature of the benefits and harms of health care interventions; education research particularly related to NPs in DNP programs; health policy analysis related to advanced practice nursing in state, national, or international environments; practice improvement or quality improvement projects; and other new and evolving advanced practice nursing issues. International submissions that address new or novel advanced practice nursing issues throughout the world are also encouraged. Manuscripts must be original, unpublished works submitted for the exclusive use of the JAANP in accordance with our current author guidelines.

\section{2 - Correspondence}

All editorial queries and commentary should be sent by email to: JAANPEditorial@wiley.com

It is not necessary to send a pre-submission query. We recommend instead that authors visit the online journal website (http://onlinelibrary.wiley.com/journal/10.1002/(ISSN)2327-6924/earlyview) and check the table of contents and abstracts for the previous 12-24 issues to view the scope of topics covered in JAANP. 


\author{
Appendix M (cont.) \\ Journal of the American Association of Nurse Practitioners Author's Guidelines for Authors
}

\title{
1.3 - Review and Response
}

All reviews are completed on-line via the ScholarOne Manuscripts ${ }^{\text {Th }}$ program and the results of reviews are sent to the authors at the email address entered into the system by the submitting author. We try to provide a first response within 60 days, however, this depends on the timeliness of the reviewers' responses. Careful consideration is given to all submissions and decisions are rarely changed. If the author believes that misconduct on the part of the reviewers may have occurred (a conflict of interest for example), the author should contact the editor-in-chief and request a review of the decision. A decision of Reject is not sufficient reason to request a review, nor is the fact that the reviewers did not understand what the author meant to say. Poorly written or plagiarized material, flawed research, or a focus that is not appropriate for the journal's audience are valid reasons for rejection.

We follow the guidelines from the Committee on Publication Ethics (COPE; www.publicationethics.com) in addressing author's concerns about ethical processes. If the author believes that misconduct on the part of the editors is a concern, the appropriate person to contact is the nursing journals division of the publisher (John Wiley \& Sons).

\section{Section 2: Manuscript Submission Criteria}

Manuscripts must be submitted via the ScholarOne Manuscripts ${ }^{\mathrm{TM}}$ JAANP online submission site at http://mc.manuscriptcentral.com/jaanp The steps must be followed exactly to assure your submission is complete. If all authors on the manuscript do not receive an automated e-mail response confirming the submission, the manuscript has not been successfully entered into the system.

\section{1 - Publication Ethics}

The JAANP adheres to the principles stated in the Uniform Requirements for Manuscripts Submitted to Biomedical Journals. (http://www.icmje.org/urm_main.html) All authors should meet the criteria for authorship as stated in the ICMJE Uniform Requirements. The required Cover Letter must include a declaration all authors have contributed to the manuscript, a statement that the submitted manuscript has been read and approved by all the listed authors, and that the work is original and not under consideration by any other journal. All authors must also make a declaration of competing interests either in the cover letter or by completing the ICMJE Conflict of Interest Disclosure Form (available at $\mathrm{http}: / / w w w . i c m j e . o r g / c o n f l i c t s-o f-i n t e r e s t /$ ) and attaching that to the submission. A separate statement regarding conflicts of interest within the manuscript may also be required at the editor's discretion and is covered in great detail in the section titled Acknowledgements (3.4).

All authors should have made substantial contribution to the manuscript submitted and be prepared to defend any content included therein. A statement about the role of each author must be included in the Title Page. To fully understand the issues of Authorship and Conflicts of Interest, authors are encouraged to read the full text of the Uniform Requirements for Manuscripts Submitted to Biomedical Journals at (http://www.icmje.org/urm_full.pdf). If changes are made to authorship following a revised submission, all authors must agree to the change by completing the Change of Authorship Form, available from the editor on request. Consider acknowledging those who do not qualify as authors based on the ICMJE authorship criteria.

The JAANP is a member of the Committee on Publication Ethics (COPE) and adheres to the ethical publication practices. The JAANP adheres to the Good Publications Practice Guidelines, version 2, available online at http://www.gpp-guidelines.org/ for all sponsored material. 


\author{
Appendix M (cont.) \\ Journal of the American Association of Nurse Practitioners Author's Guidelines for Authors
}

Sponsorship must be clearly stated and all authors must complete the ICMJE Conflict of Interest Form.

All manuscripts are submitted to iThenticate, a plagiarism detection program, prior to peer review. Manuscripts that appear to be duplicate submissions will not be reviewed and all authors will be notified of the iThenticate report. Significant issues of apparent ethical misconduct will be addressed according to the COPE guidelines (available at http://publicationethics.org), which may include notification of Deans, supervisors, and/or institutional oversight or funding agencies of ethical breaches. Submitted manuscripts are treated as confidential material; however, the editor will share information on submissions for the purposes of investigating potential misconduct. Any sharing of confidential information will proceed according to COPE guidelines.

\title{
2.2 - Manuscript Files and Format
}

This section provides general guidelines for format and length of manuscripts and some specific guidelines for selected types of manuscripts. It is important that the submitter review the submission to assure that files are uploaded properly and that any author identifying information is removed to assure a fair and blinded review process.

Manuscript text should not include page numbers, running heads, headers/footers, or hard returns at the end of each sentence (use the word wrapping feature of the word processor). Tables and figures should not be included in the body of the Main Document file. They should be in separate Table and Figure files and labeled appropriately (e.g., Table 1). More specific information about tables, figures, and graphics can be found in section 3.6 .

Prior to submission you will need to do a word count (available on the MS Word Tools menu) of the Main Document file, excluding the abstract and references. This word count is to be entered in a specified data field of ScholarOne Manuscripts ${ }^{T w}$ during the submission process.

\section{3 - Categories of Articles}

We support the use of appropriate guidelines for reporting health research. Where appropriate in the following guidelines, we have mentioned specific guidelines to follow. Please consult the EQUATOR Network (http://www.equator-network.org/) for more specific information.

Research: Several types of research manuscripts may be appropriate for JAANP; however, the focus of the research must clearly relate to NP practice. A clearly stated question or purpose must be provided early in the manuscript. Study protocols will not be considered for publication and pilot studies are rarely of interest because of the small number of subjects involved. Research generated from a larger parent study must be clearly specified and copies of ALL previously published papers from that study must be submitted as either an email attachment to the editor or uploaded into the manuscript system as a supplementary file for review.

All research reports must contain a statement in the methods section about the protection of human subjects and approval by the appropriate review committee. Research conducted on Federal property must also be approved by the appropriate Federal oversight review committee. Research conducted on Native American lands must be approved by the appropriate oversight review committee. Checking the appropriate box on the Manuscript Details form in the submission process is also required.

Research references should be the most current references available. Classic articles related to methods or instruments are acceptable. Additional references may be included in a table for

Revised May 1, 2015 


\author{
Appendix M (cont.) \\ Journal of the American Association of Nurse Practitioners Author's Guidelines for Authors
}

on-line supporting information.

Observational Studies (cohort, case-control, cross-sectional): Please follow the STROBE guidelines to assure all elements are reported appropriately.

(http://www.equator-network.org/reporting-quidelines/strobe/). Some of the extension guidelines at this link may be appropriate for reporting outcomes research.

Parallel Group Randomized Trials: Please follow the CONSORT guidelines to report experimental research and include the trial registration number.

(http://www.equator-network.org/reporting-guidelines/consort). Note that there are supporting files for extensions of the CONSORT guidelines to address specific issues in other types of experimental design, such as trials assessing non-pharmacologic treatments. which may be more appropriate to reporting your study.

Qualitative Research: For qualitative research, the type of analysis and control for rigor and credibility must be clearly stated. Any identifying information in responses from subjects must be removed. Two guidelines are likely to be most useful for JAANP authors: ENTREQ and COREQ. (http://www.equator-network.org/?post_type=eg_guidelines\&eg_guidelines_study design=qualit ative-research\&eq_quidelines_clinical_specialty $=0$ \&eq_guidelines_report_section $=0 \& \mathrm{~s}=+$ ).

Quality Improvement Research: Quality improvement research must be clearly differentiated from experimental design. The appropriate guideline for reporting a QI research project is the SQUIRE guidelines (http///squire-statement.org/guidelines/). Note that any research design used in the project must be carefully reported using appropriate guidelines for research reporting as described in the EQUATOR Network (http://www. equator-network.org/reporting-quidelines/).

Statistical Reporting Guidelines: A useful guide for reporting statistical analysis and methods in research can also be found on the EQUATOR Network. The SAMPL Guidelines cover most types of statistics and methods used in quantitative research.

(http://www.equator-network.org/reporting-guidelines/sampll)

Reviews: We consider only systematic reviews either with or without meta-analysis. A systematic approach to finding relevant studies, for example the PRISMA Statement (http://www.prisma-statement.org ), the Joanna Briggs Institute (http://www.joannabriggs.edu.au/about/home.php) or the Cochrane Collaboration (http://www.cochrane.org/reviews/clibintro.htm ), should be used as a guideline for reporting reviews. Authors should clearly describe the system they used to assure they have produced an unbiased review, including search strategies, inclusion/exclusion criteria, and evaluation of the strength of the reported research. Lengthy tables reporting study findings can only be considered for online supporting information.

Sponsored Reviews, developed by authors in collaboration with medical communications companies or independent medical writers and funded by pharmaceutical or device companies, cannot be considered at this time unless the sponsoring company is willing to pay for the supplement pages required to publish the article. If sponsorship includes paying for supplementary pages to the journal, sponsored articles will be considered as long as they are unbiased and focus on entire drug/device classes or diseases, not just a single product. Off-label use of drugs in any drug review must be clearly identified. Conflict of Interest declarations must be completed by anyone submitting reviews of drug or devices. Sponsored material will be peer reviewed and must be relevant to NP practice. Contact Joann Mitchell (joamitchel@wiley.com) for further information on sponsored material. We adhere to the principles stated in Good Publication Practices Guidelines, version 2, which is available at http://www.gpp-guidelines.org 


\author{
Appendix M (cont.) \\ Journal of the American Association of Nurse Practitioners Author's Guidelines for Authors
}

Brief Reports. Manuscripts with limited focus will only be considered for Brief Report formats. These manuscripts are no longer than 3000 words and limited to 30 references. Topics must be unique and of broad interest to NPS.

Health Policy. Health policy is broadly defined by the World Health Organization as "decisions, plans, and actions that are undertaken to achieve specific health care goals within a society." Analysis of health policy issues related to NP practice are of interest to readers of JAANP. Topics must present new ideas and have broad implications for NP practice in national or international arenas.

Supplements: Supplements must have sponsorship and all proposals for supplements are first reviewed by the Wiley Development Team (joamitchel@wiley.com) and referred to the Editor. All material submitted for supplements must follow all these guidelines and go through the peer-review process. The JAANP adheres to the GPP-2 Guidelines available online at http://www.gpp-guidelines.org/ for all sponsored material.

Special Articles: Occasionally, the editorial board will solicit articles from experts in a specific filed to address a narrow topic of interest to the profession. These articles will be titled Special Articles or they may appear as part of an ongoing series such as the Scholars Corner.

\title{
2.4 - Size / Length / Fonts
}

The title should be no longer than 25 words and should reflect the content of the paper.

The body text of a typical manuscript, excluding abstract, references, tables, figures or graphics, should not exceed 4,000 words. Longer articles may be considered at the editor's discretion. Text should be double-spaced, with approximately one inch margins.

Standard Fonts such as "Times New Roman" or "Times" are preferred. For maximum clarity, use sans serif fonts "Arial" or "Helvetica" for labeling figures, and "Symbol font" for Greek letters and the MS Word symbol menu for other unusual characters. Unusual fonts may not be supported on all systems and may be lost on conversion of your documents at the time of online submission.

If you have used the Track Changes feature in the process of writing and editing your manuscript, please save a final version that accepts all the changes you intend to include before you upload your file.

\section{5 - Style and References}

The Publication Manual of the American Psychological Association 6th edition (APA) is the style manual used by the JAANP to format citations, references, headings, and other matters. The use of electronic bibliographic citation managers (such as EndNote ${ }^{\mathrm{TM}}$ ) is both acceptable and desired. There are special provisions for submission within the ScholarOne Manuscripts ${ }^{\mathrm{TM}}$ system that may make submission easier for those who use EndNote ${ }^{\mathrm{TM}}$.

DOI numbers in citations are the preferred method for all citations and in particular, for "on-line ahead of print" or "early-view" manuscripts. References for manuscripts in-press are acceptable but they must be updated before the manuscript is published. There is extensive information about the use of DOls in the APA 6th edition if you have questions.

References are limited to 50 for most articles except Brief Reports which are limited to 30 and

Revised May 1, 2015 
Appendix M (cont.)

Journal of the American Association of Nurse Practitioners Author's Guidelines for Authors

systematic reviews which may exceed 50 . Pay particular attention to the APA requirements for citation of on-line material. This has changed significantly in the latest edition.

References should be listed alphabetically in a separate section at the end of the body of the manuscript Main Document file, double-spaced under a heading titled References. Do not put them in a separate file. References should be current and journal titles should not be abbreviated. For most manuscripts, citations older than five years, other than classic works, are rarely required. It is the author's responsibility to assure that all references are complete and accurate. Manuscripts that do not conform to referencing guidelines will not be reviewed. Retracted literature should not be cited other than in the context of the retraction.

Reference works not cited in the main text should be deleted from the manuscript. In some cases it may be useful to create a table titled Useful Resources or Useful Websites for inclusion as on-line supporting information. There is also helpful information about references for systematic reviews included in the latest edition of the APA.

\section{6 - Footnotes}

Do not use footnotes in the abstract or the main body of the manuscript; parenthetical comments are preferred over footnotes but should be used sparingly. Footnotes to tables or figures should clearly spell out all abbreviations used. Statistical significance may also be indicated with footnotes.

\section{Section 3: Additional Guidelines}

The following section details specific elements of the submission that are required at the time of submission.

\section{1 - Title Page}

The information on Title Page contains more than just the title and will be used at production time to properly identify the authorship of the manuscript.

The title of 25 words or less should be descriptive, unambiguous, and entice the audience to read your work.

Following the title should be a list of all authors in the order in which they will appear in published form, along with institutional roles and affiliations. The contact author must be clearly identified (this does not have to be the first author) along with complete contact information. Alternative email addresses and phone numbers are helpful in case we encounter difficulty contacting you.

The role each author filled in the development of the manuscript must be identified in a separate statement in the Title Page. For example, Mary Jones developed the instrument and performed all the analyses; Susan Smith wrote the initial draft of the manuscript; both authors developed the research project, collected chart data, and revised the manuscript for final submission. See the ICMJE Authorship Criteria if you have difficulty deciding what roles must be included in an authorship statement.

Any disclaimers required by Federal law (e.g., military, Federal Government) should be included on the title page. 


\author{
Appendix M (cont.) \\ Journal of the American Association of Nurse Practitioners Author's Guidelines for Authors
}

\title{
3.2 - Cover Letter
}

The cover letter must contain the title of the manuscript, a statement about authorship as described previously (see section 2.1 Publication Ethics), and attestation that the manuscript is submitted in accordance with the current GFA (see version number top left of this page) for the sole consideration of the JAANP and the material has not been published in any form previously. If the material has been presented at a conference or is part of a larger study (e.g., a subgroup analysis), that should also be stated. Please attach copies of all previously published articles from the study. If articles have been submitted elsewhere but not published yet, please summarize the differences between the manuscripts in the cover letter.

If the paper reports findings from a clinical trial that has been registered, include the registration information. If the paper requires special consideration related to the NIH Public Access Mandate, please alert us with a statement in the cover letter.

\section{3 - Abstract}

The JAANP Abstract follows a structured style. It must be formatted with the following four specific headings -- each separated by a blank line: Background and Purpose; Methods; Conclusions; and Implications for Practice. Do not use citations in the abstract. The abstract (the first item in the main document) must be copied into a designated abstract field during the submission process. Reviewers receive the abstract from this field when they are asked to perform a review so it is the first impression you make on a reviewer. . NOTE: There is a firm 200 word limit for the abstract.

\section{4 - Acknowledgements}

Acknowledgements fall into two categories - Personal and Expository.

Personal acknowledgements are used to acknowledge such things as competitive grant funding and unpaid editorial assistance from mentors and colleagues. To avoid compromising the author's anonymity, these acknowledgements are to be uploaded in a separate file during submission designated as a "Supplementary file not for review".

Expository acknowledgements are used to divulge those items pertaining to conflicts of interest (COI) and funding for the development or editing of any article that mentions specific drugs, devices, or other proprietary content. This includes any editorial or writing assistance provided by pharmaceutical, manufacturing, or medical communications companies, which must be clearly acknowledged including the name of the editor/writer and the source of funding. These acknowledgements are to be uploaded in a separate file during submission and designated as a "Supplementary file for review." Details of this support must also be copied into the corresponding fields of the online Manuscript Details form. This file will be included in the information accessible by reviewers, so it's important to use author initials or author 1, 2, etc, when disclosing any funding to maintain anonymity.

NOTE: If the submitter checks "no" to the "Do you have any conflict of interest?" statement, you are declaring that: No relationship exists between any of the authors and any commercial entity or product mentioned in this article that might represent a conflict of interest. There was no solicitation of the author(s) by any commercial entity to submit the manuscript for publication.

If you have no $\mathrm{COI}$ to declare, checking the box on the Manuscript Details page in your submission is sufficient. If a failure to disclose a relevant $\mathrm{COI}$ is discovered after final publication of 
Appendix M (cont.)

Journal of the American Association of Nurse Practitioners Author's Guidelines for Authors

the manuscript, the editor may decide to retract the article, or at least publish an erratum or statement of concern.

To review the scope of $\mathrm{COI}$ go to the link on the ICMJE home page

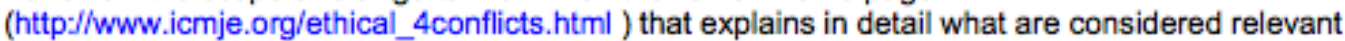
$\mathrm{COI}$. Whenever there is a possibility of a COI regarding commercial interests and the content of a manuscript, all authors are required to complete the ICMJE COI Disclosure form disclosing this potential or actual conflict-of-interest. (See editorial related to use of the uniform disclosure form at (http: $/ /$ www.icmje.org/format.pdf ). This form is available in the public domain for authors to complete and upload with their submission at http://www.icmje.org/coi_disclosure.pdf

\section{5 - Electronic File Formats}

The Main Document file of the submission must be in a .DOC, .DOCX (not DOCM or .WKS), .RTF or other Microsoft Office compatible file format. Further information on file formats can be found

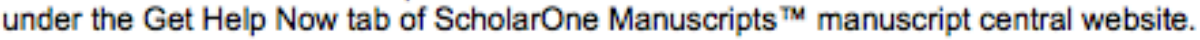

\section{6 - Tables, Figures and Graphics}

Tables, Figures, and Graphics must not simply duplicate what has been said in the body of the manuscript. If they do not enhance the text, they may be eliminated for space considerations. Tables, figures, and graphics must be cited in the text in the appropriate location (e.g., see Table 1). Footnotes to tables or figures should clearly spell out all abbreviations used. Statistical significance may also be indicated with footnotes. Online-only supporting materials (such as data tables, maps, a review matrix, and interview forms) may be considered at the time of publication at the editor's discretion.

Tables should be numbered with Arabic numbers in the order in which they are mentioned in the text. Each table should be double-spaced and include an appropriate caption. Every column must have a description or heading. Demographic tables must clearly indicate the total $\mathrm{N}$ either as a footnote or in a column heading. Use a table function to create your table - do not use tabs or the spacebar to create columns (this will result in columns that do not align properly when your submission is converted to HTML or PDF).

Tables must be in an editable file format such as .DOC or .DOCX (not PDF). Figures and graphics should use one of the file formats recommended by the publisher at:

http://authorservices.wiley.com/bauthor/illustration.asp

All figures must have captions, which can be included as a separate file labeled "Figure Captions" if it is not possible to include the caption on the figure itself. Figures that are not high resolution may be deleted from a manuscript prior to publication, so it is helpful to provide the highest quality figure on submission or with revisions to assure a timely publication.

Tables and figures should be uploaded as separate files during the submission process.

\section{7 - Permissions}

Authors must obtain any necessary permissions to reproduce previously copyrighted materials. Permissions to reprint Tables, Figures, Graphics, Instruments, or any other previously copyrighted information should accompany the manuscript at the time of submission. The copyright holder may be a publisher, an author, an agency, or any combination thereof. Be sure you have

Revised May 1, 2015 
Appendix M (cont.)

Journal of the American Association of Nurse Practitioners Author's Guidelines for Authors

requested permiseion from the actual copyright holder, which is not always the author.

If a payment for permission to reprint is required, it will be the author's responsibility to pay all fees prior to publication and submit evidence of such payment to the editor. NOTE: Do not pay fees until the manuscript has been accepted and scheduled for publication. Permissions should be scanned or copied into a file and uploaded as a "Supplementary file not for review." Permissions must include both print and electronic publication. Permissions granted to students for materials included in a dissertation or project do not cover publication in commercial journals; therefore, a separate permit is required.

\section{8 - Copyright Transfer Agreement (CTA)}

The CTA is a legal document required by the publisher prior to publication. A link to the electronic CTA form will be provided by the production services and must be completed for publication to continue. The copyright is assigned to the AANP as the owner of the JAANP; however, the CTA further outlines your retained rights and permitted uses and allows for the posting of NIH grant-funded work to PubMed Central upon acceptance of the final manuscript. There are also special provisions for work produced by employees of the U.S. Federal Government (which includes all military services), as well as other government employees, so that your work will reside in the public domain.

\section{Section 4: Guidelines for the online submission process}

The JAANP uses the ScholarOne Manuscripts (S1M) online submission processing system.

Submission site URL: http://mc.manuscriptcentral.com/jaanp

To make a submission you must login to your S1M JAANP account. If you do not have such an account you must create one. (NOTE: most S1M JAANP MC Accounts can be dual role Author/Reviewer accounts so if you are an active JAANP reviewer you should already have an account.) If you are creating a new account, that account will only be for Author status.

A submission by an author's agent is acceptable. If you are a submitting agent for the manuscript (i.e., a project manager or administrative assistant), you should enter all the required submitter information under your own name and check the appropriate box so that you will not be listed as an author.

\section{1- PRIOR TO LOGIN}

Before you log in to create/update your account and start a submission we suggest that you print out this file, read it, and then use it as a reference.

Have an email address for all authors and have a permanent backup webmail address (e.g., hotmail, yahoo, Gmail) for yourself and any second author.

Decide how you wish you and your co-author(s) to be addressed:

Dr. Miss Mr. Mrs. Ms or Prof

(NOTE: If your manuscript is accepted for publication you will be able to update your credentials, address, affiliation, etc. at proof reading time.)

Make sure that there are no page numbers in your main document. (Nothing should be in the header or footer.)

Determine the approximate number of words in your main document.

Select keywords for both your account and submission. (See Key word Tips below)

Revised May 1, 2015 
Appendix M (cont.)

Journal of the American Association of Nurse Practitioners Author's Guidelines for Authors

Limit your Title to 30 words.

Limit your Running Head to 50 characters (letters, punctuation, and spaces.

Limit your Abstract to 200 words and ensure it is structured according to the JAANP Author Guidelines.

Create a cover letter document that includes the required information described above. You may enter or copy and paste your cover letter text into a "Cover Letter" box OR you can attach a file containing your cover letter following the onscreen instructions.

NOTE: Submissions that do not comply with the GFA will incur delays or may be rejected immediately.

\section{2 - Be prepared to:}

- Confirm that the manuscript has been submitted solely to this journal and is not published, in press, or submitted elsewhere.

- Confirm that all the research, citations, and authorship statements meet appropriate ethical guidelines, including adherence to the legal requirements of the study country. By confirming this statement you are declaring that you have read and understood the ethical guidelines published by the International Committee of Medical Journal Editors (ICMJE) available online at http://www.icmje.org/

- Confirm that you have prepared a complete text minus the title page, acknowledgments, and running head with no author names, to allow blinded review.

- State if you have any conflicts of interest.

\section{3 - AFTER YOU HAVE LOGGED IN}

NOTE: If necessary, you may interrupt the submission process and logout. When you are ready to resume, just login, go to the author dashboard and click the "Continue submission" button.

In the "Degree" field please enter only your highest academic degrees.

\section{4 - KEYWORD TIPS}

You will be required to select four keywords for the creation of your account and each submission. The JAANP keyword selection list found in $\mathrm{S} 1 \mathrm{M}$ is fixed. It contains almost 800 broad-based nursing science keywords that should be suitable for most submissions. Your account keywords should reflect your areas of professional expertise and interest. The keywords selected for your submission should reflect the content of your manuscript. You may provide a list of additional keywords in the TitlePage.doc if you do not find suitable ones in the S1M list but you will need to select 4 keywords from the list in order to proceed.

TIP: When selecting keywords from the list, enter three or four letters AND an asterisk (wild card symbol) to filter the list.

Upload your submission files in the upload-order specified below.

NOTE: The JAANP conducts a blinded peer-review. When uploading your manuscript you must upload a Main Document file with no author identifying information in it (designated as the Main Document) and a separate title page (designated as theTitle Page) with all author identifying details including an email address for all authors. This is the author information you would like the readers to see in a published article. The next section details file type and naming conventions. 
Appendix M (cont.)

Journal of the American Association of Nurse Practitioners Author's Guidelines for Authors

\section{5 - Manuscript File Naming for Submission}

The S1M system will demand that you designate your files as one of the following types:

Title Page is required. It should include the title of the submission and complete author contact and work affiliation information. Authors should be listed in proper order of contributorship and the corresponding author must be clearly identified. See section 3.1 for more detail about the Title Page.

NOTE: The title page is not included in the reviewer files when the manuscript is sent out for review.

Main Document is required. It includes the body of the text and references with all author identifying information removed, no page numbers, no running head (which is entered in $\mathrm{S} 1 \mathrm{M}$ in a separate data field), and no embedded tables or figures. If you have been using Track Changes to make final editorial corrections to your document, be sure to accept all changes and save the corrected file with Track Changes turned off. (Track changes leaves contributors' names visible in the document unless this step is completed.)

Tables and Figures should be separated into individual files and uploaded with appropriate labels applied as requested during the submission process.

Supplementary Files Not for Review may be uploaded to provide specific information such as permission to reprint material, a completed and signed ICMJE conflict of interest disclosure if required, or a copy of the letter of approval to conduct research from the appropriate review board.

Suggested upload-file name conventions:

(Contact Author Last name and_Initial followed by file type).

NOTE: The S1M system uses the following user selectable file designations

Title Page, Main Document, Figure, Table, or Supplemental (may or may not be designated for review) This is the specified upload-order.

Smith_A TitlePage.doc

Smith_A MainDoc.doc

Smith_A Figure-1.tif

Smith_A Table-1.doc

Smith_A SupFile-Acknowledgments

Smith_A SupFile-Permit.doc

In all cases the Main Doucument file should have the Contact Author's name prepended to it. eg. Smith_A Adolecent Obesity article MainDoc.doc 


\author{
Appendix M (cont.) \\ Journal of the American Association of Nurse Practitioners Author's Guidelines for Authors
}

During the upload process your files will be converted into both HTML and PDF format for use by the reviewers. Sometimes the conversion process takes a while or fails. If it seems to be taking too long, close the conversion-in-progress window and check to see if a file conversion actually occurred. If the file conversion appears stalled or failed, follow any instructions that appear on the screen. Otherwise delete any corrupted files and start the process over.

Please be aware that $\mathrm{S} 1 \mathrm{M}$ services millions of users and sometimes you may experience a glitch in file conversion processing (e.g. "Unable to convert file Author_N1 CL.doc [PDF]" it did make an $\mathrm{HTML}$ ) and you may have to delete a botched job and restart the process.

Once your submission is complete you will receive an automatic email from the S1M system verifying your submission and providing you with your Manuscript ID Number. You will be able to track the progress of your submission from your Author Center in the S1M system.

It is not possible for authors to change or add anything once the submission is complete. If you fail to follow the guidelines or you need to add or change something to your submission, we will have to "unsubmit" your manuscript for you to resubmit your corrected files. This can cause delays!

\title{
4.6 After your submission is complete
}

All authors will receive an automated confirmatory email that the submission has been accomplished. Any further communication regarding the review, revisions, decisions, or production details are only sent to the contact author (or submitting agent). It is the contact author's (or agent's) responsibility to maintain communication with all other authors throughout the process. Failure to do so may result in production delays.

If you need to query the editors about your submission, please include the Manuscript ID number you received in the confirmatory email. This makes finding your submission easy and accurate.

All manuscripts are first reviewed by the editor-in-chief for appropriateness and suitability for the journal audience. If your submission is not appropriate, if there are problems with overlap with previously published material, or if the writing style and content are not a the level needed for our readers, the manuscript may be rejected by the editor without sending it to peer reviewers.

Thoughtful, high quality peer review takes time, so we ask for your patience with this process. We will give your manuscript every possible consideration but we do receive many more submissions than we can possibly publish so we have to reject a lot of submissions. Some of those rejected manuscripts may even be well written and appropriate for publication in other journals. When possible, the editor will try to suggest other venues for publication of your manuscript. In general, we receive the largest number of submissions just before summer and year-end holidays, so the review process can take longer during the summer months and between the US Thanksgiving and New Year's holidays. 


\section{Critical Care Ultrasound and Potential Practice Implications for Acute Care Nurse Practitioners}

Abbye Solis, DNP, ACNP-BC, PCCN; Deborah Dillon, DNP, ACNP-BC, CCRN, CHFN; Pedro Alejandro Mendez-Tellez, MD; Dorothy Tullmann, PhD, RN, CNL

Dr. Solis is an acute care nurse practitioner in a surgical intensive care unit at The Johns Hopkins

Hospital. Dr. Dillon is an Assistant Professor of Nursing at The University of Virginia. Dr. Mendez-Tellez is the Medical Director of Respiratory Care Services, Assistant Professor of Anesthesiology and Critical Care Medicine, and Assistant Professor of Surgery at The Johns Hopkins Hospital and The Johns Hopkins School of Medicine. Dr. Tullmann is an Associate Professor of Nursing and Director of the MSN and DNP programs at The University of Virginia.

Contact Author: Abbye Solis ars9uy@virginia.edu

Dr. Solis wrote this manuscript. Drs. Dillon, Mendez-Tellez, and Tullmann edited the manuscript. 


\begin{abstract}
Background and Purpose: Critical care ultrasound (CCU) is a skill that is considered standard care for a patient requiring medical care in an intensive care unit (ICU). Despite numerous organizations supporting the use of CCU by all providers in the ICU, no organizations have statements or training programs that include acute care nurse practitioners (ACNPs) as providers who can perform and interpret CCU.
\end{abstract}

Conclusions: Determining a patient's volume status is a clinical question many intensivists have when caring for a critically ill patient. Growing use of ACNPs in the ICU setting as intensivists should support ACNP use of CCU. Although no statements exist about the use of CCU by ACNPs, nurse practitioners who work in the ICU setting should be educated in CCU. Competency of CCU remains a controversial subject for both ACNPs and physicians.

Implications for Practice: Diagnosing a patient's health status is a core skill of any ACNP. Regulatory agencies require that ICU providers document assessment of volume status and tissue perfusion for patients with diagnosed shock; CCU is a skill that can and should be used to fulfill this requirement. However, acceptance of ACNPs' use of CCUS in the ICU setting has yet to be determined. 


\section{Introduction: Critical Care Ultrasound}

Use of ultrasound in the healthcare setting is not a new technology; the first cardiac ultrasound was applied in the clinical setting in 1956 to diagnose patients with pericardial effusions by Edler and Hertz (as cited in Singh \& Goyal, 2007) who pioneered the use of Doppler and M-mode ultrasonography. Recent applications of echocardiography include its use in the critical care setting and is seen as "the true stethoscope, for it permits us to see what occurs beneath the surface of the skin" (Singh \& Goyal, 2007, p. 437). Progress in bioengineering has led to the miniaturization of ultrasound machines (Roelandt, 2004), allowing for critical care ultrasound, and specifically critical care ultrasound (CCU) to emerge as a feasible skill for the clinician in daily practice. A leader of the CCU movement, Paul Mayo, states "echocardiography has unparalleled utility in the intensive care unit...allow[ing] the clinician to make immediate visual diagnosis and to guide the ongoing management of the case...[and is] a key skill for the frontline intensivist" (Mayo, 2011, no page).

Numerous national and international organizations have supported the use of CCU in the intensive care unit (ICU) setting (Intensive Care Medicine, 2014; Intensive Care Medicine, 2011; Mayo et al., 2009; Price et al., 2008). Pustavoitau et al. (n.d.) reported that the American Medical Association, the American College of Emergency Physicians, and The American Society of Echocardiography support the use of limited cardiac echography/critical care cardiac ultrasound by trained providers in ICU settings for patients requiring intensive care. Additionally, standardization of proficiency for ICU providers in bedside, or basic/limited, echocardiography is supported by both the Society of Critical Care Medicine and Pulmonary Critical Care Medicine's (SCCM) recommendations for competencies for their respective fellowships (Buckley et al., 2009). In fact, the Society of Critical Care Medicine published an official 
statement regarding recommendations for limited critical care echocardiography, supporting the standardization of echocardiography and critical care cardiac ultrasound in all ICUs (Buckley et al., 2009).

Internationally, the Competency-Based Training in Intensive Care Medecine in Europe (CoBaTrICE), sponsored by the European Society of Intensive Care Medicine, is a suborganization whose mission is to standardize training in intensive care medicine worldwide. CoBaTrICE lists "a method for measuring cardiac output and derived hemodynamic variables" (European Society of Intensive Care Medicine, n.d.) as a competency of which all ICU providers should be proficient.

Despite the overwhelming support of intensive care organizations for $\mathrm{CCU}$, no society has taken an official position regarding training and/or competency of acute care nurse practitioners (ACNP) who employ critical care ultrasound diagnostically. Critical care cardiac ultrasound core objectives allow for measuring of hemodynamic states and can assist the ACNP in achieving this important ICU skill. Moreover, this skill is important for evaluating patients and could greatly improve the care of the critically ill patient, saving lives.

\section{Basics of Critical Care Ultrasound}

According to SCCM, any CCU educational program should begin with reviewing the basic physics of ultrasound, ultrasound anatomy of the heart, concepts of Doppler ultrasound, and basic functions of ultrasound machines--including 'knobology', which is step by step instruction about what knob on the echocardiography machine does what function (Fagley et al., 2015). It is of upmost importance to understand these concepts to perform even the most basic CCU task.

Understanding the echocardiographic anatomy of the heart can be challenging to the 
novice CCU performer and interpreter. Images, collected in a non-invasive manner, are obtained using ultrasound wave trajectories that are sometimes misinterpreted because images are flipped, or are mirror images, from traditional understanding of anatomy. Determining one's orientation in accordance with probe dynamics and resulting images should be an initial focus when attempting to attain basic cardiac images (Odom, 2015).

CCU views are obtained from three areas of the thorax: left parasternal, apical, and subcostal. Critical care cardiac ultrasound examination from the left parasternal view allows for parasternal long axis (PLAX) and parasternal short axis views (SAX). The apical area results in an apical four-chamber (A4C) view of the heart. Subcostal critical care cardiac ultrasound view allows for obtaining subcostal long-axis view as well as views of the inferior vena cava. These five views of the heart are considered to be paramount to interpreting any information obtained from CCU and, therefore, are called a Focused Cardiac Ultrasound, or "FoCUS exam" (Odom, 2015; Fagley et al., 2015; Strugess et al., in Lumb, 2014).

CCU allows the provider to enhance their diagnostic skills in hemodynamic monitoring to detect cardiovascular insufficiency, leading to a diagnosis of underlying pathophysiology (Strugess et al., in Lumb, 2014). Determining a critically ill patient's volume status is a clinical question that many intensivists have when caring for a critically ill patient. Cardiac output is the product of stroke volume and heart rate. Two measures are widely used to determine stroke volumes: the biplane method of disks and the product of the Doppler Velocity Time Integral (VTI) and cross-sectional area (CSA) of the sampling site. The biplane method of disks, also called the modified Simpson rule, calculates volume estimations of the left ventricle, thereby estimating stroke volume. Fractional area change compares area volume at end diastole and at end systole to determine the percentage of blood exiting the ventricle. Left ventricular outflow 
tract (LVOT) is measured from views obtained in the parasternal long axis view. Stroke volume (SV) is directly calculated by the product of the Doppler velocity time integral (VTI) and the cross-sectional area (CSA) of the Left ventricle outflow tract (LVOT). The mathematical equation is $\mathrm{SV}=\mathrm{CSA} \times \mathrm{VTI}$. Heart rate can then be used to calculate the cardiac output $(\mathrm{CO}=$ HR x SV). These methods of determining stroke volume are widely used from FOCUS exam basic views (Strugess et al., in Lumb, 2014).

Determining a patient's volume status is just one of many diagnostic utilities of CCU.

\section{ACNPs in the Intensive Care Unit Setting}

Providing care for patients in an intensive care unit requires specialty education by a multi-disciplinary team of providers. Due to physician shortages and implementation of acute care nurse practitioner programs in the early 1990's, modern definitions of the term "provider" in intensive care units have evolved. In 2004, over 5,000 acute care nurse practitioners were licensed by the American Nurses Credentialing Center, of which 68\% (about 2,800) were working in an intensive care setting (Kleinpell \& Goolsby, 2004). ACNPs are educated in proficiencies that include critical care education and skills in coursework of advanced pharmacology, physiology, pathophysiology, and patient care management (Kleinpell, Ely, \& Grabenkort, 2008). ACNPs are specifically prepared to perform basic intensive care skills such as chest tube insertion, arterial and central line placement, endotracheal intubation, ventilator management, and hemodynamic monitoring (Kleinpell, Hravnak, \& Werner, 2006; Kleinpell et al., 2008).

The Accreditation Council for Graduate Medical Education's (ACGME) oversight and restriction on physician residency hours adds to the paradigm shift for how the term "provider" is defined in the ICU. Estimates indicate that there will be insufficient numbers of ICU trained 
physicians as high as $22 \%$ of demand by 2020 and as high as $35 \%$ of demand by 2030 (Angus, Shorr, White, Schmitz, \& Kelley, 2006). ACNPs have the education and training to become proficient ICU care providers (Pastores et al., 2011). Given the opportunity to obtain proficiency in bedside critical care echocardiography, ACNPs that work in an ICU setting have the ability, and perhaps even the duty, to provide evidence-based practice medicine for all of their patients.

A report by the Health and Human Resources and Services Administration (HRSA), concluded that the increased demand of critical care trained personnel could be addressed by the use of non-physician providers, such as nurse practitioners (Squires, King, Wagner, Ashby, \& Parmley, 2013). SCCM's position paper on ICU staffing incorporates HRSA's recommendations. In fact, SCCM has taken a major stance in removing language that only refers to physicians, noting that ACNPs, if properly trained, can become safe and efficient providers in the ICU setting.

\section{Critical Care Cardiac Ultrasound Competency}

Competence is the combination of knowledge, skills, and behavior required to perform a specific function in an adequate and well-qualified manner (Mayo et al., 2014). Competency standards are used extensively in healthcare, especially within ACNP education and training (O’Connell, Gardner, \& Coyer, 2014). A national survey by Becker et al. (2006), found that 67\% of ACNP respondents currently worked in an ICU setting. The concept of competency within the scope of education and training of intensivists [general term encompassing ACNPs] has been of discussion since the introduction and daily integration of CCU for the care of the ICU patient. Mayo et al. (2014) described CCU as "a standard skill for the intensivist" (p. 655) and competence within that skill is defined as achievement in a minimum standard for routine ICU skills, including CCU (Mayo, 2011). 
Standards of competency for expert echocardiographers have been well established with physician residencies and certification exams (Intensive Care Medicine, 2011). However, expert panels and societal position statements have concluded that an intensivist should not be expected to achieve competencies equal to that of an expert echocardiographer; intensivists need only to achieve competency in basic echocardiography (Fagley et al., 2015, Intensive Care Medicine, 2014; Intensive Care Medicine, 2011; Mayo et al., 2009; Price et al., 2008). Defining how intensivists meet competency in CCU remains a controversial subject and has yet to be resolved. In addition, the standardization of how (and even if) ACNPs achieve competency in CCU has also not yet been resolved.

Despite the utility of CCU to augment traditional care for patients requiring medical care in the ICU, training for CCU in the ICU setting remains a debated and sparsely studied subject. This was evident when attempting to search for quality evidenced-based research examining the literature for a standard training program. However, the view of the importance of CCU in the care of ICU patients is obvious by the numerous, major national and international societal position statements regarding CCU's use. Mayo (2011) reports that statements “of competence are very specific; statements on training are less so" (no page).

More studies are needed to determine the best strategies for developing CCU educational programs, with inclusion of ACNPs as part of skilled providers. Although many organizations have published position statements regarding CCU use in the ICU setting, few studies have been conducted examining how or why providers actually change their approach to care. More specific outcomes need to be identified when assessing quality of educational curricula, including how many exams are needed to deem one competent in CCU. The overarching limitation is lack of ACNP inclusion in societal statements and studies that examine the utility of 
CCU in the ICU setting. Moreover, more studies should examine the potential impact that ACNPs could have when utilizing CCU in the care they provide to critically ill patients.

\section{Implications for ACNPs in CCU Education}

The American Association of Colleges of Nursing (AACN), the professional body by which ACNP programs are accredited, states a core competency of ACNP education is diagnosis of health status. ACNPs are educated to manage and evaluate acute, critical, and chronically ill patients "through ordering, interpretation, performance, and supervision of diagnostic testing and clinical procedures" (AACN, 2012, p. 18). The Centers for Medicare and Medicaid Services (CMS) have recently began, as of October 10, 2015, requiring that ICU providers document assessment of volume status and tissue perfusion for patients with diagnosed shock. This assessment includes a bedside cardiovascular ultrasound/echocardiograph and documentation of assessment of fluid responsiveness. CMS designates that a critical care echocardiograph is an appropriate way to obtain this assessment. This 'core measure' assessment is to be completed within six hours of the patient's presentation to an acute care setting (Kleinpell, 2015). Septic patients are admitted to critical care units at all hours of the day and all ICU providers must be competent in assessing a patient's cardiovascular assessment and fluid responsiveness, as this core measure stipulates. For ACNPs to comply with these CMS requirements, ACNPs must be skilled in all ICU procedures to provide adequate care.

Because ACNPs are being utilized currently and will be utilized more as part of ICU provider models in the near future (Squires et al., 2013), education and maintenance of core competencies for ICU providers must include ACNPs. A current structure exists for ACNPs to be included in the concept that "basic level critical care echocardiography should be a required part of training of every ICU physician” (Mayo, 2011, no page) but acceptance of ACNPs has 
yet to be achieved - at least in the language of position statements and formal recommendations for training. 


\section{References}

American Association of Colleges of Nursing. (2012). Adult-gerontology acute care nurse practitioner competencies. Washington, DC: American Association of Colleges of Nursing.

Angus, D.C., Shorr, A.F., White, A., Schmitz, R.J., Kelley, M.A. (2006). Critical care delivery in the United States: Distribution of services and compliance with leapfrog recommendations. Critical Care Medicine, 34,1016-1024.

Becker, D., Kaplow, R., Muenzen, P., \& Hartigan, C. (2006). Activities performed by acute and critical care advanced practice nurses: American association of critical-care nurses study of practice. American Journal of Critical Care, 15, 130-148.

Buckley, J.D., Addrizzo-Harris, D.J., Clay, A.S., Curtis, J.R., Kotloff, R.M., Lorin, S.M., Murin, S., Sessler, C.N., Rogers, P.L., Rosen, M.J., Spevetz, A., King, T.E., Malhotra, A., \& Parsons, P.E. (2009). Multisociety Task Force Recommendations of Competencies in Pulmonary and Critical Care Medicine. American Journal of Respiratory and Critical Care Medicine, 180(4), 290-295.

European Society of Intensive Care Medicine (n.d.) Competency-Based training in intensive care medecine in Europe: CoBaTrICE. Retrieved from the CoBaTrICE website: http://www.cobatrice.org/en/index.asp.

Fagley, R., Haney, M., Beraud, A., Comfere, T., Kohl, B., Merkel, M., Pustavoitau, A., von Homeyer, P., Wagner, C.E., \& Wall, M. (2015). Critical care basic ultrasound learning goals for American anesthesiology critical care trainees: Recommendations from an expert group. Anesthesia Analgesia, 120(5), 1041-1053. 
Intensive Care Medicine. (2011). International expert statement on training standards for critical care ultrasonography. Intensive Care Medicine, 37, 1077-1083.

doi:10.1007/s00134-011-2246-9

Intensive Care Medicine. (2014). International consensus statement on training standards for advanced critical care echocardiography. Intensive Care Medicine, 40, 654-666.

Kleinpell, Ruth. (2015). Fluid Replacement in Septic Shock. Podium presentation at ACNP Bootcamp at Vanderbilt University, Nashville, Tennessee.

Kleinpell, R.M., Ely, E.W., \& Grabenkort, R. (2008). Nurse practitioners and physician assistants in the intensive care unit; An evidence-based review. Critical Care Medicine. 36, $10,2888-2897$.

Kleinpell, R.M., \& Goolsby, M.J. (2004). American Academy of Nurse Practitioner national nurse practitioner sample survey; Focus on acute care. Journal of the American Academy of Nurse Practitioners, 18, 393-394.

Kleinpell, R.M., Hravnak, M., \& Werner, K.E. (2006). Skills taught in acute care NP programs: A national survey. Nurse Practitioner. 31(7), 11-13.

Kleinpell, R. M., Hudspeth, R., Scordo, K. A., \& Magdic, K. (2012). Defining NP scope of practice and associated regulations: Focus on acute care. Journal of the American Academy of Nurse Practitioners, 24(1), 11-18. doi:10.1111/j.1745-7599.2011.00683.

Mayo, Paul. H. (2011). Training in critical care echocardiography. Annals of Intensive Care, 1(36). doi:10.1186/2110-5820-1-36.

Mayo, Paul.H., and Vieillard-Baron, A. (2014). International consensus statement on training standards for advanced critical care echocardiography. Intensive Care Medicine, 40(5), 654666. 
Mayo, P. H., Beaulieu, Y., Doelken, P., Feller-Kopman, D., Harrod, C., Kaplan, A., Oropello, J., Vielliard-Baron, A., Lichtenstein, D., Maury, E., \& Vignon, P. (2009). American college of chest Physicians/La societe de reanimation de langue francaise statement on competence in critical care ultrasonography. Chest, 135(4), 1050-1060. doi:10.1378/chest.08-2305.

O'Connell, J., Gardner, G., \& Coyer, F. (2014). Beyond competencies: Using a capability framework in developing practice standards for advanced practice nursing. Journal of American Nursing, 70(12), 2728-2735. doi:10.1111/jan12475

Odom, Stephen. (2015). Proceedings from Ultrasonography for Intensivists and Emergency Medicine Clinicians: Ultrasound Anatomy of the Heart, Basic TTE Views and Eyeballing Principle. Boston, MA: Harvard Medical School/Beth Israel Deaconess Medical Center.

Pastores S, O’Connor M, \& Kleinpell R. (2011). The accreditation council for graduate medical education resident duty hour new standards: history, changes, and impact on staffing of intensive care units. Critical Care Medicine, 39, 2540-2549.

Price, S., Via, G., Sloth, E., Guarracino, F., Breitkreutz, R., Catena, E., \& Talmor, D. (2008). Echocardiography practice, training and accreditation in the intensive care: Document for the world interactive network focused on critical ultrasound (WINFOCUS). Cardiovascular Ultrasound, 6, 49-7120-6-49. doi:10.1186/1476-7120-6-49 [doi]

Pustavoitau, A., Blaivas, M., Brown, S., Gutierrez, C., Kirkpatrick, A., Kohl, B., Oren-Grinberg, A., \& Frankel, H.L. (n.d.). Recommendations for achieving and maintaining competence and credentialing in critical care ultrasound with focused cardiac ultrasound and advanced critical care echocardiography. Retrieved from The Society of Critical Care Medicine website: http://journals.lww.com/ccmjournal/Documents/Critical\%20Care\%20Ultrasound.pdf 
Roelandt, J. R. T. C. (2004). Ultrasound stethoscopy. European Journal of Internal Medicine, $15(6), 337-347$.

Singh, S., \& Goyal, A. (2007). The origin of echocardiography: A tribute to Inge Edler. Texas Heart Institute Journal / from the Texas Heart Institute of St.Luke's Episcopal Hospital, Texas Children's Hospital, 34(4), 431-438.

Squires, J., King, J., Wagner, C., Ashby, N., \& Parmley, C. L. (2013). ACNP intensivist: A new ICU care delivery model and its supporting educational programs. Journal of the American Association of Nurse Practitioners, 25, 119-125.

Sturgess, D., Hamilton, D., Sargsyan, A., Lumb, P., \& Karakitsos, D. (2014). Hemodynamic monitoring considerations in the intensive care unit. In P. Lumb (Ed.), Critical care ultrasound: Expert consult (193-199). Philadelphia, PA: Elsevier. 